\title{
Otorhinolaryngologic manifestations of 22q11.2 deletion syndrome
}

\author{
Emmy Verheij
}


Printing of this thesis was kindly supported by Emid audiologische apparatuur, Dos Medical, Chipsoft, Meditop, Stichting ORLU, Sonova, Beter Horen, ALK, Pentax, Makker hoortoestellen and UMC Utrecht Brain Center

$\begin{array}{ll}\text { Cover concept } & \text { Mariëtte Meijers en Emmy Verheij } \\ \text { (Cover) Lay-Out } & \text { Ilse Modder | www.ilsemodder.nl } \\ \text { Printed by } & \text { Gildeprint, Enschede | www.gildeprint.nl } \\ \text { ISBN/EAN: } & 978-94-6419-310-7\end{array}$

\section{$\sqrt{2} \underset{\substack{\text { Mix } \\ \text { Papar trom }}}{\operatorname{mos}}$ \\ FSC repponation sourceot}

(c) E. Verheij, 2021 All rights reserved. No part of this thesis may be multiplied and/or published by means of print, photocopy, and microfilm or otherwise, without explicit permission of the author. 


\section{Otorhinolaryngologic manifestations of 22q11.2 deletion syndrome}

Manifestaties binnen de keel-, neus- en oorheelkunde van het 22q11.2 deletie syndroom

(met een samenvatting in het Nederlands)

Proefschrift

ter verkrijging van de graad van doctor aan de

Universiteit Utrecht

op gezag van de

rector magnificus, prof.dr. H.R.B.M. Kummeling,

ingevolge het besluit van het college voor promoties

in het openbaar te verdedigen op

donderdag 28 oktober 2021 des middags te 4.15 uur

door

Emmy Verheij

geboren op 31 augustus 1989

te Leiden 


\section{Promotoren:}

Prof. dr. R.J. Stokroos

Prof. dr. A.B. Mink van der Molen

\section{Copromotor:}

Dr. H.G.X.M. Thomeer 


\section{CONTENT}

$\begin{array}{lll}\text { CHAPTER } 1 & \text { General introduction } & 9\end{array}$

OTOLOGY

CHAPTER 2 Prevalence of hearing loss and clinical otologic

manifestations in patients with 22.11.2 deletion syndrome:

A literature review

CHAPTER 3 Otologic and audiologic findings in 22q11.2 deletion syndrome

CHAPTER 4 Anatomic malformations of the middle and inner ear in 22q11.2 deletion syndrome: Case series and literature review

CHAPTER 5 Challenging otologic surgery in patients with 22q11.2 deletion syndrome; a case report

\section{VESTIBULOLOGY}

CHAPTER 6 Vestibular symptoms in adolescents with 22q11.2 deletion syndrome: an exploratory, cross sectional cohort study

\section{LARYNGOLOGY}

CHAPTER 7 Congenital respiratory tract disorders in 22q11.2 deletion syndrome

APPENDIX

Summary

Nederlandse samenvatting

Dankwoord 
564555-L-bw-Verheij

Processed on: 16-9-2021 


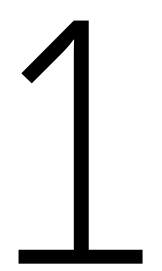

GENERAL INTRODUCTION 


\section{2q11.2 DELETION SYNDROME}

22q11.2 deletion syndrome (22q11DS) is a genetic disorder caused by a microdeletion on the long arm of chromosome 22, band 11, subband 22. ${ }^{1,2}$ In the 1990's when genetic testing became more commonly applied, different clinical syndromes, including DiGeorge syndrome and velocardiofacial syndrome, were found to be caused by the same genetic anomaly. ${ }^{3-5}$ Subsequently, these different syndromes were combined to one, 22q11DS. 22q11DS is the most common microdeletion syndrome. It is estimated to occur in 1 in 3000-6000 live births, although this might be a conservative estimation. ${ }^{2,6,7}$

Approximately $85 \%$ of 22q11DS patients have a typical 3 million base pair (Mb) deletion, which affects the same genetic region. On the 22 q11.2 region four low copy repeats (LCR) blocks are identified, LRC22A, LRC22B, LRC22C and LRC22D. Low copy repeats or segmental duplications are segments of DNA which are highly identical. During meiosis LCRs may cause genetic rearrangements leading to deletion, duplication or inversion. In the 22q11.2 region, a deletion is mostly prevalent, but a 22q11.2 duplication can also occur. The typical 3Mb deletion in 22q11DS extends from LRC22A - LRC22D. Smaller atypical nested deletions can also be present in patients with 22q11DS (Figure 1).1,2,8

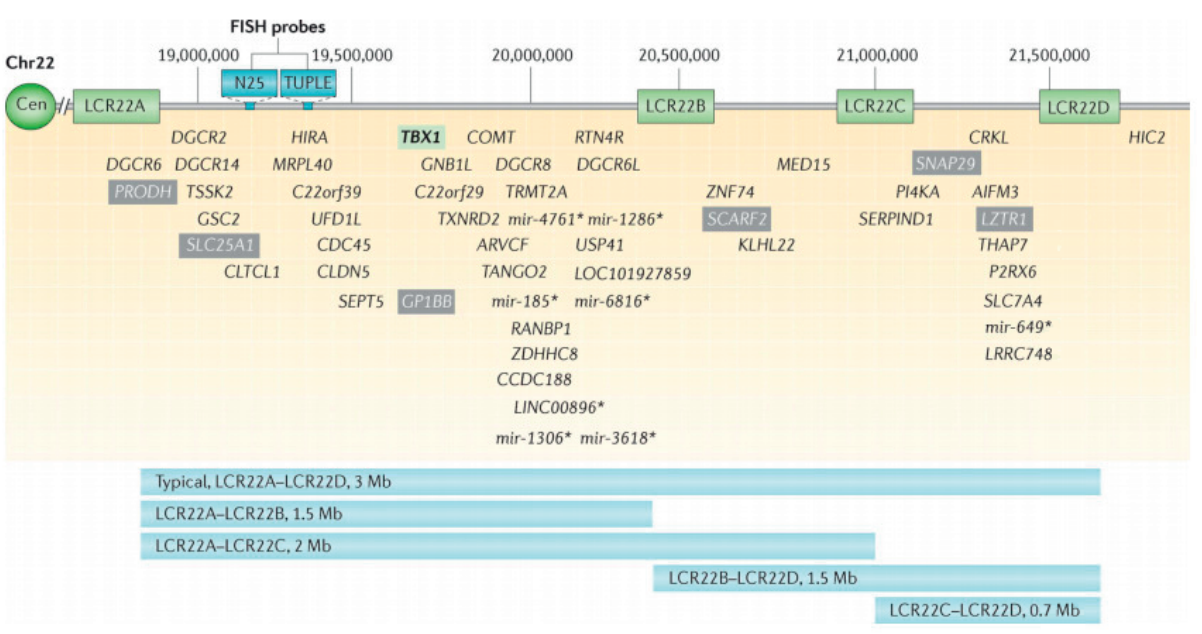

Figure 1. The 22q11.2 region, with the typical (LCR22A - LCR22D) and atypical deletions in 22q11DS.

Adopted from McDonald-McGinn et al. 22q11.2 deletion syndrome. Nat Rev Dis Primers. 2015 Nov 19;1:15071 
Previously, 22q11DS was diagnosed with fluorescence in situ hybridization (FISH), however this tool only detects deletions located on LCR22A-B, missing smaller more distal nested deletions. Therefore, more accurate genetic tests, including multiplex ligation-dependent probe amplification (MLPA), have become more commonly used. $90 \%$ of the deletions in patients with 22q11DS occur de novo. ${ }^{2}$

The 22q11.2 microdeletion can cause many different deformities; over 180 manifestations have been described..$^{9}$ Interestingly, clinical manifestations vary greatly among patients. The clinical diversity is also present in the typically deleted patients, implying that there are other variables than the deletion length which play an important role in the phenotypic expression. ${ }^{1,2}$

The most important clinical features are: heart defects ( 75\%), including Tetralogy of Fallot, immunodeficiency ( 75\%) including lower T-cell counts, hypocalcaemia ( 50\%), palatal anomalies ( 75\%) including velopharyngeal insufficiency ( 30-90\%), speech and language delay ( 70\%), feeding and swallowing difficulties ( 30\%), orthopedic anomalies including scoliosis ( 60\%), genitourinary anomalies ( 33\%), lower intelligence with a mean $\mathrm{IQ}$ of approximately 70 and psychiatric disorders including schizophrenia ( 25\%). 1,2,9-11 Regarding otorhinolaryngologic manifestations, recurrent upper respiratory tract infections including otitis media, hearing loss, vestibular dysfunction and airway anomalies are reported. 12,13,14-21,22-26

In the Wilhelmina Children's Hospital (WKZ) of the University Medical Center Utrecht (UMCU), a clinical multidisciplinary team assesses children with 22q11DS. The team consists of a general pediatrician, plastic surgeon, dentist, speech therapist, otorhinolaryngologist, orthopedic surgeon, psychologist and medical geneticist. Many patients nationwide are referred to this team. The standard minimal clinical care of patients in this 22q11DS outpatient clinic is based on international guidelines. 27,28

\section{The ear}

Hearing and balance are the two main functions for which the ear houses important sensory organs. The peripheral auditory system and the peripheral vestibular system will be briefly discussed.

\section{The peripheral auditory system}

In general, soundwaves travel through the outer ear canal, tympanic membrane and middle ear to reach the cochlea, where acoustic signals trigger the auditory nerve. The tympanic membrane separates the outer ear canal and middle ear. In the middle ear, three hearing ossicles, the malleus, incus and stapes, conduct sound waves to the cochlea. The stapes footplate rests on the oval window, vibrations of the stapes footplate cause waves in the perilymph in the cochlea. As a result, the basilar membrane vibrates and hair cells in the organ of Corti will depolarize, thus exciting the auditory nerve. The normal human cochlea has 2.5 turns and is tonotopically 
CHAPTER 1

organized, meaning that high frequency sounds are processed in the basal turn and low frequency sounds in the apical turn. The human ear can perceive sound between $20 \mathrm{~Hz}$ and $20 \mathrm{kHz} .{ }^{29}$ An overview of the anatomy of the outer ear canal, middle ear and inner ear is shown in Figure 2.

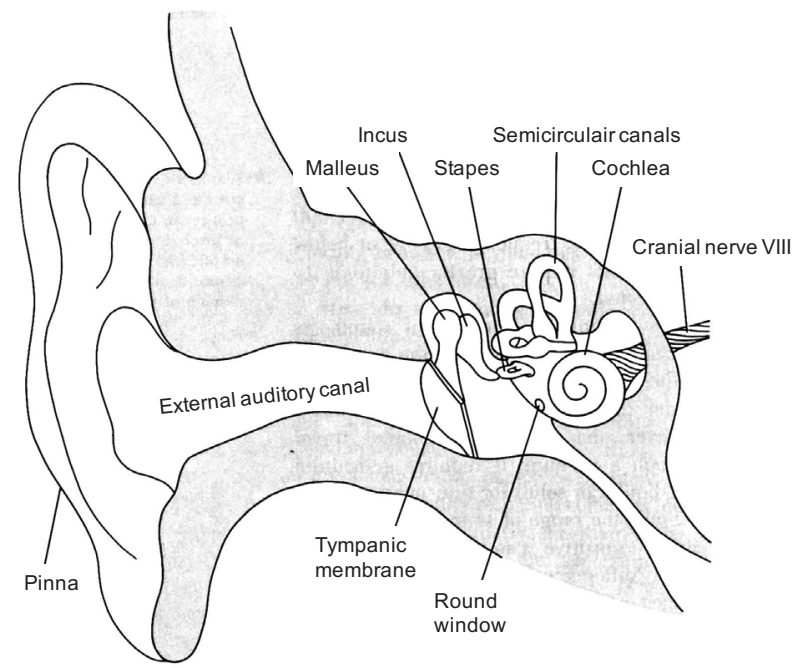

Figure 2. An overview of the anatomy of the outer ear canal, middle ear and inner ear

\section{The peripheral vestibular system}

The vestibular system is an essential feature for balance, postural stability and detecting motion. Important sources providing input to this system are vision and propriocepsis for balance and orientation. The vestibular system consists of a central and peripheral part. The peripheral vestibular system is part of the labyrinth and therefore continuous with the membranes of the cochlea. It comprises five organs (Figure 3): the lateral (or horizontal), anterior (or superior) and posterior (or inferior) semicircular canal and two otolith organs: the utricule and saccule. The semicircular canals detect angular accelerations. The utricule and saccule are sensitive for linear accelerations (including gravity), the utricule for movements in the horizontal plane, the saccule for movements in the vertical plane. The lateral, anterior and posterior semicircular canals are positioned 90 degrees in relation to each other. In this way in combination with the utricule and saccule, they detect accelerations in all directions. All five different parts of the peripheral vestibular system have hair cells which deflect in reaction to accelerations. Deflections of these hair cells will trigger nerve fibers. In the semicircular canals the hair cells are situated in the ampulla, at the end of each canal. All five organs respond to accelerations. Therefore, when moving at a constant speed, the hair cells will show a neutral rest activity. With regard to the vestibular system, the contralateral side has a 
complementary reaction to motions. For instance, an angular movement to the left in the horizontal plane will be detected by the left lateral semicircular canal (depolarization, deflection of the stereocilia towards the kinocilia, the kinocillia are in this canal oriented towards the utricle) and right (hyperpolarization) lateral semicircular canal. ${ }^{30}$

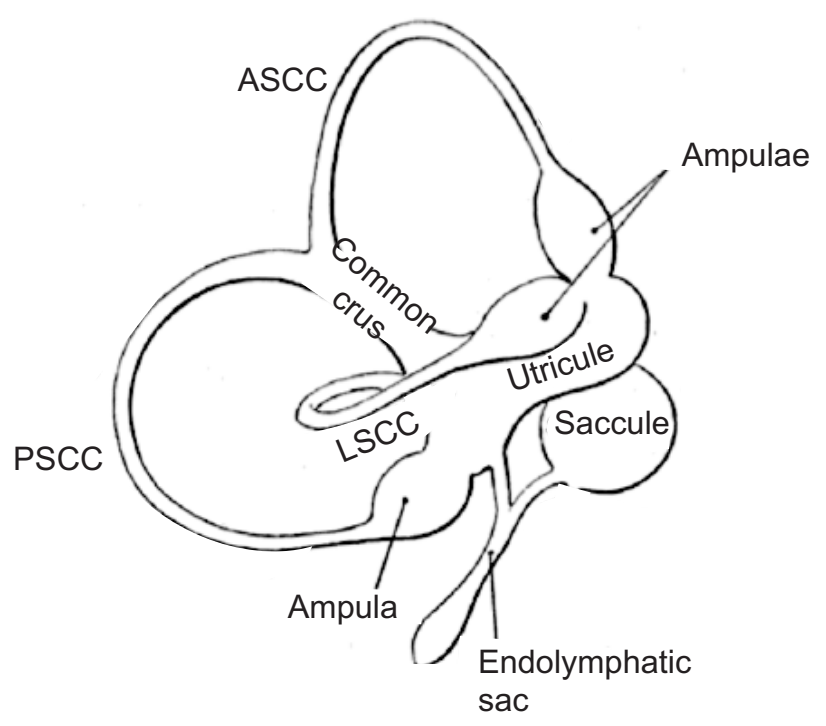

Figure 3. The Lateral semicircular canal (LSCC), anterior semicircular canal (ASCC), posterior semicircular canal (PSCC), utricule and saccule. The PSCC and ASCC have a common crus. Adopted from Al Abbasi A and Dehsyes SM. Chapter 1 introduction. The Effect Of Noise Generated By Mastoid Drill On the Contralateral Normal Ear. 2018 doi 10.13140/RG.2.2.23266.89280

\section{Embryology}

The middle ear cavity is formed from the first pharyngeal pouch. The cavity is initially filled with neural crest cells, which disappear first in the later hypotympanum and mesotympanum, and then in the epitypanum, surrounding the hearing ossicles with air. This occurs between week 12 to 32 of gestation. The malleus and incus are formed from the first pharyngeal arch and the stapes is formed from the second arch. The hearing ossicles ossify around 16 weeks of gestation, first the incus, then the malleus and lastly the stapes, finishing at 26 weeks. The stapes footplate seems to originate from both the oval window of the otocyst and from the second pharyngeal arch. ${ }^{31}$

During this formation of the ossicular chain, deformities might occur leading to congenital, non-progressive hearing loss after birth. Congenital middle ear deformities can be classified using the Teunissen Cremers classification (Table 1). This classification (amongst many other reported classifications) supports in decision making regarding surgery as an option, and in predicting the surgical outcome. ${ }^{32}$ 
CHAPTER 1

Table 1. Classification of congenital middle ear malformations according to Teunissen and Cremers

\begin{tabular}{ll}
\hline Malformations \\
\hline Class 1 & Congenital isolated stapes ankylosis \\
Class 2 & Congenital isolated stapes ankylosis in combination with a congenital anomaly of the ossicular chain \\
Class 3 & Congenital anomalies of the ossicular chain and at least a mobile stapes footplate \\
Class 4 & Aplasia or severe dysplasia of the oval window or round window \\
\hline Adopted from Teunissen EB, Cremers CWRJ. Classification of congenital middle ear anomalies report on 144
\end{tabular}
ears. Ann Otol Rhinol Laryngol. 1993;102(8):606-612. doi:10.1177/000348949310200807

The inner ear arises from the otocyst. At week 4 and 5 of gestation the semicircular canals and vestibule form from the dorsal side of the otocyst. The semicircular canals are developed one by one, first the anterior, then the posterior and lastly the lateral canal. At week 7 the ampulla in the semicircular canals can be identified, and a cleft is formed between the utricle and saccule. The cochlea develops from the ventral side of the otocyst, starting from a tubular structure which rotates at week 8 and 9 of gestation. At week 10, the cochlea has 2.5 turns. By 17 to 19 weeks of gestation, the labyrinth has reached adult size, and in week 20 and 21 a bony ossification surrounding the membranous labyrinth forms. ${ }^{33}$

In 22q11DS, the gene Tbx1, which is hemizygously deleted in 22q11DS patients, could be involved in the reported inner ear malformations. ${ }^{34,35}$ In mouse studies with mutated knockout $\mathrm{Tb} \times 1^{-/}$mice, the inner ear is absent. ${ }^{36,37}$ In addition, mice in which Tbx1 was ablated in the otic vesicle and pharyngeal pouch endoderm, had an absent outer and middle ear. ${ }^{38}$

\section{Loss of function of the ear Hearing loss}

Hearing loss can be categorized in conductive, sensorineural and mixed hearing loss. A pure conductive hearing loss refers to the hearing impairment caused by a defect in the external auditory canal, tympanic membrane or middle ear. Here, sound is muffled and presented to the cochlea at a lower sound level. In sensorineural hearing loss, the problem lies in the cochlea or retrocochlear (auditory nerve or brain stem). As a consequence, frequency range of sounds is reduced. Sensorineural hearing loss is permanent whereas conductive hearing loss is not necessarily so. For instance, conductive hearing loss caused by otitis media with effusion usually dissolves when the fluid in the middle ear disappears. Mixed hearing loss is a combination of conductive and sensorineural hearing loss. On a pure tone audiogram, a difference between airconduction and bone-conduction thresholds (air-bone gap) indicates a conductive hearing loss component. High hearing thresholds in combination with an absent airbone gap suggests sensorineural hearing loss. ${ }^{29}$

All types of hearing loss are described in patients with 22q11DS, but conductive hearing loss is most frequently present. ${ }^{39}$ It is thought that this hearing loss is caused 
by recurrent otitis media. Abnormalities of the ossicular chain are also reported, 20,23,34,40 which could lead to conductive hearing loss; as a result of recurrent otitis media, though a congenital origin is also possible. ${ }^{34}$ Sensorineural hearing loss in 22q11DS can be caused by inner ear malformations, such as an incomplete partition type II of the cochlea, or malformations of the lateral semicircular canal. ${ }^{20,34} \mathrm{~A}$ malformed lateral semicircular canal is previously reported to occur with sensorineural hearing loss, but also with conductive hearing loss. ${ }^{41,42}$

\section{Vestibular loss of function}

Vestibular dysfunction can lead to a diverse set of symptoms: dizziness, imbalance, vertigo, oscillopsia, other visual problems, fatigue, attention disorders, and specifically in children a delayed motor development. ${ }^{30}$ The present symptoms depend on the aetiology (a chronic or acute disorder) and if there is bilateral or unilateral involvement of the labyrinth. In this thesis we focus on congenital vestibular malformations. In congenital malformations, vertigo and dizziness are usually not present. But a delayed motor development and more subtle signs such as trouble walking in the dark, or an incoordination during fast and unsuspected movements, are. ${ }^{30}$ Of these problems, a delayed motor development is frequently described in 22q11DS. ${ }^{43-48}$ However, motor development depends also on many other factors, such a hypotonia (which is also described in 22q11DS ${ }^{43,48,49}$ ). Willlaert et al investigated 23 patients with 22q11DS with a caloric test. $55 \%$ of patients had an unilateral caloric hypofunction, $90 \%$ had an unilateral or bilateral weak caloric response. ${ }^{17}$ Patients can compensate a vestibular anomaly, as was shown by a case report of a patient with 22q11DS, bilateral malformed lateral semicircular canals and moments of disequilibrium but performing as a nationallevel competitive gymnast. ${ }^{50}$

\section{Malformations of the ear}

There are several forms of congenital malformations of the labyrinth, Sennaroglu et al. classified those based on embryologic developmental arrests. ${ }^{51}$ See Figure 4 for a systematic overview. In patients with 22q11DS an incomplete partition type II is frequently described. ${ }^{34}$ Here the basal turn of the cochlea is normal, but the middle and apical turns are confluent and cystic. This occurs in combination with a dilated vestibule and an enlarged vestibular aqueduct. In patients with 22q11DS, the inner ear does not seem to follow this exact combination of malformations, since an enlarged vestibular aqueduct is not previously reported. Therefore, in this thesis when we report on an incomplete partition type II, we refer to solely the malformation of the cochlea. The malformations of the vestibular system and vestibular aqueduct are separately described.

In addition, there in 22q11DS middle ear malformations are also described. A dense stapes superstructure was frequently encountered in our retrospective study where 
CHAPTER 1

we analyzed CT scans, and by Loos et al. ${ }^{34,35}$ Loos et al suggested that a dense stapes could be of congenital origin since it was found in a patient of 9 days old. ${ }^{34}$ Also other malformations of the middle ear affecting the incus and malleus are described in literature, however it seems to a lesser extent. $20,34,52,53$

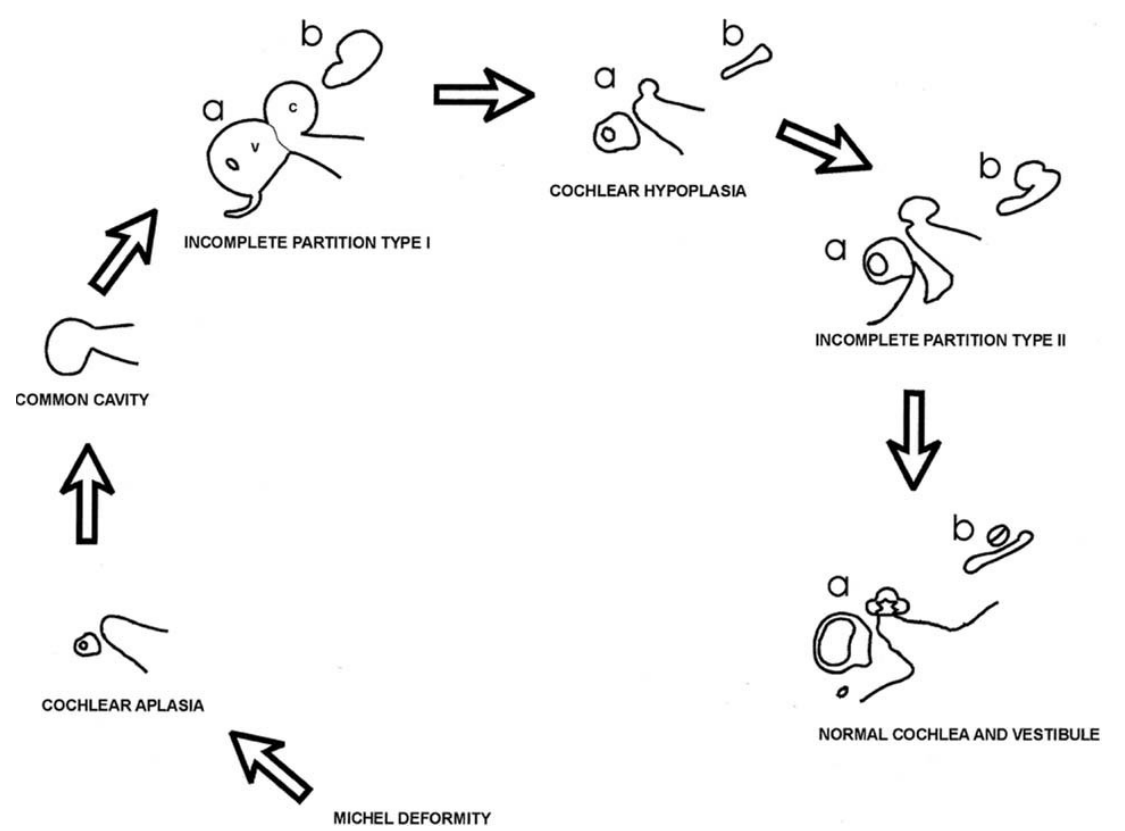

Figure 4. Schematic overview of Sennaroglu classification of inner ear malformations Adopted from Sennaroglu L, Saatci I. A new classification for cochleovestibular malformations. Laryngoscope. 2002;112(12):2230-2241. doi:10.1097/00005537-200212000-00019

\section{THE UPPER AIRWAY}

The upper airway begins at the nose cranially and ends at the carina caudally. Most anomalies described in 22q11DS are located at the larynx or more caudally. ${ }^{13,14,21,22,25}$ The larynx functions are protecting the airway during swallowing, phonation, breathing, facilitating the Valsalva maneuver and coughing..$^{54-56}$ Three parts of the larynx can be distinguished, the supraglottis, glottis and subglottis (Figure 4). The larynx cartilage includes the epiglottis, arytenoids, thyroid and cricoid cartilage. Intrinsic muscles opens, closes, lengthens and tenses the larynx. ${ }^{54}$ Intrinsic laryngeal muscles are innervated by the vagal nerve; the superior laryngeal nerve innervates the cricothyroid muscle and the recurrent laryngeal nerve the remaining intrinsic muscles. ${ }^{55}$ The subglottic area ends caudally at the inferior margin of the cricoid cartilage, there the trachea arises. 
The trachea is mainly supported by its cartilaginous C-shaped tracheal rings. ${ }^{54}$

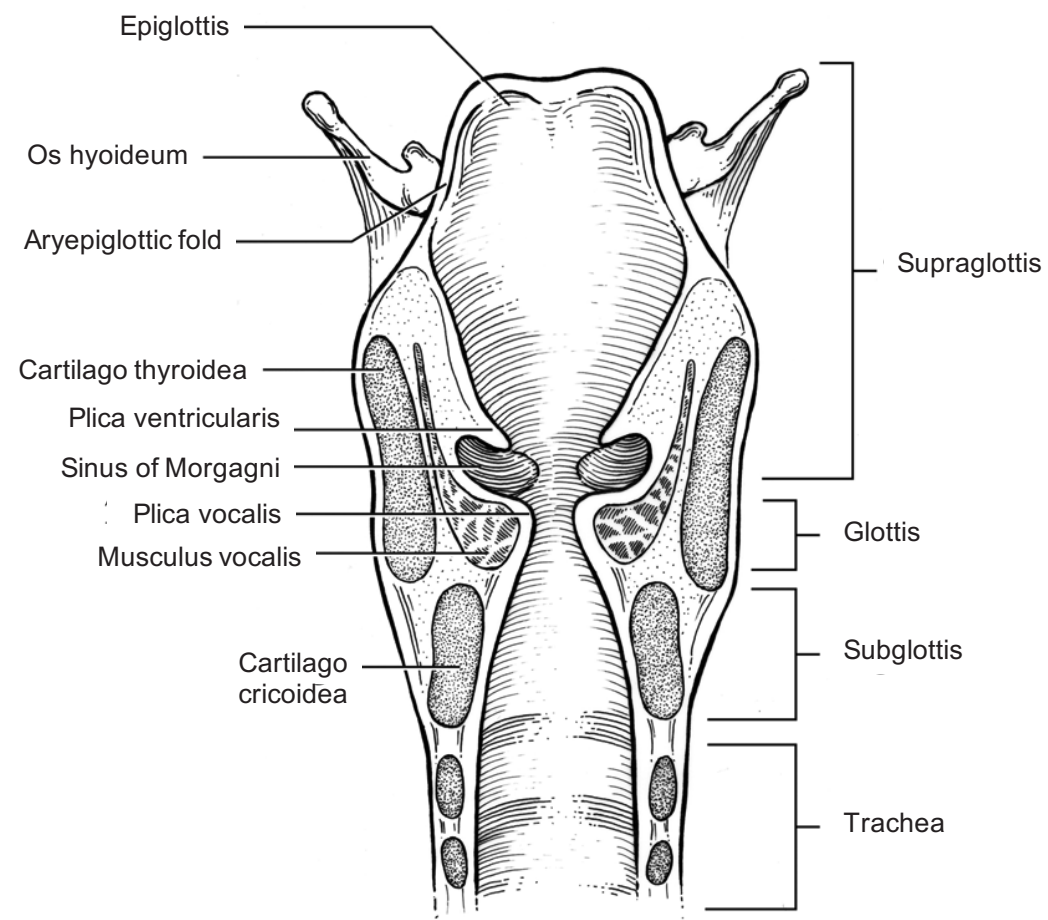

Figure 5. Coronal view of the larynx.

Adopted from Lewis, J., \& Chernock, R. (2015) Larynx and trachea. In M. Wick, V. LiVolsi, J. Pfeifer, E. Stelow, \& P. Wakely, Jr (Eds.), Silverberg's Principles and Practice of Surgical Pathology and Cytopathology (pp. 1178-1203). Cambridge: Cambridge University Press. doi:10.1017/9781139137201.01

\section{Embryology}

The larynx develops from the respiratory diverticulum, which is part of the foregut lumen. The tracheoesophageal septum divides the oesophagus from the laryngeotracheal tube. The endoderm forms the laryngeal epithelium. The laryngeal cartilages and muscles are thought to derive from the fourth and sixth pharyngeal arch. The lumen of the larynx will be obliterated due to proliferation of the epithelium, but the larynx reopens by 10 weeks of gestation. ${ }^{57}$ There are many different congenital airway anomalies (see below), the majority caused by a disruption in embryologic development. ${ }^{57}$ Other than in ear malformations, 22q11DS mouse models have not specifically reported on laryngeal or tracheal malformations to our knowledge.

Interestingly, in 22q11DS, structures derived from pharyngeal arches are frequently malformed and the more pharyngeal caudal arches seemed to be more severely affected in mouse models. ${ }^{2,58,59}$ However, an embryo study has shown no evidence for 
CHAPTER 1

the thyroid, cricoid and arytenoid cartilages to arise from pharyngeal arches, proposing a hypothesis that these cartilages originate directly from mesoderm. ${ }^{60}$

\section{Congenital upper airway anomalies}

In general, upper airway anomalies are diagnosed with fiberoptic laryngoscopy, and subsequently by a direct laryngoscopy and bronchoscopy, under general anesthesia. In 22q11DS, a laryngeal cleft, laryngeal web, (sub)glottic stenosis and airway malacia are important anomalies ${ }^{13,14,21,22,25}$ and are discussed separately below. The severity of these anomalies can range from mild to life threatening. In some cases, a tracheostomy is needed to secure the airway.

\section{Laryngeal cleft}

In patients with a laryngeal cleft the interarytenoid tissues, cricoid cartilage or the tracheoesophageal septum are not fused normally. As a result there is an abnormal connection between the larynx and oesophagus. ${ }^{57}$ Clinical symptoms vary much depending on the severity of the cleft. In grading the severity, the classification of Benjamin and Inglis is used. They distinguish between four types of severity. A type 1 cleft is limited to the interartytenoid region, cranial of the vocal cords. A type 2 cleft extends partially through the cricoid cartilage. In a type 3 cleft there is a defect through the entire cricoid and the cervical part of the tracheoesophagal septum. And lastly, in a type 4 cleft the intrathoracic trachea is involved. ${ }^{61}$ The diagnosis of a type 1 or 2 cleft can easily be delayed until childhood due to mild symptoms. A type 3 or 4 cleft however are usually presented by severe respiratory symptoms and are diagnosed shortly after birth. ${ }^{57,62} \mathrm{~A}$ laryngeal cleft should always be considered in patients with recurrent lower respiratory tract infections, feeding difficulties (including dysphagia) or stridor after feeding. ${ }^{57}$ Due to a frequent delay in diagnosis, an exact prevalence is hard to find. However, it is reported that patients who undergo direct laryngoscopy for recurrent respiratory tract infections, the incidence of a laryngeal cleft is $0.2-7.6 \%{ }^{63}$

\section{Laryngeal web}

A laryngeal web represents a form of laryngeal atresia. It arises from a failure in recanalization of the laryngeal tube during the embryologic development. $75 \%$ of the webs are located at the vocal cords. ${ }^{62}$ The severity and type of symptoms depend on the grade of laryngeal web. The most commonly used severity classification in glottic webs is the classification from Cohen et al. who described four types. A type 1 web extends to $35 \%$ of the glottis, the vocal cords are visible and there is little or no subglottic involvement. A type 2 involves $35-50 \%$ of the glottis. Here, the web is thin or moderately thick and usually does not cause an airway obstruction, although this can occur in situations with stress, infection or intubation trauma. A type 3 web involves $50-75 \%$ of the glottis, the web is thick anterior and thinner posterior. The 
anterior part extends to the subglottic area. The vocal cords are not as clearly visible compared to type 1 or 2 . There is an airway obstruction for which intubation may be needed. Type 4 is the most severe type of web, involving more than $75 \%$ of the glottis and which is anteriorly and posteriorly thick. It extends in the subglottic area, causing a threated airway. Tracheotomy is required directly after birth. ${ }^{64}$ Surgical treatment for any type of web is frequently delayed to age 3 or 4 years. Small webs can be surgically incised, for large webs a single or double stage laryngotracheal reconstruction can be performed. ${ }^{57,62,65,66}$ Interestingly, in a study where all patients with an anterior glottic web were tested for 22q11DS with FISH, $65 \%$ tested positively. ${ }^{67}$

\section{Subglottic stenosis}

As described above, in severe laryngeal webs a subglottic stenosis can occur, but there can also be an isolated subglottic stenosis. Just as a laryngeal web, a congenital stenosis results from a failure in recanalization of the laryngeal tube and can be membranous or cartilaginous. The Myer-Cotton classification is widely used, where type 1 represents a stenosis obstructing to $50 \%$ of the airway, in a type 2 the airway is for $51-70 \%$ obstructed, in a type $371-99 \%$ and in a type 4 no lumen can be detected. ${ }^{68}$ Symptoms and the therapeutic options depend on the severity of stenosis. Mild stenosis can be symptomatic only during a respiratory infection, this can usually be treated conservatively. A severe stenosis however can be life threatening and surgery will be needed. There are different surgical options, such as dilation or laryngotracheal reconstruction. $57,62,69$

\section{Airway malacia}

Airway malacia refers to a weaker or softer airway which can easily collapse, for instance during feeding or a supine position. Laryngomalacia is the most frequently present form, but malacia can also be localized in the trachea, bronchi or even in the pharynx. In literature, airway malacia is sometimes referring to tracheo- or bronchomalacia. In this thesis however, the term airway malacia is used for all types of malacia. Most cases of airway malacia are mild in severity and improve rapidly when the child ages and the airway grows. ${ }^{70,71}$ Other than a weaker airway causing symptoms, malacia can also be caused by an abnormal course of nearby structures compressing the airway. This is especially important in 22q11DS, where vascular anomalies are frequently present, such as a right sided aortic arch. ${ }^{2,72}$ These vascular malformations can flatten the airway causing respiratory symptoms. 
CHAPTER 1

\section{OUTLINE OF THIS THESIS}

The objective of this thesis was to expand our knowledge on the phenotype of 22q11DS regarding otorhinolaryngologic manifestations. In chapter 2 an overview over literature is provided regarding hearing loss and otologic manifestations in 22q11DS. Chapter 3 describes the prevalence of hearing loss and otologic manifestations in patients with 22q11DS who attended the multidisciplinary 22q11DS team in the WKZ. In chapter 4 radiologic anomalies retrospectively encountered on Computed Tomography (CT) or Magnetic Resonance Imaging (MRI) of the middle and inner ear in patients from the UMCU and from the Children's Hospital of Philadelphia are described. Chapter $\mathbf{5}$ consists of a case report, describing two cases with challenging otologic surgery in 22q11DS. Chapter 6 describes a cross-sectional study where subjective vestibular anomalies are reported. Subjective vestibular symptoms were assessed using a questionnaire. Finally, chapter 7 gives an overview of congenital airway anomalies in 22q11DS patients. 


\section{REFERENCES}

1. Kobrynski LJ, Sullivan KE. Velocardiofacial syndrome, DiGeorge syndrome: the chromosome $22 q 11.2$ deletion syndromes. Lancet. 2007;370(9596):1443-1452

2. McDonald-McGinn DM, Sullivan KE, Marino B, et al. 22q11.2 deletion syndrome. Nat Rev Dis Prim 2015;1:15071. doi:10.1038/nrdp.2015.71.22q11.2

3. Kelley R, Zackai E, Emanuel B, Kistenmacher M, Greenberg F, Punnet H. The association of the DiGeorge anomalad with partial monosomy of chromosome 22. J Pediatr. 1982;101(2):197-200.

4. Scambler P, Kelly D, Lindsay E, et al. Velo-cardio-facial syndrome associated with chromosome 22 deletions encompassing the DiGeorge locus Viral-associated Viral-associated haemophagocyte syndrome in. Lancet. 1992;339:1138-1139.

5. Driscoll DA, Budarf ML, Emanuel BS. A Genetic Etiology for DiGeorge Syndrome : Consistent Deletions and Microdeletions of 22q I I. Published online 1992:924-933.

6. Devriendt K, Fryns JP, Mortier G, Van Thienen MN, Keymolen K. The annual incidence of DiGeorge/ velocardiofacial syndrome. :7-9.

7. Óskarsdóttir S, Vujic M, Fasth A. Incidence and prevalence of the 22 q11 deletion syndrome: a populationbased study in Western Sweden. Arch Dis Child. 2004:89:148-152. doi:10.1136/adc.2003.026880

8. Emanuel BS. Molecular mechanisms and diagnosis of chromosome 22q11.2 rearrangements. Dev Disabil Res Rev. 2008;14(1):11-18. doi:10.1002/ddrr.3

9. Robin NH, Shprintzen RJ. Defining the clinical spectrum of deletion 22q11.2. J Pediatr. 2005;147(1):90-96

10. Ryan AK, Goodship JA, Wilson DI, et al. Spectrum of clinical features associated with interstitial chromosome 22q11 deletions: a European collaborative study. J Med Genet. 1997;34(10):798-804. doi:10.1136/jmg.34.10.798

11. Shprintzen RJ, Higgens AM, Antshel K, Fremont W, Roizen N, Kates W. Velo-cardio-facial syndrome. Curr Opin Pediatr. Published online 2005:725-730.

12. Dyce O, McDonald-McGinn DM, Kirschner RE, Zackai E, Young K, Jacobs IN. Otolaryngologic manifestations of the 22q11.2 deletion syndrome. Arch Otolaryngol Head Neck Surg. 2002;128(12):14081412.

13. Ebert B, Sidman J, Morrell N, Roby BB. Congenital and iatrogenic laryngeal and vocal abnormalities in patients with 22q11.2 deletion. Int J Pediatr Otorhinolaryngol. 2018;109(March):17-20. doi:10.1016/j. ijporl.2018.03.006

14. Verheij E, Speleman L, Mink van der Molen AB, Thomeer HGXM. Congenital respiratory tract disorders in 22q11.2 deletion syndrome. Int J Pediatr Otorhinolaryngol. 2018;104. doi:10.1016/j.ijporl.2017.10.028

15. Verheij E, Kist AL, Mink Van Der Molen A, Stegeman I. Otologic and audiologic findings in 22q11.2 deletion syndrome. Eur Arch Oto-Rhino-Laryngology. 2017;274:765-771. doi:10.1007/s00405-016-4365-y

16. Weir FW, Wallace SA, White DR, Hatch JL, Nguyen SA, Meyer TA. Otologic and Audiologic Outcomes in Pediatric Patients With Velo-Cardio-Facial (22q11 Deletion) Syndrome. Otol Neurotol. 2016;38(1):73-78. doi:10.1097/MAO.0000000000001226

17. Willaert A, Van Eynde C, Verhaert N, et al. Vestibular dysfunction is a manifestation of 22 q11.2 deletion syndrome. Am J Med Genet Part A. 2019;179(3):448-454. doi:10.1002/ajmg.a.7

18. Zarchi O, Attias J, Raveh E, Basel-Vanagaite L, Saporta L, Gothelf D. A comparative study of hearing loss in two microdeletion syndromes: velocardiofacial (22q11.2 deletion) and Williams (7q11.23 deletion) syndromes. J Pediatr. 2011;158(2):301-306. doi:10.1016/j.jpeds.2010.07.056

19. Ford LC, Sulprizio SL, Rasgon BM. Otolaryngological manifestations of velocardiofacial syndrome: a retrospective review of 35 patients. Laryngoscope. 2000;110(3 Pt 1):362-367.

20. Jiramongkolchai $P$, Kumar MS, Chinnadurai $S$, Wootten $C T$, Goudy SL. Prevalence of hearing loss in children with 22q11.2 deletion syndrome. Int J Pediatr Otorhinolaryngol. 2016;87:130-133. doi:10.1016/j. ijporl.2016.06.005

21. Jones JW, Tracy M, Perryman M, Arganbright JM. Airway Anomalies in Patients With 22q11.2 Deletion Syndrome:A5-YearReview.AnnOtolRhinolLaryngol.2018;127(6):384-389. doi:10.1177/0003489418771711

22. Leopold C, De Barros A, Cellier C, Drouin-Garraud V, Dehesdin D, Marie J-P. Laryngeal abnormalities are frequent in the 22q11 deletion syndrome. Int J Pediatr Otorhinolaryngol. 2012;76(1):36-40. doi:10.1016/j. ijporl.2011.09.025

23. Persson C, Friman V, Oskarsdottir S, Jonsson R. Speech and hearing in adults with 22 q11.2 deletion 
CHAPTER 1

syndrome. Am J Med Genet A. 2012;158A(12):3071-3079. doi:10.1002/ajmg.a.35589

24. Reyes MRT, LeBlanc EM, Bassila MK. Hearing loss and otitis media in velo-cardio-facial syndrome. Int $J$ Pediatr Otorhinolaryngol. 1999;47(3):227-233.

25. Sacca R, Zur KB, Crowley TB, Zackai EH, Valverde KD, Mcdonald-mcginn DM. Association of airway abnormalities with 22q11. 2 deletion syndrome. Int J Pediatr Otorhinolaryngol. 2017;96:11-14. doi:10.1016/j.ijporl.2017.02.012

26. Van Eynde C, Swillen A, Lambeens E, et al. Prevalence and Nature of Hearing Loss in 22q11.2 Deletion Syndrome. J Speech, Lang Hear Res. 2016;59(3):583-589. doi:10.1044/2015

27. Bassett AS, Mcdonald-mcginn DM, Devriendt K, et al. Practical Guidelines for Managing Patients with 22q11.2 Deletion Syndrome. J Pediatr. 2011;159(2):332-339.e1. doi:10.1016/j.jpeds.2011.02.039

28. Habel A, Herriot R, Kumararatne D, et al. Towards a safety net for management of 22 q11.2 deletion syndrome: guidelines for our times. Eur J Pediatr. 2014;173:757-765. doi:10.1007/s00431-013-2240-z

29. Kapteyn, Lamoré. 6.2.1(2). De functies van het perifere gehoor- en evenwichtsorgaan. Nederlands leerboek audiologie. Nederlandse Vereniging voor Audiologie. Published 2017. Accessed November 9 , 2017. http://www.audiologieboek.nl/

30. Kingma H, van de Berg R. Chapter 1. Anatomy, Physiology, and Physics of the Peripheral Vestibular System. Vol 137. 1st ed. Elsevier B.V.; 2016. doi:10.1016/B978-0-444-63437-5.00001-7

31. Anthwal N, Thompson $\mathrm{H}$. The development of the mammalian outer and middle ear. J Anat. 2016;228(2):217-232. doi:10.1111/joa.12344

32. Teunissen EB, Cremers CWRJ. Classification of congenital middle ear anomalies report on 144 ears. Ann Otol Rhinol Laryngol. 1993;102(8):606-612. doi:10.1177/000348949310200807

33. Lim R, Brichta AM. Anatomical and physiological development of the human inner ear. Hear Res. 2016;338:9-21. doi:10.1016/j.heares.2016.02.004

34. Loos E, Verhaert N, Willaert A, et al. Malformations of the Middle and Inner Ear on CT Imaging in 22 q11 Deletion Syndrome. Am J Med Genet Part A. 2016;170(11):2975-2983. doi:10.1002/ajmg.a.37872

35. Verheij E, Elden L, Crowley TB, et al. Anatomic Malformations of the Middle and Inner Ear in $22 q 11.2$ Deletion Syndrome: Case Series and Literature Review. AJNR Am J Neuroradiol. 2018;39(5):928-934.

36. Raft S, Nowotschin S, Liao J, Morrow B. Suppression of neural fate and control of inner ear morphogenesis by Tbx1. Development. 2004;131(8):1801-1812. doi:10.1242/dev.01067

37. Vitelli F, Viola A, Morishima M, Pramparo T, Baldini A, Lindsay E. TBX1 is required for inner ear morphogenesis. Hum Mol Genet. 2003;12(16):2041-2048.

38. Arnold JS, Braunstein EM, Ohyama T, et al. Tissue-specific roles of Tbx1 in the development of the outer middle and inner ear, defective in 22q11DS patients. Hum Mol Genet. 2006;15(10):1629-1639. doi:10.1093/ $\mathrm{hmg} / \mathrm{ddl084}$

39. Verheij E, Derks LSM, Stegeman I, Thomeer HGXM. Prevalence of hearing loss and clinical otologic manifestations in patients with 22q11.2 deletion syndrome: A literature review. Clin Otolaryngol. 2017; 42:1319-1328. doi:10.1111/coa.12874

40. Solot CB, Knightly C, Handler SD, et al. Communication disorders in the 22Q11.2 microdeletion syndrome. J Commun Disord. 2000;33(3):184-187.

41. Johnson J, Lalwani AK. Sensorineural and conductive hearing loss associated with lateral semicircular canal malformation. Laryngoscope. 2000;110(10 Pt 1):1673-1679. doi:10.1097/00005537-20001000000019

42. Jackler R, Luxford W, House W. Cochlear Malformations of the inner ear: A classification based on embryogenesis. Laryngoscope. 1987:97(3 Pt 2 Suppl 40):2-14.

43. Óskarsdóttir S, Belfrage M, Sandstedt E, Viggedal G, Uvebrant P. Disabilities and cognition in children and adolescents with 22q11 deletion syndrome. Dev Med Child Neurol. 2005;47(3):177-184. doi:10.1017/ S0012162205000320

44. Roizen NJ, Antshel KM, Fremont W, et al. 22q11.2DS Deletion Syndrome: Developmental Milestones in Infants and Toddlers. J Dev Behav Pediatr. 2007;28(2):119-124. doi:10.1097/01.DBP.0000267554.96081.12

45. Roizen NJ, Higgins AM, Antshel KM, Fremont W, Shprintzen R, Kates WR. 22q11.2 deletion syndrome: Are motor deficits more than expected for IQ level? J Pediatr. 2010;157(4):658-661. doi:10.1016/j jpeds.2010.04.073

46. Sobin C, Monk SH, Kiley-Brabeck K, Khuri J, Karayiorgou M. Neuromotor deficits in children with the 22q11 deletion syndrome. Mov Disord. 2006;21(12):2082-2089. doi:10.1002/mds.21103

47. Van Aken K, De Smedt B, Van Roie A, et al. Motor development in school-aged children with 22 q11 deletion (velocardiofacial/DiGeorge syndrome). Dev Med Child Neurol. 2007;49(3):210-213. doi:10.1111/ 
j.1469-8749.2007.00210.x

48. Gerdes M, Solot C, Wang PP, et al. Cognitive and behavior profile of preschool children with chromosome 22q11.2 deletion. Am J Med Genet. 1999;85(2):127-133.

49. Swillen A, Devriendt K, Legius $E$, et al. The behavioural phenotype in velo-cardio-facial syndrome (VCFS) from infancy to adolescence. Genet Couns. 1999;10(1):79-88.

50. Moxham LMR, Mallinson Al. Vestibular function correlates with radiologic findings in a gymnast with 22Q11.2DS. Am J Case Rep. 2020;21:2-5. doi:10.12659/AJCR.922908

51. Sennaroglu L, Saatci I. A new classification for cochleovestibular malformations. Laryngoscope. 2002;112(12):2230-2241. doi:10.1097/00005537-200212000-00019

52. Cunningham M, Perry RJ, Eby PR, Gibson RL, Opheim KE, Manning S. Primary Pulmonary Dysgenesis in Velocardiofacial Syndrome : A Second Patient. Am J Med Genet. 2003;179(February):177-179. doi:10.1002/ ajmg.a.20142

53. Devriendt K, Swillen A, Schatteman I, Lemmerling $M$, Dhooge I. Middle and inner ear malformations in velocardiofacial syndrome. Am J Med Genet A. 2004;131(2):225-226. doi:10.1002/ajmg.a.30326

54. Proctor DF. State of the Art. The Upper Airways. II The larynx and trachea. Am Rev Respir Dis. 1977;115:315342.

55. Hoerter JE, Chandran SK. Anatomy, Head and Neck, Laryngeal Muscles. StatPearls. Published online 2020:1-5. http://www.ncbi.nlm.nih.gov/pubmed/31424849

56. Noordzij JP, Ossoff RH. Anatomy and physiology of the larynx. Otolaryngol Clin North Am. 2006;39(1):110. doi:10.1016/j.otc.2005.10.004

57. Windsor A, Clemmens C, Jacobs IN. Rare Upper Airway Anomalies. Paediatr Respir Rev. 2016;17:24-28 doi:10.1016/j.prrv.2015.07.001

58. Arnold JS, Werling $U$, Braunstein EM, et al. Inactivation of Tbx1 in the pharyngeal endoderm results in 22q11DS malformations. Development. 2006;133(5):977-987. doi:10.1242/dev.02264

59. Baldini A. Dissecting contiguous gene defects: TBX1. Curr Opin Genet Dev. 2005;15(3 SPEC. ISS.):279284. doi:10.1016/j.gde.2005.03.001

60. de Bakker BS, de Bakker HM, Soerdjbalie-Maikoe V, Dikkers FG. The development of the human hyoidlarynx complex revisited. Laryngoscope. 2018;128(8):1829-1834. doi:10.1002/lary.26987

61. Benjamin B, Inglis A. Minor congenital laryngeal clefts: diagnosis and classification. Ann Otol Rhinol Laryngol. 1989;98:417-420

62. Hartnick CJ, Cotton RT. Congenital laryngeal anomalies. Laryngeal atresia, stenosis, webs, and clefts Otolaryngol Clin North Am. 2000;33(6):1293-1308

63. Johnston DR, Watters K, Ferrari LR, Rahbar R. Laryngeal cleft: Evaluation and management. Int J Pediatr Otorhinolaryngol. 2014;78(6):905-911. doi:10.1016/j.jporl.2014.03.015

64. Cohen SR. Congenital glottic webs in children. A retrospective review of 51 patients. Ann Otol Rhinol Laryngol Suppl. 1985;121:2-16

65. De Trey LA, Lambercy K, Monnier P, Sandu K. International Journal of Pediatric Otorhinolaryngology Management of severe congenital laryngeal webs - a 12 year review. Int J Pediatr Otorhinolaryngol. 2016;86:82-86. doi:10.1016/j.jporl.2016.04.006

66. Goudy S, Bauman N, Manaligod J, Smith RJH. Congenital Laryngeal Webs : Surgical Course and Outcomes. Ann Otol Rhinol Laryngol. 2010;119(10):704-706.

67. Miyamoto RC, Cotton RT, Rope AF, et al. Association of anterior glottic webs with velocardiofacial syndrome (chromosome 22q11 . 2 deletion ). Otolaryngol Head Neck Surg. 2004;130(4):415-417. doi:10.1016/j.otohns.2003.12.014

68. Myer III CM, O'Connor DM, Cotton RT. Proposed grading system for subglottic stenosis based on endotracheal tube sizes. Ann Otol Rhinol Laryngol. 1994;103:319-323.

69. Schroeder JW, Holinger LD. Congenital Laryngeal Stenosis. Otolaryngol Clin North Am. 2008;41:865-875 doi:10.1016/j.otc.2008.04.015

70. Ayari S, Aubertin G, Girschig H, Van Den Abbeele T, Mondain M. Pathophysiology and diagnostic approach to laryngomalacia in infants. Eur Ann Otorhinolaryngol Head Neck Dis. 2012;129(5):257-263. doi:10.1016/j. anorl.2012.03.005

71. Austin J, Ali T. Tracheomalacia and bronchomalacia in children : pathophysiology, assessment, treatmen and anaesthesia management. Paediatr Anaesth. 2003;13(1):3-11.

72. McDonald-McGinn DM, Kirschner R, Goldmuntz E, et al. The Philadelphia story: the 22q11.2 deletion report on 250 patients. Genet Couns. 1999;10(1):11-24. 
564555-L-bw-Verheij

Processed on: 16-9-2021 
$\bigcirc \quad T O L O G \quad Y$ 
564555-L-bw-Verheij

Processed on: 16-9-2021 


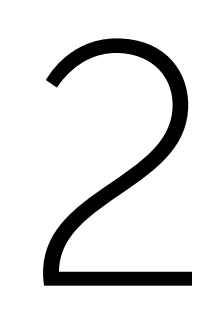

\section{PREVALENCE OF HEARING LOSS \\ AND CLINICAL OTOLOGIC MANIFESTATIONS IN PATIENTS WITH 22q11.2 DELETION SYNDROME: A LITERATURE REVIEW}




\section{ABSTRACT}

\section{Background}

Hearing loss and otitis media are frequently reported in patients with 22q11.2 deletion syndrome.

\section{Objective of review}

Our objective was to review the current literature on the prevalence of hearing loss and otologic manifestations in patients with 22q11.2 deletion syndrome.

\section{Type of review}

Systematic review.

\section{Search strategy}

We conducted a systematic search in PubMed and Embase combining the term '22q11.2 deletion syndrome' and synonyms with 'hearing loss' and 'otologic manifestations' and synonyms.

\section{Evaluation method}

We screened title/abstract and full text of all retrieved articles on predefined in- and exclusion criteria. The remaining articles were assessed on risk of bias. Outcome measures included the prevalence of hearing loss and otologic manifestations such as otitis media.

\section{Results}

Our search yielded 558 unique studies of which a total of 25 articles were included for critical appraisal and data extraction. Twenty-one studies reported on hearing loss and 21 studies on otologic manifestations. The prevalence of hearing loss varied from $6.0 \%$ to $60.3 \%$, where in most studies conductive hearing loss was most prevalent. Rates of recurrent or chronic otitis media varied from $2.2 \%$ to $89.8 \%$.

\section{Conclusion}

Although a very broad range in prevalences is reported in different studies, hearing loss and recurrent or chronic otitis media are frequently present. Regular check-ups and audiometric testing are advised in patients with 22q11.2 deletion syndrome. 


\section{INTRODUCTION}

The 22q11.2 deletion syndrome (22q11DS) is an autosomal dominant disorder caused by a microdeletion on the long arm of chromosome $22^{1-3}$ and has an estimated prevalence of 1 in 4000 live births. ${ }^{4,5}$ The syndrome is characterized by a heterogenic phenotype in both the individual patient as the patient population ${ }^{6}$, whereby some patients are severely affected, while others have only minor features. ${ }^{7}$ Within this broad range of manifestations, otitis media and (subsequent) conductive hearing loss are frequently reported. ${ }^{1-3,8-11}$ Sensorineural and mixed hearing loss are also described, but less frequently. $3,6,8-11$

The conductive hearing loss in 22q11DS patients is presumably to a large extent caused by otitis media and consequences thereof such as a perforation of the tympanic membrane. ${ }^{8-12}$ However, there are also case reports and one radiologic study describing middle ear malformation, including a dens stapes superstructure, that might result in conductive hearing loss. ${ }^{13-15}$ There are a few hypothesis regarding potential causes of sensorineural hearing loss in patients with 22q11DS. Some authors speculate on cochlear damage secondary to vascular damage or recurrent otitis media, ${ }^{16,17}$ others reported on patients with anatomical malformations of the inner ear. ${ }^{13}$ Recently, a retrospective radiologic study analyzed the CT scans of the temporal bone in 11 patients with 22q11DS and found an incomplete partition type II of the cochlea in $55 \%$ of the analyzed ears. ${ }^{15}$

In addition, Tbx1 is identified as a candidate gene responsible for ear abnormalities in mouse models. ${ }^{18-20}$ In mice, inactivation of the Tbx1 gene in the otic vesicle leads to disruption of inner ear development. ${ }^{21}$ Furthermore, the Tbx1 gene is needed to develop the outer and middle ear. ${ }^{21,22}$ In general, a phenotype genotype relation however, is in humans not yet found. ${ }^{23}$

Hearing is essential for speech and language development ${ }^{24}$ and early identification of permanent hearing loss (not originating from otitis media or other transient ear diseases) is suggested to lead to better language abilities on primary-school age. ${ }^{25}$ In addition, late-identified hearing loss can have a negative impact on social development. ${ }^{26}$ Many patients with 22q11DS experience speech and language difficulties even when not affected by hearing loss, ${ }^{27,28}$ making it essential to diagnose hearing loss in an early stage and optimize hearing in this specific population.

Given the large clinical variability of 22q11DS in combination with the need for early identification and treatment of hearing impairment, more insight on prevalence of otologic manifestations in 22q11DS is necessary. Therefore, in this systematic review we provide an overview of the prevalence of hearing loss and otologic manifestations of patients with 22q11DS reported in the current literature. 


\section{METHODS}

\section{Search strategy and selection}

On the $16^{\text {th }}$ of January 2017, we performed a literature search in PubMed and Embase, combining synonyms for the search term '22q11.2 deletion syndrome', 'hearing loss' and different otologic manifestations (Supplement 1). Two authors (EV and LD) independently screened all retrieved articles on title and abstract and subsequently on full text using predefined in- and exclusion criteria (Figure 1). Articles reporting the prevalence of hearing loss or otologic manifestations in children and adults with a confirmed 22q11.2 microdeletion were included. With this search strategy there is a possibility of missing articles that report our outcome measures as secondary outcome. Therefore, we performed a thorough cross-reference check of the selected articles using Web of Science. In case of an overlapping population between studies, we selected only the most recent or most comprehensive study.

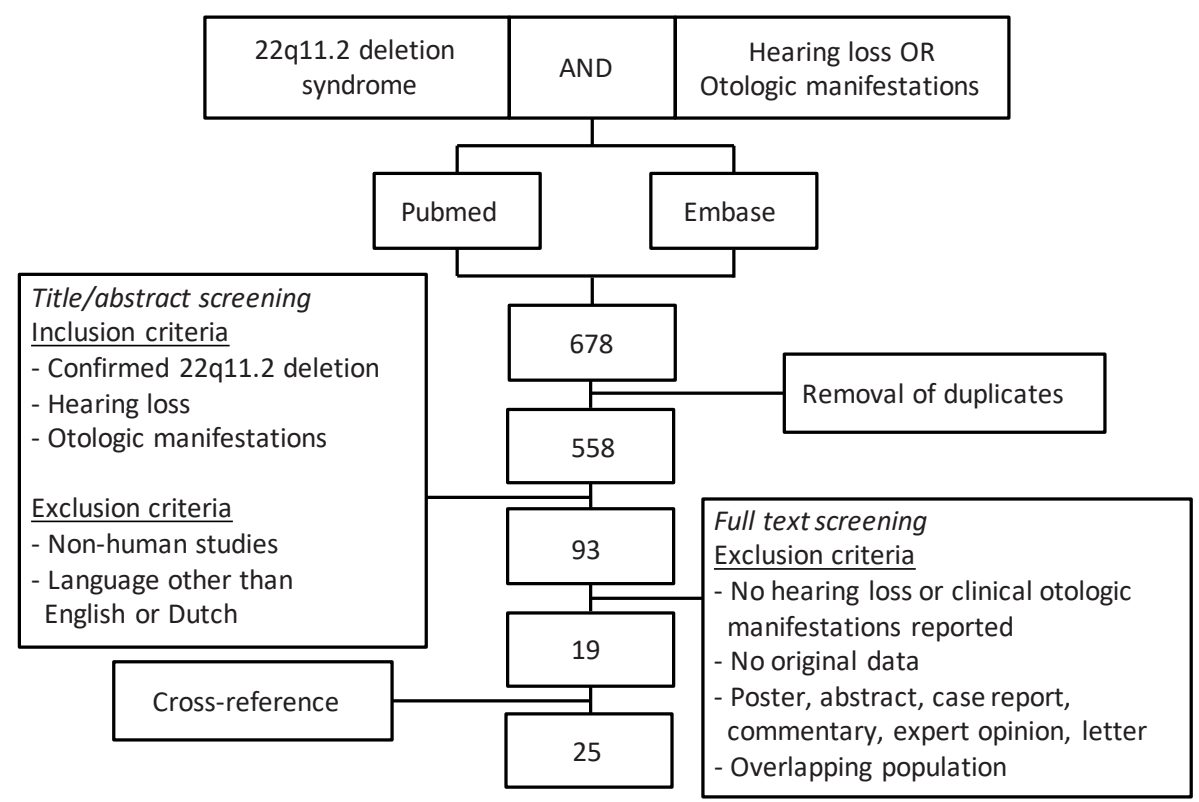

Figure 1. Flowchart demonstrating study selection process

\section{Quality assessment}

After screening on title, abstract and full text the remaining articles were critically appraised for risk of bias. Risk of bias assessment included selection bias, standardization, recall bias, missing data and lost to follow-up. 
Table 1. Critical appraisal

\begin{tabular}{|c|c|c|c|c|c|c|c|c|c|c|}
\hline \multirow{3}{*}{ Authors } & \multicolumn{3}{|c|}{ Study } & \multicolumn{7}{|c|}{ Risk of Bias } \\
\hline & \multirow{2}{*}{$\begin{array}{c}\text { Publication } \\
\text { year }\end{array}$} & \multirow{2}{*}{ Design } & \multirow{2}{*}{$\begin{array}{l}\text { Sample } \\
\text { size }\end{array}$} & \multicolumn{5}{|c|}{ Standardization } & \multirow[b]{2}{*}{ MD } & \multirow[b]{2}{*}{ FU } \\
\hline & & & & SB & DM & $\mathrm{HL}$ & OM & RB & & \\
\hline Basset et al. ${ }^{29}$ & 2005 & $\mathrm{RCS} / \mathrm{CS}$ & 78 & - & - & o & o & $?$ & - & NA \\
\hline Cancrini et al. ${ }^{30}$ & 2014 & RCS/PCS & 228 & $\bullet$ & $\bullet$ & ० & o & $?$ & o & $?$ \\
\hline Digilio et al. ${ }^{8}$ & 1999 & $?$ & 27 & $?$ & $\bullet$ & $\bullet$ & ○ & - & ○ & NA \\
\hline Dyce et al. ${ }^{9}$ & 2002 & RCS & 102 & $\bullet$ & $\bullet$ & o & - & $\bullet$ & $?$ & NA \\
\hline Finkelstein et al. ${ }^{31}$ & 1993 & $\mathrm{RCS}^{*}$ & 21 & $\circ$ & $\bullet$ & $\circ$ & $\circ$ & $\bullet$ & $\bullet$ & NA \\
\hline Ford et al. ${ }^{10}$ & 2000 & RCS & 35 & $\bullet$ & $\bullet$ & o & o & $\bullet$ & o & NA \\
\hline Jiramonkolchai et al. ${ }^{32}$ & 2016 & RCS & 58 & $\bullet$ & $\bullet$ & $\bullet$ & ० & $\bullet$ & $?$ & NA \\
\hline Jyonouchi et al. ${ }^{33}$ & 2009 & RCS & 564 & $\bullet$ & • & o & NA & $\bullet$ & ० & NA \\
\hline Kornfeld et al. ${ }^{34}$ & 2000 & RCS & 13 & $\bullet$ & • & NA & ० & 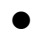 & $\bullet$ & NA \\
\hline Lay-Son et al. ${ }^{35}$ & 2012 & $\mathrm{RCS} / \mathrm{CS}$ & 201 & o & $\bullet$ & NA & o & $\bullet$ & $\bullet$ & NA \\
\hline Lima et al. ${ }^{36}$ & 2010 & $\mathrm{RCS} / \mathrm{CS}$ & 60 & $\bullet$ & - & NA & ○ & $\circ$ & - & NA \\
\hline Liu et al. ${ }^{37}$ & 2014 & RCS & 18 & $\bullet$ & $\bullet$ & o & ० & $\circ$ & $\bullet$ & NA \\
\hline Márquez-Ávila et al. ${ }^{38}$ & 2015 & PCS* & 62 & $\bullet$ & $\bullet$ & $\circ$ & NA & $\bullet$ & ० & NA \\
\hline Óskardóttir et al. ${ }^{39}$ & 2004 & RCS & 100 & $\bullet$ & - & NA & - & $\bullet$ & ० & $?$ \\
\hline Persson et al. ${ }^{28}$ & 2003 & CS & 65 & $\bullet$ & $\bullet$ & $\bullet$ & NA & $\bullet$ & $\bullet$ & NA \\
\hline Persson et al. ${ }^{40}$ & 2012 & CS & 24 & - & $\bullet$ & $\bullet$ & o & - & • & NA \\
\hline Ravnan et al. ${ }^{41}$ & 1996 & $\mathrm{RCS} / \mathrm{CS}$ & 31 & $\bullet$ & $\bullet$ & $\circ$ & ० & $\bullet$ & $\bullet$ & NA \\
\hline Reyes et al. ${ }^{11}$ & 1999 & RCS & 89 & $\circ$ & $\bullet$ & $\bullet$ & $\bullet$ & $\bullet$ & $\bullet$ & NA \\
\hline Ryan et al. ${ }^{12}$ & 1997 & RCS & 558 & $\bullet$ & 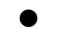 & o & ○ & $?$ & ० & NA \\
\hline Solot et al. ${ }^{27}$ & 2000 & PCS* & 305 & $\bullet$ & $\bullet$ & $\bullet$ & - & $\bullet$ & ० & NA \\
\hline Van Eynde et al. ${ }^{17}$ & 2016 & CS & 40 & $\bullet$ & $\bullet$ & $\bullet$ & $\bullet$ & $\bullet$ & $\bullet$ & NA \\
\hline Verheij et al. ${ }^{42}$ & 2016 & RCS & 199 & $\bullet$ & - & - & - & $\bullet$ & $\bullet$ & ० \\
\hline Vieira et al. ${ }^{43}$ & 2015 & CS & 35 & $\circ$ & $\bullet$ & ० & NA & $\bullet$ & o & NA \\
\hline Weir et al. ${ }^{44}$ & 2016 & RCS & 406 & $\bullet$ & - & - & ○ & $\bullet$ & ० & $?$ \\
\hline Zarchi et al. ${ }^{16}$ & 2011 & CS & 62 & $\bullet$ & 0 & $\bullet$ & $\bullet$ & $\bullet$ & $\bullet$ & $\mathrm{NA}$ \\
\hline
\end{tabular}

Abbreviations: Not applicable (NA); *results collected from cross-sectional assessment

Legend:

Study design: PCS = prospective cohort study; RCS = retrospective cohort study; $C S=$ cross-sectional study

Selection bias (SB): - patients selected upon domain (diagnosis 22q11 syndrome); 0 = patients selected based on disease characteristics; ? = not mentioned.

Standardization:

- Standardization of diagnostic method (DM): $\mathbf{0}$ = diagnosis confirmed by presence of deletion; $0=$ diagnosis

confirmed by phenotype; ? = diagnosis not confirmed or not mentioned.

- Standardization of hearing loss $(\mathrm{HL}):-1=$ predefined criteria for $\mathrm{HL} ; \mathrm{O}=$ no predefined criteria for $\mathrm{HL}$

- Standardization of otologic manifestations $(\mathrm{OM})$ : $\mathbf{0}=$ provided for all described manifestations; $\mathrm{O}=$ no

definition provided

Recall bias (RB): - data collected prospectively or by chart review; $0=$ data collected retrospectively by

questionnaires; ? = method of data collection not described.

Missing data (MD): $\bullet=<10 \%$ or method of handling described; $0=>10 \%$ and method of handling not

described; ? = not reported

Loss to follow up (FU): $=<10 \% ; \bigcirc=>10 \%$; ? = not described.

\section{Data extraction}

After critical appraisal we extracted study characteristics and descriptive data on hearing loss and otologic manifestations from the included studies. If the prevalence was not given in the article, it was calculated by dividing the number of affected patients by the total number of assessed patients. For complete and transparent reporting of results, this review was written according to the preferred reporting items for systematic reviews and meta-analysis (PRISMA) statement checklist. ${ }^{45}$ 
CHAPTER 2

\section{RESULTS}

\section{Search strategy and selection.}

The study selection process is shown in Figure 1. Our search yielded a total of 558 unique studies. After screening for title, abstract and title and cross-reference checking, we included 25 articles, which we critically appraised (Table 1).

In four studies selection bias could not be excluded as they included patients based on specific disease characteristics. These characteristics were velopharyngeal insufficiency, ${ }^{31,35}$ and/or palatal abnormalities. ${ }^{11,43}$

\section{Data extraction}

Study characteristics and descriptive data are presented in Table 2. In total, there were 3381 patients included (25 studies). Due to heterogeneity among the different studies, we could not pool the extracted data.

\section{Hearing loss}

Twenty-one studies reported on hearing loss (Table 2). Different definitions of hearing loss were used: most studies defined hearing loss as a pure tone average (PTA) of greater then (or equal to) 20 decibel hearing level (dB HL), 8,11,27,28,32,40,42 in two studies a threshold of $>15 \mathrm{~dB} H \mathrm{H}$ was used, ${ }^{17,44}$ and in one study $\geq 25 \mathrm{~dB}$ HL. ${ }^{16}$ Also, the frequencies at which the PTA was calculated differed as some authors used $0.5,1$ and $2 \mathrm{kHz}$, $81,17,27$ others used the frequencies $0.5,1,2$ and $4 \mathrm{kHz} .{ }^{28,40,42}$ and one study defined hearing loss at a hearing threshold below $15 \mathrm{~dB}$ at any frequency. ${ }^{44}$ In two articles the method of calculation was not mentioned. ${ }^{16,32}$ Rates of hearing loss, all types of hearing loss included, varied from $6.0 \%$ to $60.3 \%$. Aside from decreased hearing thresholds in standard frequencies, Zarchi et al. and Van Eynde et al. found hearing loss to be more present and more severe in the high tones (Van Eynde et al. measured thresholds at 4, 8, 9, 10 and $11.2 \mathrm{kHz}$ and Zarchi et al. at (4), 6 and $8 \mathrm{kHz}$ ). ${ }^{16,17}$ Conductive hearing loss was most prevalent in most studies (range $5.6 \%$ to $53 \%$ ), in only two studies sensorineural hearing loss or mixed hearing loss was present in more patients compared to conductive type hearing loss. ${ }^{16,37}$ The rate of sensorineural and mixed hearing loss in the included studies differed from $0 \%$ to $19.4 \%$ and from $0 \%$ to $28.2 \%$ respectively. The severity of hearing loss was reported by nine studies and was mostly of mild severity $(\leq 40 \mathrm{~dB}){ }^{8,16,17,27,31,32,40,42,44}$

\section{Otologic manifestations}

Twenty-one studies reported on otologic manifestations (Table 2). There were seven cross-sectional studies describing otoscopic findings, 16,17,27,30,31,40,42 and 16 studies reporting the medical history of otologic manifestations, including recurrent or chronic otitis media. ${ }^{8-12,30,32-36,38-42}$ This was either defined as the occurrence of more 
than three episodes per year ${ }^{8,36}$ or an episode lasting more than 30 days, ${ }^{9}$ three or more infections in the past six months or four or more per year, ${ }_{11}^{11}$ or more than ten middle ear infections. ${ }^{39} \mathrm{~A}$ medical history of recurrent or chronic otitis media was present in $2.2 \%$ to $89.8 \%$. Cross-sectional results revealed a prevalence of $3.8 \%$ to $25.8 \%$ of otitis media, including otitis media with effusion (serous) diagnosed with otoscopy and/or tympanometry. ${ }^{16,17,27,31,40,42}$

The prevalence of other otologic manifestations in patients with 22q11DS reported in the included articles are reported in Table 2 or summed up below. In addition to Table 2, Solot et al. reported on 16 patients with otitis media, eardrum retraction or tympanic membrane perforation, all diagnosed with hearing loss. ${ }^{27}$ One study reported on otologic surgery in patients' history, which included a tympanomastoidectomy $(n=1)$ and an ossiculoplasty $(n=2) .{ }^{10}$ In the study by Jiramongkolchai et al. nine patients required hearing aids. ${ }^{32}$ 


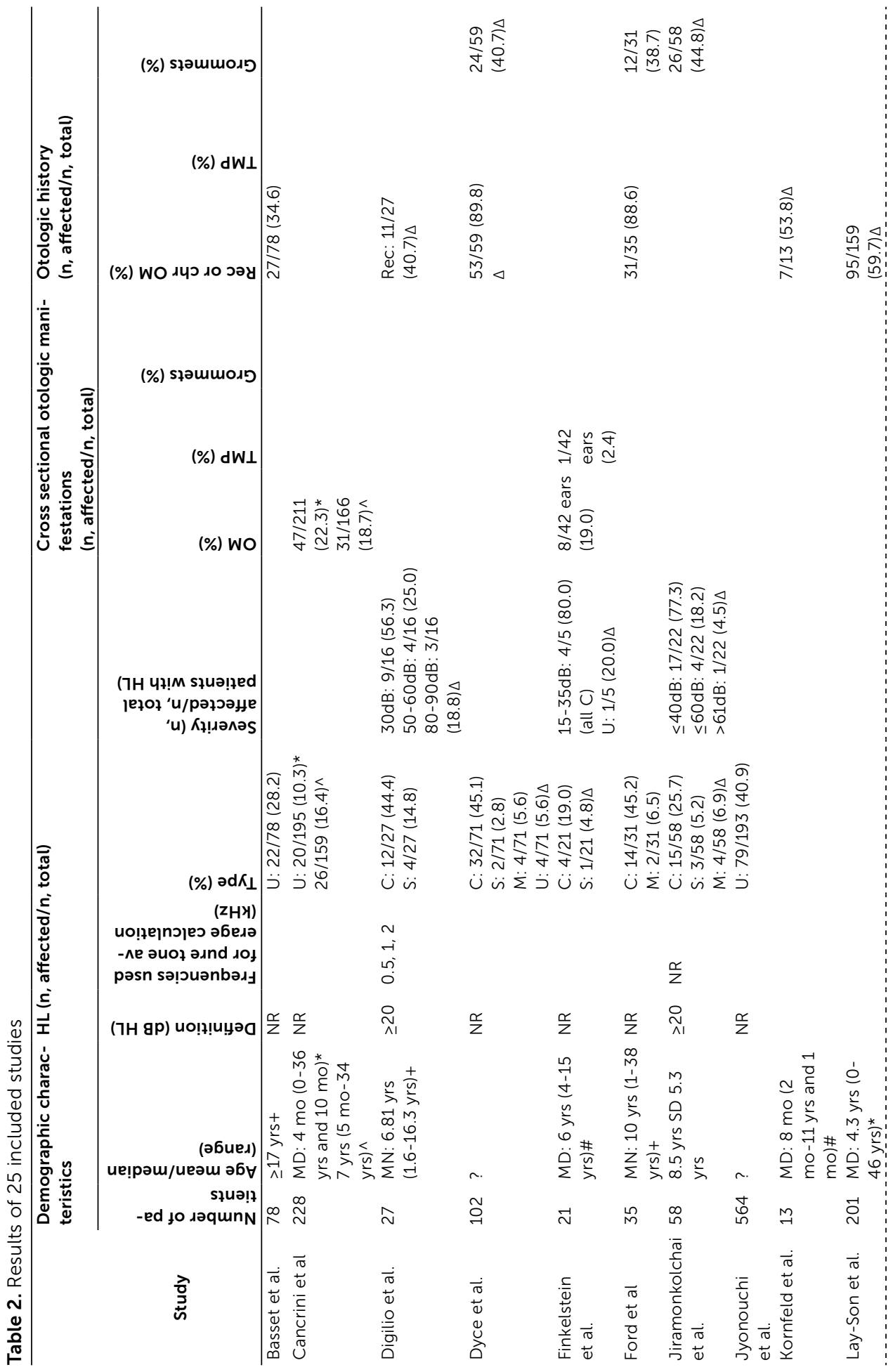




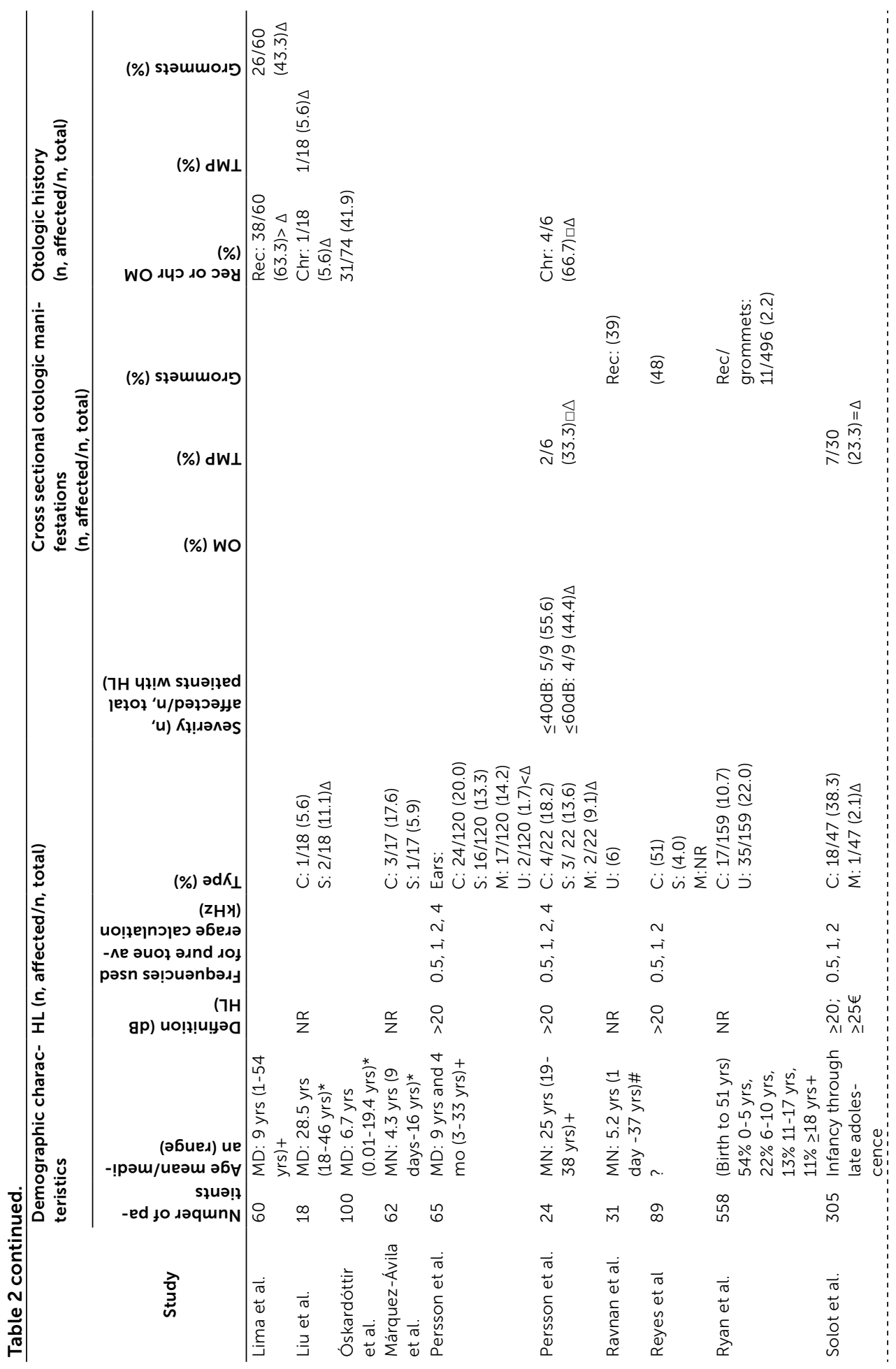




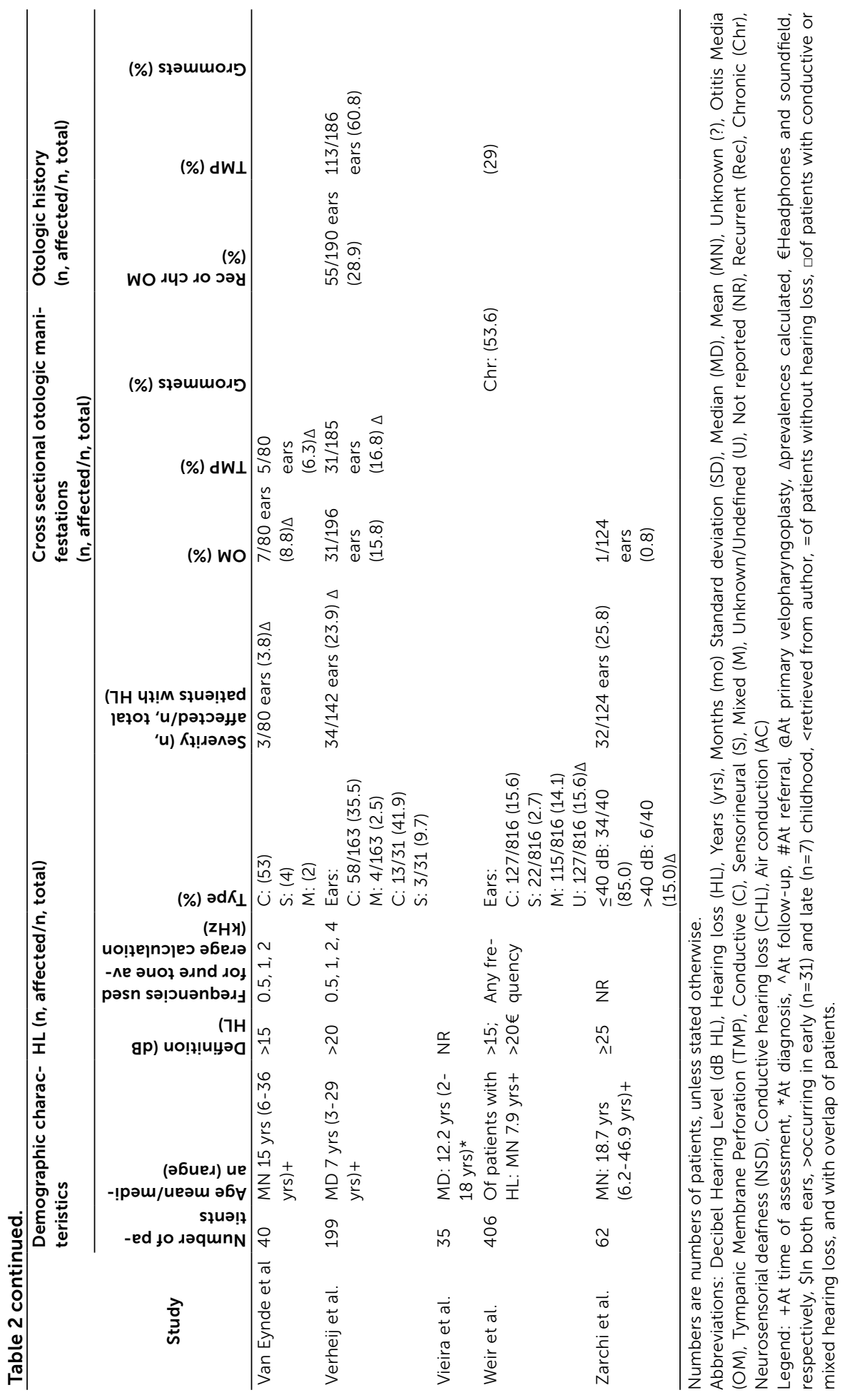




\section{DISCUSSION}

\section{Summary of main results}

Hearing loss and recurrent or chronic otitis media are common problems in patients with 22q11DS. We found a prevalence of hearing loss ranging from $6.0 \%$ to $60.3 \%$. Conductive hearing loss was reported in $5.6 \%$ to $53 \%$, sensorineural hearing loss in $0 \%$ to $19.4 \%$ and mixed hearing loss in $0 \%$ to $28.2 \%$ in the included studies. In addition, we found a prevalence of recurrent or chronic otitis media ranging from $2.2 \%$ to $89.8 \%$.

\section{Comparison with general population}

Comparing the prevalence of hearing loss and recurrent otitis media to the general population shows that these conditions are more common in patients with 22q11DS. In a population-based cross sectional survey, a prevalence of hearing loss of $14.9 \%$ was found in children aged six to 19 years. ${ }^{46}$ In another population-based study, also among children aged six to 19 years, a prevalence of $4.7 \%$ was found for hearing loss (>20 dB HL averaged over $0.5,1,2,4 \mathrm{kHz}$ ). ${ }^{47}$ They furthermore estimated that less than $2.2 \%$ of children in this age group had sensorineural hearing loss and less than $3.5 \%$ of children between three and 19 years had conductive hearing loss. ${ }^{47}$ Although the outcome of our included studies differed much, 20 of 21 studies found a prevalence of hearing loss greater than the previously reported $14.9 \%$ hearing loss in the general population. ${ }^{8-12,16,17,27,28,29-33,37,38,40,42-44}$

Regarding recurrent otitis media, in a population-based study among 50.474 children (data was collected from birth until the age of three) $7.8 \%$ had recurrent otitis media, defined as four or more physician visits in one year, or three or more visits in six months. ${ }^{48}$ As shown in the current review this prevalence appears to be considerably higher in the 22q11DS population.

\section{Possible pathophysiologic factors of otitis media and hearing loss}

As in patients with 22q11DS, otitis media is also frequently present in (non-syndromatic) children with a cleft palate, which is presumably caused by Eustachian tube dysfunction. ${ }^{49,50} \mathrm{~A}$ cleft palate (mostly submucosal) is an important feature of 22q11DS and present in many patients with 22q11DS.2,12 Possibly, the same pathophysiology is causing otitis media in patients with a cleft palate and in patients with 22q11DS. This is supported by the fact that in mouse models for 22q11DS a hypoplastic levator veli palatini muscle was found and related to otitis media. ${ }^{51}$

Subsequently, otitis media could lead to conductive hearing loss is in 22q11DS, and in some cases even to cochlear damage which could lead to sensorineural hearing loss. ${ }^{52}$ Interestingly however, Loos et al. analyzed the CT scans of the temporal bone in 11 patients and found anatomical malformations of as well the middle ear as the inner ear. ${ }^{15}$ The authors described a malleus fixated to the tympanic annulus, and a thin 
CHAPTER 2

and horizontally positioned long process of the incus in two of 22 analyzed ears. In addition, the stapes was abnormally orientated in one ear, and there was a dense stapes superstructure in $45 \%$ of ears. This latter malformation was suggested not to arise from recurrent middle ear infections since one patient showed to have this abnormality at only 9 days of age. Furthermore, they reported on a larger basal turn of the cochlea in two ears and an incomplete partition in 12 ears (55\%). ${ }^{15}$ Ossicular chain abnormalities are also reported by Persson et al., Solot et al. and Jiramongkolchai et al., (although these studies were included in this review, these data were not) and they described a total of eight patients with ossicular chain malformations. ${ }^{27,32,40}$ Presumably, hearing loss in patients with 22q11DS is a multifactorial issue.

\section{Variation in outcome}

Regarding the reported prevalences in this review, the broad range is striking. The heterogeneity of the included studies could have contributed to this diversity of prevalences. One of the varying factors was the age of included patients ranging from birth to adulthood. In the general population, otitis media is most prevalent in young children. ${ }^{53,54}$ It is likely that also in patients with 22q11DS, adults experience fewer and less severe episodes of recurrent or chronic otitis media compared to children. Furthermore, age could also influences hearing results, showing an increase of sensorineural hearing loss with age. One included study found a positive relation between age and decreasing hearing thresholds in the high tones in 22q11DS, suggesting a progressive high tone hearing loss. ${ }^{16}$ This could be due to aging, but recurrent otitis media might also lead to cochlear damage, ${ }^{16,17}$ emphasizing the necessity of early diagnosis and treatment.

Several other factors contributed to the large heterogeneity between the included studies. First, 11 of 21 studies did not provide a definition of hearing loss. 9,10,12,29-31,33,37,38,41,43 This does not only make these results hard to interpret and compare to other studies but might also result in an increased risk of bias due to lack of standardization. Also, different definitions of recurrent or chronic otitis media and hearing loss were used. The definitions for hearing loss varied between a pure tone average of greater than 15 $\mathrm{dB}$ ( two studies), 17,44 greater than (or equal to) $20 \mathrm{~dB}$ (seven studies), , 11,27,28,32,40,42 and greater than or equal to $25 \mathrm{~dB}$ (one study). ${ }^{16}$ Moreover, the pure tone average used in these definitions varied among the studies. These differences in methods could easily affect the results of studies and therefore contribute to the large variation in outcome. In addition, of the included studies, there were four studies which only included patients with velopharyngeal insufficiency and/or cleft palate. ${ }^{11,31,35,43}$ Patients with velopharyngeal insufficiency or cleft palate have a higher risk of middle ear diseases and subsequently conductive hearing loss, which might have introduced bias. ${ }^{50,55}$ 


\section{Limitations}

The main limitation of this review is that despite the thorough literature search, screening and cross-reference check of retrieved articles, there is a possibility that articles reporting on hearing outcome and otologic manifestations as secondary outcome measures were missed.

In addition, Dyce et al., Jyonouchi et al., Solot et al. and Weir et al. all included patients from the database of Children's Hospital of Philadelphia.9,27,33,44 Therefore, we could not rule out the possibility of overlapping populations.

For future research prospective cohort studies with standardized regular, otologic and audiologic assessments would be very informative for more insight on the evolvement of hearing loss and otologic manifestations in patients with 22q11DS.

\section{CONCLUSION}

Although there is a great diversity in reported prevalence rates in the different studies, it can be concluded that hearing loss and recurrent or chronic otitis media are frequently present in the 22q11DS population. To prevent adverse health and social related consequences of hearing loss and frequently occurring otologic manifestations of 22q11DS regular check-ups and audiometric testing by an otolaryngologist is advised, especially at a young age. 


\section{REFERENCES}

1. Shprintzen RJ, Higgens AM, Antshel K, Fremont W, Roizen N, Kates W. Velo-cardio-facial syndrome. Curr Opin Pediatr. Published online 2005:725-730.

2. Bassett AS, Mcdonald-mcginn DM, Devriendt K, et al. Practical Guidelines for Managing Patients with 22q11.2 Deletion Syndrome. J Pediatr. 2011;159(2):332-339.e1. doi:10.1016/j.jpeds.2011.02.039

3. Kobrynski LJ, Sullivan KE. Velocardiofacial syndrome, DiGeorge syndrome: the chromosome $22 \mathrm{q} 11.2$ deletion syndromes. Lancet. 2007;370(9596):1443-1452.

4. Devriendt K, Fryns JP, Mortier G, Van Thienen MN, Keymolen K. The annual incidence of DiGeorge/ velocardiofacial syndrome. :7-9.

5. Óskarsdóttir S, Vujic M, Fasth A. Incidence and prevalence of the 22q11 deletion syndrome: a populationbased study in Western Sweden. Arch Dis Child. 2004;89:148-152. doi:10.1136/adc.2003.026880

6. Robin NH, Shprintzen RJ. Defining the clinical spectrum of deletion 22q11.2. J Pediatr. 2005;147(1):90-96.

7. Digilio M, Angioni A, De Santis $M$, et al. Spectrum of clinical variability in familial deletion $22 q 11$. 2 : from full manifestation to extremely mild clinical anomalies. 2003; (January 1993):308-313.

8. Digilio MC, Pacifico C, Tieri L, Marino B, Giannotti A, Dallapiccola B. Audiological findings in patients with microdeletion 22q11 (diGeorge/velocardiofacial syndrome). Br J Audiol. 1999;33(5):329-333.

9. Dyce O, McDonald-McGinn DM, Kirschner RE, Zackai E, Young K, Jacobs IN. Otolaryngologic manifestations of the 22q11.2 deletion syndrome. Arch Otolaryngol Head Neck Surg. 2002;128(12):14081412

10. Ford LC, Sulprizio SL, Rasgon BM. Otolaryngological manifestations of velocardiofacial syndrome: a retrospective review of 35 patients. Laryngoscope. 2000;110(3 Pt 1):362-367.

11. Reyes MRT, LeBlanc EM, Bassila MK. Hearing loss and otitis media in velo-cardio-facial syndrome. Int $\mathrm{J}$ Pediatr Otorhinolaryngol. 1999;47(3):227-233.

12. Ryan AK, Goodship JA, Wilson DI, et al. Spectrum of clinical features associated with interstitia chromosome 22q11 deletions: a European collaborative study. J Med Genet. 1997;34(10):798-804. doi:10.1136/jmg.34.10.798

13. Devriendt K, Swillen A, Schatteman I, Lemmerling M, Dhooge I. Middle and inner ear malformations in velocardiofacial syndrome. Am J Med Genet A. 2004;131(2):225-226. doi:10.1002/ajmg.a.30326

14. Cunningham M, Perry RJ, Eby PR, Gibson RL, Opheim KE, Manning S. Primary Pulmonary Dysgenesis in Velocardiofacial Syndrome : A Second Patient. Am J Med Genet. 2003;179(February):177-179. doi:10.1002/ ajmg.a.20142

15. Loos E, Verhaert N, Willaert A, et al. Malformations of the Middle and Inner Ear on CT Imaging in $22 \mathrm{q} 11$ Deletion Syndrome. Am J Med Genet Part A. 2016;170(11):2975-2983. doi:10.1002/ajmg.a.37872

16. Zarchi O, Attias J, Raveh E, Basel-Vanagaite L, Saporta L, Gothelf D. A comparative study of hearing loss in two microdeletion syndromes: velocardiofacial (22q11.2 deletion) and Williams (7q11.23 deletion) syndromes. J Pediatr. 2011;158(2):301-306. doi:10.1016/j.jpeds.2010.07.056

17. Van Eynde C, Swillen A, Lambeens E, et al. Prevalence and Nature of Hearing Loss in 22q11.2 Deletion Syndrome. J Speech, Lang Hear Res. 2016;59(3):583-589. doi:10.1044/2015

18. Fuchs JC, Zinnamon FA, Taylor RR, et al. Hearing loss in a mouse model of 22q11.2 Deletion Syndrome. PLoS One. 2013;8(11):e80104. doi:10.1371/journal.pone.0080104

19. Funke B, Epstein JA, Kochilas LK, et al. Mice overexpressing genes from the 22 q11 region deleted in velo-cardio-facial syndrome/DiGeorge syndrome have middle and inner ear defects. Hum Mol Genet. 2001;10(22):2549-2556.

20. Vitelli F, Viola A, Morishima M, Pramparo T, Baldini A, Lindsay E. TBX1 is required for inner ear morphogenesis Hum Mol Genet. 2003;12(16):2041-2048

21. Arnold JS, Braunstein EM, Ohyama T, et al. Tissue-specific roles of Tbx1 in the development of the outer middle and inner ear, defective in 22q11DS patients. Hum Mol Genet. 2006;15(10):1629-1639. doi:10.1093/ $\mathrm{hmg} / \mathrm{ddl} 084$

22. Jerome LA, Papaioannou VE. DiGeorge syndrome phenotype in mice mutant for the T-box gene, Tbx1. Nat Genet. 2001;27(3):286-291.

23. Michaelovsky E, Frisch A, Carmel M, et al. Genotype-phenotype correlation in 22q11.2 deletion syndrome. Published online 2012

24. Tomblin JB, Harrison M, Ambrose SE, Walker EA, Oleson JJ, Moeller MP. Language Outcomes in Young Children with Mild to Severe Hearing Loss. Published online 2015:76-91

25. Kennedy CR, McCann DC, Campbell MJ, et al. Language Ability after Early Detection of Permanent Childhood Hearing Impairment. Published online 2006:2131-2141.

26. Yoshinaga-itano C. Early intervention after universal neonatal hearing screening: impact on outcomes. 2003:266:252-266 doi:10.1002/mrdd 10088

27. Solot CB, Knightly C, Handler SD, et al. Communication disorders in the 22Q11.2 microdeletion syndrome 
J Commun Disord. 2000;33(3):184-187.

28. Persson C, Lohmander A, Jönsson R, Oskarsdóttir S, Söderpalm E. A prospective cross-sectional study of speech in patients with the 22q11 deletion syndrome. J Commun Disord. 2003:36(1):13-47. http://www. ncbi.nlm.nih.gov/pubmed/12493636

29. Bassett AS, Chow EWC, Husted J, et al. Clinical features of 78 adults with $22 q 11$ deletion syndrome. Am J Med Genet. 2005;138 A(4):307-313. doi:10.1002/ajmg.a.30984

30. Cancrini C, Puliafito P, Digilio MC, et al. Clinical features and follow-up in patients with 22 q11.2 deletion syndrome. J Pediatr. 2014;164(6):1475-1480. doi:10.1016/j.jpeds.2014.01.056

31. Finkelstein $Y$, Zohar $Y$, Nachmani A, et al. The otolaryngologist and the patient with velocardiofacial syndrome. Arch Otolaryngol Head Neck Surg. 1993:119(5):563-569.

32. Jiramongkolchai P, Kumar MS, Chinnadurai S, Wootten CT, Goudy SL. Prevalence of hearing loss in children with 22q11.2 deletion syndrome. Int J Pediatr Otorhinolaryngol. 2016;87:130-133. doi:10.1016/j. ijporl.2016.06.005

33. Jyonouchi S, McDonald-McGinn DM, Bale S, Zackai EH, Sullivan KE. CHARGE (coloboma, heart defect, atresia choanae, retarded growth and development, genital hypoplasia, ear anomalies/deafness) syndrome and chromosome 22q11.2 deletion syndrome: a comparison of immunologic and nonimmunologic phenotypic features. Pediatrics. 2009;123(5):e871-7. doi:10.1542/peds.2008-3400

34. Kornfeld SJ, Zeffren B, Christodoulou CS, Day NK, Cawkwell G, Good RA. DiGeorge anomaly: a comparative study of the clinical and immunologic characteristics of patients positive and negative by fluorescence in situ hybridization. J Allergy Clin Immunol. 2000;105(5):983-987. doi:10.1067/mai.2000.105527

35. Lay-Son G, Palomares M, Guzman ML, Vasquez M, Puga A, Repetto GM. Palate abnormalities in Chilean patients with chromosome 22q11 microdeletion syndrome. Int J Pediatr Otorhinolaryngol. 2012;76(12):1726-1728. doi:10.1016/j.ijporl.2012.08.010

36. Lima K, Folling I, Eiklid KL, Natvig S, Abrahamsen TG. Age-dependent clinical problems in a Norwegian national survey of patients with the 22q11.2 deletion syndrome. Eur J Pediatr. 2010;169(8):983-989. doi:10.1007/s00431-010-1161-3

37. Liu APY, Chow P-C, Lee PPW, et al. Under-recognition of 22q11.2 deletion in adult Chinese patients with conotruncal anomalies: implications in transitional care. Eur J Med Genet. 2014;57(6):306-311. doi:10.1016/j.ejmg.2014.03.014

38. Márquez-ÁvilaCS, Vizcaíno-AlarcónA, García-DelgadoC, etal.Velocardiofacial syndromein Mexicanpatients: Unusually high prevalence of congenital heart disease. Int J Pediatr Otorhinolaryngol. 2015;79(11):18861891. http://www.embase.com/search/results? subaction=viewrecord\&from $=$ export\&id $=$ L606662795

39. Óskarsdóttir S, Persson C, Eriksson BO, Fasth A. Presenting phenotype in 100 children with the 22q11 deletion syndrome. Eur J Pediatr. 2005;164(3):146-153. doi:10.1007/s00431-004-1577-8

40. Persson C, Friman V, Oskarsdottir S, Jonsson R. Speech and hearing in adults with 22q11.2 deletion syndrome. Am J Med Genet A. 2012;158A(12):3071-3079. doi:10.1002/ajmg.a.35589

41. Ravnan BJ, Chen E Golabi M. Lebo RV Chromosome 22q11.2 microdeletions in velocardiofacial syndrome patients with widely variable manifestations. Am J Med Genet. 1996;66(3):250-256. doi:10.1002/ (SICI)1096-8628(19961218)66:3<250::AID-AJMG2>3.0.CO;2-T

42. Verheij E, Kist AL, Mink Van Der Molen A, Stegeman I. Otologic and audiologic findings in 22q11.2 deletion syndrome. Eur Arch Oto-Rhino-Laryngology. 2017;274:765-771. doi:10.1007/s00405-016-4365-y

43. Vieira TP, Monteiro FP, Sgardioli IC, et al. Clinical Features in Patients With 22q11.2 Deletion Syndrome Ascertained by Palatal Abnormalities. Cleft Palate Craniofac J. 2015:52(4):411-416. doi:10.1597/13-233

44. Weir FW, Wallace SA, White DR, Hatch JL, Nguyen SA, Meyer TA. Otologic and Audiologic Outcomes in Pediatric Patients With Velo-Cardio-Facial (22q11 Deletion) Syndrome. Otol Neurotol. 2016:38(1):73-78. doi:10.1097/MAO.0000000000001226

45. Moher D, Liberati A, Tetzlaff J, Altman DG, Group TP. Preferred Reporting Items for Systematic Reviews and Meta-Analyses: The PRISMA Statement. 2009:6(7). doi:10.1371/journal.pmed.1000097

46. Niskar AS, Kieszak SM, Holmes A, Esteban E, Rubin C, Brody DJ. Prevalence of Hearing Loss Among Children 6 to 19 Years of Age The Third National Health and Nutrition Examination Survey. 2017:279(14).

47. Feder KP, Michaud D, Mcnamee J, Fitzpatrick E, Ramage-morin P, Beauregard Y. Prevalence of Hearing Loss Among a Representative Sample of Canadian Children and Adolescents, 3 to 19 Years of Age. 2017;(2015):7-20.

48. Maclntyre EA, Karr CJ, Koehoorn M, et al. Otitis media incidence and risk factors in a population-based birth cohort. 2010;15(7):437-442

49. Heidsieck DSP, Smarius BJA, Oomen KPQ, Breugem CC. The role of the tensor veli palatini muscle in the development of cleft palate-associated middle ear problems. Clin Oral Investig. Published online 2016:1389-1401. doi:10.1007/s00784-016-1828-x

50. Sheahan P, Miller I, Sheahan JN, Earley MJ, Blayney AW. Incidence and outcome of middle ear disease in cleft lip and/or cleft palate. 2003;5876:785-793. doi:10.1016/S0165-5876(03)00098-3

51. Fuchs JC, Linden JF, Baldini A, Tucker AS. A defect in early myogenesis causes Otitis media in two mouse models of 22q11.2 Deletion Syndrome. Hum Mol Genet. 2015;24(7):1869-1882. doi:10.1093/hmg/ddu604 
CHAPTER 2

52. Wilhelm T, Stelzer T, Wiegand S, Gu C, Hagen R, Gu T. Toxic inner ear lesion following otitis media with effusion: a comparative CT-study regarding the morphology of the inner ear. Published online 2015:36353643. doi:10.1007/s00405-014-3425-4

53. Schilder A, Zielhuis GA, Broek PVANDEN. The otological profile of a cohort of Dutch 7.5-8-year-olds. Clin Otolaryngol. 1993;18:48-54.

54. Martines F, Bentivegna D, Di F, Gioacchino P, Sciacca V, Martines E. The point prevalence of otitis media with effusion among primary school children in Western Sicily. Eur Arch Otorhinolaryngol. 2010;267:709714. doi:10.1007/s00405-009-1131-4

55. Sheahan P, Miller I, Earley MJ, Sheahan JN, Blayney AW. Middle Ear Disease in Children With Congenital Velopharyngeal Insufficiency. 1999;(1976):2-5. 


\section{SUPPLEMENT}

Supplement 1. Search strategy

\begin{tabular}{|c|c|c|}
\hline Database & Syntax (January $16^{\text {th }} 2016$ ) & Results \\
\hline PubMed & $\begin{array}{l}\text { ((22q11*[tiab] OR VCF*[tiab] OR "velo cardio facial"[tiab] OR Velocardiofacial[tiab] OR } \\
\text { "velo-cardio-facial"[tiab] OR DiGeorge*[tiab] OR "Pharyngeal Pouch Syndrome"[tiab] } \\
\text { OR "Shprintzen Syndrome"[tiab] OR "Conotruncal Anomaly Face Syndrome"[tiab] OR } \\
\text { "22q11 deletion syndrome"[MeSH] OR "DiGeorge syndrome"[MeSH]) AND (Ear[tiab] OR } \\
\text { Auricular[tiab] OR Hearing[tiab] OR Deaf*[tiab] OR Audio* [tiab] OR Auditor*[tiab] OR } \\
\text { Otol* [tiab] OR Otorhino*[tiab] OR Ent[tiab] OR Otitis[tiab] OR "hearing loss"[tiab] OR } \\
\text { "hearing loss"[MeSH] OR "Otorhinolaryngologic Diseases"[MeSH])) }\end{array}$ & 388 \\
\hline Embase & Accustomed search designed for Embase & 290 \\
\hline Total & & 678 \\
\hline
\end{tabular}


564555-L-bw-Verheij

Processed on: 16-9-2021 


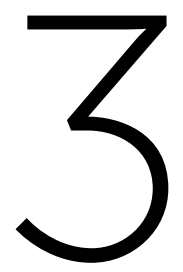

\title{
OTOLOGIC AND AUDIOLOGIC FINDINGS IN 22q11.2 DELETION SYNDROME
}

Eur Arch Otorhinolaryngol. 2017; 274(2): 765-771. doi: 10.1007/s00405-016-4365-y

\author{
Emmy Verheij \\ Alwine L. Kist \\ Aebele B. Mink van der Molen \\ Inge Stegeman \\ Gijsbert A. van Zanten \\ Wilco Grolman \\ Hans G.X.M. Thomeer
}


CHAPTER 3

\section{ABSTRACT}

Hearing loss is frequently present in the 22q11.2 deletion syndrome. Our aim was to describe the audiologic and otologic features of patients with 22q11.2 deletion syndrome. We conducted a retrospective cohort study in a single tertiary referral center. We reviewed medical files of all patients with $22 q 11.2$ deletion syndrome who visited an otolaryngologist, plastic surgeon or speech therapist, for audiologic and otologic features. Hearing loss was defined as a pure tone average (of 0.5, 1, 2 and 4 $\mathrm{kHz}$ ) of $>20$ decibel hearing level. 102 out of 199 included patients had an available audiogram, there were 163 ears with an audiogram where the frequencies $0.5-4 \mathrm{kHz}$ were measured. Median age at time of most recent audiogram was 7 years (range 3 to 29 years). In 62 out of 163 ears (38\%) hearing loss was present. Most ears had conductive hearing loss $(n=58)$ and four ears had mixed hearing loss. The severity of hearing loss was most frequently mild (pure tone average of $\leq 40$ decibel hearing (evel). In $22.5 \%$ of ears otitis media with effusion was observed at time of most recent audiogram. Age was not related to mean air conduction hearing thresholds or to otitis media with effusion ( $p=0.43$ and $p=0.11$ respectively). In conclusion, hearing loss and otitis media are frequently present in patients with $22 q 11.2$ deletion syndrome. Moreover, our results suggest that children with 22q11.2 deletion syndrome remain susceptible for otitis media as they age. 


\section{INTRODUCTION}

First identified in 1983 and later confirmed in the 1990's, patients with velocardiofacial syndrome, diGeorge syndrome and conotruncal anomaly face syndrome were found to have a microdeletion in the same genetic region, the $22 q 11.2$ region. ${ }^{1-4}$ This led to one united syndrome, the 22q11.2 deletion syndrome (22q11DS). ${ }^{5}$ This syndrome has a heterogenic phenotype and is characterized by congenital heart anomalies, immunodeficiency, kidney abnormalities, cleft palate (from bifid uvula to complete cheilo-gnatho-palato cleft), velopharyngeal insufficiency, speech and language impairment. ${ }^{5-10}$

Many patients diagnosed with this syndrome are known to have recurrent otitis media and hearing loss. $5,6,15-18,7-14$ The reported prevalence of hearing loss in 22q11DS varies between 40 and $64.5 \%$, which is considerably higher compared to the prevalence rate in the general population. ${ }^{11-19}$ Hearing loss in 22q11DS is mostly conductive, but sensorineural and mixed hearing loss is also described. ${ }^{11-18}$ Conductive hearing loss in patients diagnosed with 22q11DS is associated with recurrent otitis media. ${ }^{10-14,16,17,19}$

Causes of otitis media and conductive hearing loss in 22q11DS are presumably multifactorial. Many patients with 22q11DS suffer from immunodeficiency with recurrent respiratory tract infections. In addition, dysfunction of the Eustachian tube is suggested to be an important factor in developing otitis media. 12,13,16,17 Mouse models of 22q11DS have shown a relation between otitis media and conductive hearing loss. ${ }^{20,21}$ In addition, in mouse models of 22q11DS a hypoplastic levator veli palatini muscle, an intrinsic muscle of the Eustachian tube, was found. Interestingly, in the case of unilateral otitis media with effusion, the levator veli palatini muscle in mice was significantly smaller on the side of otitis media compared to the non-inflamed side. ${ }^{22}$ In addition, congenital middle ear malformations are also described in patients. ${ }^{14,23,24}$

Regarding the sensorineural hearing loss, cochlear damage as a result of chronic otitis media has been suggested as a possible underlying cause. ${ }^{17,18}$ Furthermore, Tbx1, a gene located on the $22 q 11.2$ region (the same region where the microdeletion in 22q11DS is located), is suggested to be required for inner ear development. ${ }^{25,26}$ Along with this finding, congenital malformation of the cochlea is described in a case report. ${ }^{24}$

Our tertiary referral center contains a cohort of approximately 22022 q11DS patients who are evaluated and treated by a multidisciplinary team. We aimed to describe the otologic and audiologic findings of these patients. In addition, we analyzed the influence of aging on hearing thresholds and otologic manifestations. 


\section{MATERIAL AND METHODS}

\section{Patients}

We conducted a retrospective cohort study in a single Dutch tertiary referral center. All patients diagnosed with 22q11DS after multidisciplinary outpatient intake and examination (including plastic surgeon, otolaryngologist and speech therapist) until 12th November 2015 were included. We reviewed medical files for audiologic and otologic features including a history of otitis media (acute or chronic (with effusion)), grommet insertion, tympanic membrane perforation, cholesteatoma, adenoidectomy, adaptation of hearing aids (air or bone conduction) and history of otologic surgery. In addition, we collected all available conventional pure tone audiograms and we reviewed otoscopic reports specifically at time of most recent audiogram. If these reports were lacking, information on tympanic membrane perforations and grommets could be reasoned if there was a tympanic membrane perforation or grommet in place sometime before and after the most recent audiogram. Then we assumed that those findings were also present during most recent audiogram.

\section{Audiometric examination}

We defined hearing loss as a pure tone average (PTA) (of 0.5, 1, 2 and $4 \mathrm{kHz}$ ) of more than 20 decibel hearing level ( $\mathrm{dB} \mathrm{HL}$ ), in concordance with the AAO-HNS 1995 guidelines (apart from $3 \mathrm{kHz}$ where we used $4 \mathrm{kHz}$ ). ${ }^{27}$ Conductive hearing loss was determined as an average air conduction (AC) threshold of $>20 \mathrm{~dB} \mathrm{HL}$ in combination with an air-bone gap ( $A B G$ ) of $\geq 10 \mathrm{~dB}$ at one or more frequencies. Sensorineural hearing loss was defined as hearing loss with an $A B G<10 \mathrm{~dB}$ in all frequencies and mixed hearing loss as an average $A C$ and bone conduction (BC) threshold of $>20 \mathrm{~dB} \mathrm{HL}$, and an $A B G$ of $\geq 10 \mathrm{~dB}$ at one or more frequencies. Hearing loss was classified as mild (21$40 \mathrm{~dB}$ ), moderate (41-60 dB), moderate to severe (61-70 dB), severe (71-90 dB) and profound $(\geq 91 \mathrm{~dB})$. In the cases of absent bone conduction measurement at first or most recent audiometric evaluation, $\mathrm{BC}$ thresholds from earlier or later measurements were evaluated. If previous or later $B C$ measurements were lacking, the $B C$ from the contralateral ear was adapted. We defined immeasurable $A C$ thresholds due to bad hearing (marked by a downward arrow on the audiogram) as a threshold of $130 \mathrm{~dB} \mathrm{HL}$. For immeasurable BC thresholds with measurable AC, consensus between authors (EV, GvZ and $\mathrm{HT}$ ) was reached on how to interpret these findings. When two audiograms or more were performed with an interval of at least one year, we compared the hearing thresholds from the first and the most recent audiogram.

\section{Statistical processing and analysis}

Due to various practical reasons, in some audiograms not all hearing thresholds were measured for every frequency. Those missing data were assumed to be missing 
at random, implying that the missing at random (MAR) assumption was applicable. Therefore, multiple imputation was used to handle missing hearing thresholds. ${ }^{28}$ We generated ten imputation sets.

We used the Mann-Whitney $U$ test to analyze the relation between age and otologic pathology. Linear regression was used to evaluate the effect of age on hearing thresholds. In this evaluation, we did one sensitivity analysis where we excluded outliers. We employed SPSS version 21 for statistical analysis.

\section{RESULTS}

\section{Missing data}

$\mathrm{BC}$ hearing thresholds were not measured in 79 ears in most recent audiogram. Earlier measurements were evaluated in 28 ears, and the $B C$ thresholds from the contralateral ear were adapted in 41 ears. In five patients and ten ears, the BC was never measured, nor was there a BC threshold measured in the contralateral ear. All these ears had AC conduction thresholds in the normal range. In these cases, since they had normal hearing, we assumed that there was no ABG. In 49 ears, where there were at least two audiograms with an interval of at least one year, $B C$ thresholds were not measured in the first audiogram. Later measurements were evaluated in 38 ears, and the BC thresholds form the contralateral ear were adapted in 11 ears. Next, in the most recent and first pure tone audiogram there were $16 \%$ and $25.5 \%$ missing hearing thresholds respectively.

\section{Medical history}

We included a total of 199 patients, 102 men and 97 women. Audiometric measurements were available for 102 patients and 204 ears. Characteristics are shown in Table 1. Median age at most recent audiogram was 7 years (range 3 to 29 years). Median age at start of study was 11 years (range 2.5 months to 30 years). Many patients had an otologic history; in $61 \%$ of patient's grommets were inserted, varying between once to 17 times. 15 patients were adapted with conventional hearing aids and four patients with a bone conduction device (BCD) on a softband. One patient received a percutaneous BCD, but was a non-user. Six patients were using an assistive listening device at school, coupled to a conventional hearing aid in four patients and to ear phones in two patients. 14 patients underwent otologic surgery, comprising more than one surgical intervention in six of these patients. One patient received a canalplasty for an acquired stenosis of the external auditory canal. Five out of 14 patients underwent middle ear surgery for chronic otitis media including mastoidectomy, attico-antrotomy or a combination of surgical approaches to treat the pathology. Ten out of 14 patients underwent tympanoplasty, two patients on both ears, seven patients on one ear. In four 
CHAPTER 3

out of 14 patients an epithelial rim boarding the tympanic membrane perforation was removed to stimulate spontaneous closure. In addition, 47 patients (25\%) underwent adenoidectomy.

Considering otoscopic reports at time of the most recent audiograms, a tympanic membrane perforation was present in 31 of 196 ears (15.8\%). Grommets were present and patent in 29 of 185 ears (15.7\%), otitis media with effusion (OME) was present in 32 of 142 ears (22.5\%), 22 of these 32 ears had a history of grommet insertion. In addition, 2 of 142 ears (1.4\%) had acute otitis media (OMA) while a grommet in place (purulent otorrhoea).

Table 1. Demographic characteristics and medical history of 199 patients

\begin{tabular}{ll}
\hline & Patients $(\mathrm{n}=199)(\%)$ \\
\hline Male & $102(51)$ \\
Audiogram available & $102(51)$ \\
Median age in years at most recent audiogram (range) ( $\mathrm{n}=102$ patients) & $7(3-29)$ \\
History of ventilation tubes ( $\mathrm{n}=186$ patients) & $113(61)$ \\
History of adenoidectomy ( $\mathrm{n}=192$ patients) & $47(24)$ \\
History of cholesteatoma ( $\mathrm{n}=192$ patients) & $0(0)$ \\
History of tympanic membrane perforation ( $\mathrm{n}=190$ patients) & $55(29)$ \\
Use of hearing aids/BCD ( $\mathrm{n}=194$ patients) & $19(10)$ \\
Otologic surgery ( $\mathrm{n}=194$ patients) & $14(7)$ \\
\hline Abbreviations: Pure tone average (PTA) Bone conduction device (BCD)
\end{tabular}

Abbreviations: Pure tone average (PTA), Bone conduction device (BCD)

\section{Most recent audiogram}

There were two ears with immeasurable $B C$ thresholds with measurable $A C$ thresholds. In one of those two ears there was an immeasurable $B C$ threshold at $4 \mathrm{kHz}$, where the $\mathrm{AC}$ threshold at $4 \mathrm{kHz}$ was $100 \mathrm{~dB} \mathrm{HL}$, the frequencies $0.5-2 \mathrm{kHz}$ showed an $\mathrm{ABG}$ of 10-30dB, and we interpreted this audiogram as mixed hearing loss. The other ear had immeasurable $B C$ thresholds at 0.5 and $1 \mathrm{kHz}$ with $A C$ thresholds of 60 and $65 \mathrm{~dB} \mathrm{HL}$, interpreted as a pure sensorineural hearing loss in the low frequencies, but overall as a mixed hearing loss, because the $A B G$ was $20 \mathrm{~dB}$ at 2 and $4 \mathrm{kHz}$.

Overall, patients had received their most recent audiogram between 1995 and 2015. The median of PTA AC thresholds was $17.5 \mathrm{~dB} \mathrm{HL}$ (range -1.3 to $57.5 \mathrm{~dB} \mathrm{HL}$ ) and the median of PTA BC thresholds was $2.4 \mathrm{~dB} \mathrm{HL}$ (range -9.4 to $46.3 \mathrm{~dB} \mathrm{HL}$ ). There were 163 ears where every frequency $(0.5,1,2,4 \mathrm{kHz})$ was measured, hearing loss was found in 62 of 163 ears (38\%) (Figure 1). After imputation of missing data, there were 77 of 204 ears with hearing loss (38\%). Most ears with hearing loss suffered from a pure conductive form.

Frequently, hearing loss was mild, but seven ears belonging to seven patients had a moderate conductive hearing loss. Two of these seven ears were diagnosed with $\mathrm{OME}$ at the time of audiometric evaluation, one ear had a tympanic tube in place 
and otitis media, one ear with a tympanic membrane perforation, one ear without any otologic problem at time of audiometric evaluation and finally two ears had no available otoscopic information. One of these two ears had an acquired stenosis of the external auditory canal after chronic obliterative otitis externa. The other ear without an obvious cause for the hearing loss had tympanosclerosis involving the ossicular chain, shown on a Computed Tomography (CT) scan (patients history revealed chronic otitis media).

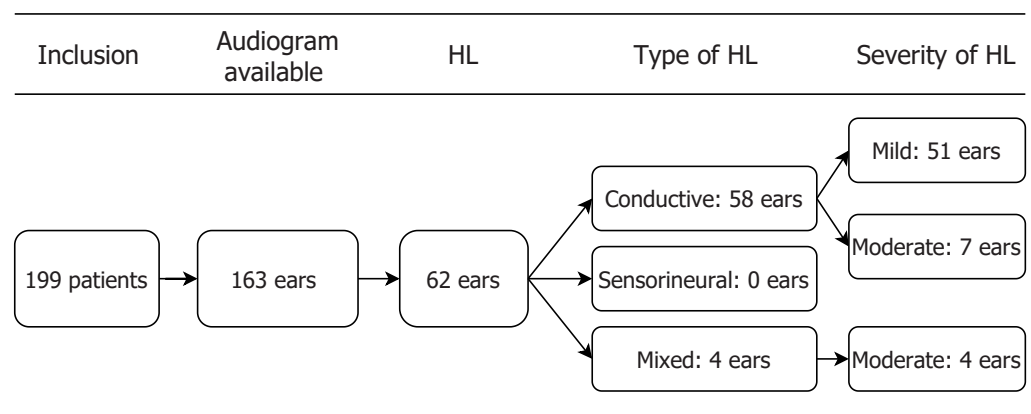

Figure 1. Flowchart of audiogram results in 163 patients. Abbreviation: Hearing loss (HL)

In four ears (three patients) a sensorineural component in combination with a conductive hearing loss (mixed hearing loss) was observed. In all these ears the severity of hearing loss was moderate with median of PTA AC thresholds of $50.6 \mathrm{~dB} \mathrm{HL}$ (range 46.3 to 56.3 $\mathrm{dB} \mathrm{HL}$ ) and median of PTA BC thresholds of $37.5 \mathrm{~dB} \mathrm{HL}$ (range 33.8 to $46.3 \mathrm{~dB} \mathrm{HL}$ ). CT scanning of one patient (out of three) with bilateral mixed hearing loss revealed soft tissue opacification of the right middle ear, but no malformations. Another patient with unilateral mixed hearing loss had an anterior inferior cerebellar artery loop on the same side (left) as the ear with mixed hearing loss, shown on Magnetic Resonance Imaging of the petrous bone including the cerebellopontine angle. However, no specific cause for the hearing loss could be found. The last patient with unilateral mixed hearing loss was diagnosed with a tympanic membrane perforation on both ears, but no other pathology potentially causing the mixed hearing loss was identified.

\section{Hearing thresholds in relation to age}

Figure 2 shows the mean $A C$ and $B C$ threshold plotted against the age of patients. The linear regression line shows no relation between hearing thresholds and age for average $A C$ thresholds $(p=0.43)$. However, age was significantly related to average $B C$ thresholds $(p=0.03)$, the slope for this linear regression line was very small $(0.27)$. There were two outliers (two ears from one patient), aged 29 years with poor hearing. In the 
CHAPTER 3

sensitivity analysis without these outliers, there was no significant relation between age and $A C$ or $B C$ hearing thresholds $(p=0.38$ and $p=0.46$ for average $A C$ and $B C$ hearing thresholds respectively). Median age of patients with OME during most recent audiogram was 7 years (range 3 to 14 years). Age at time of most recent audiogram was not related to the presence of OME $(p=0.11)$.

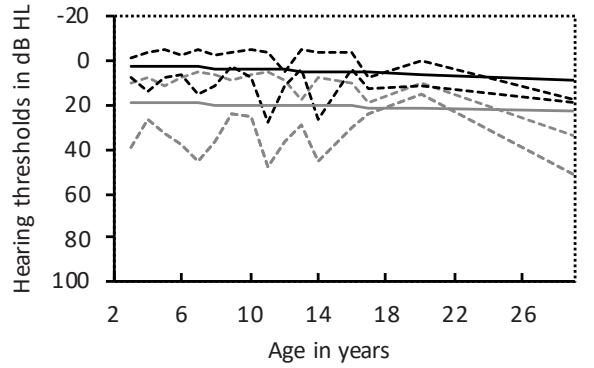

igure 2. Average hearing thresholds plotted against age and linear regression lines. P5 and P95 of bone conduction (black) and air conduction (grey) thresholds are shown in dotted lines, linear regression lines are shown in continuous lines.

a. Linear regression analysis: no relation between age and air conduction thresholds $(p=0.43)$, and a significant relation between age and bone conduction thresholds $(p=0.03)$.

b. Results without two outliers. Linear regression analysis: no relation between age and air conduction thresholds or bone conduction thresholds ( $p=0.38$ and $p=0.46$ respectively).

\section{Progression over time}

In 104 ears at least two audiograms were available with at least one-year interval (Figure 3). 31 of these 104 ears showed worsening of the $A C$ threshold at $1 \mathrm{kHz}$ (median decrease $10 \mathrm{~dB}$ (range 5 to $50 \mathrm{~dB}$ )), 18 ears had exactly the same PTA over time and 55 of 104 ears showed improvement (median improvement $10 \mathrm{~dB}$ (range 5 to $35 \mathrm{~dB}$ )). In 23 of 104 ears at least $20 \mathrm{~dB}$ difference was shown (range 20-50 dB) between the first and most recent $A C$ threshold at $1 \mathrm{kHz}$. Nine of these 23 ears showed worsening (median $20 \mathrm{~dB}$ ) whereas the remaining 14 ears showed improvement (median $27 \mathrm{~dB}$ ). Of those 23 ears, 13 ears were diagnosed with an otologic abnormality during otoscopy at time of first or most recent audiogram, four had a tympanic membrane perforation, six ears had (otoscopically confirmed) OME and two ears had OMA in combination with a grommet in place. One ear had a recurrent stenosis of external auditory canal, not present at time of first audiogram.

For $\mathrm{BC}$ at $1 \mathrm{kHz}, 37$ of 104 ears had the same hearing level over time, 40 ears showed improvement (median improvement was $5 \mathrm{~dB}$ (range 4 to $20 \mathrm{~dB}$ ) and 27 ears (24 ears before multiple imputation) showed worsening (median decrease $9 \mathrm{~dB}$ (range 4 to $26 \mathrm{~dB}$ ). Seven of 104 ears showed a difference of $\geq 20 \mathrm{~dB}$ in $\mathrm{BC}$ at $1 \mathrm{kHz}$ between 
first and most recent audiogram. Evaluation of other frequencies shows a roughly similar trend (Figure 4).

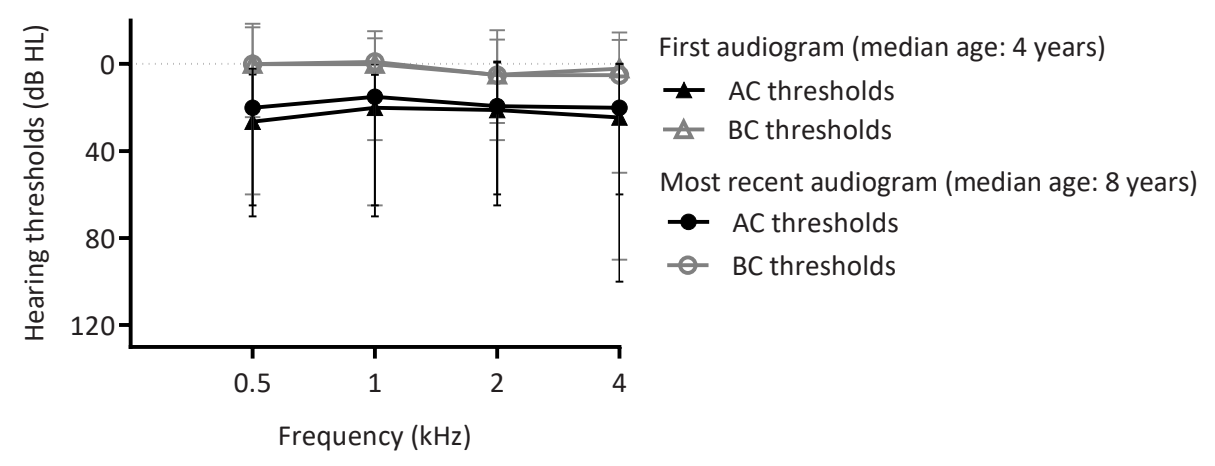

Figure 3. Median thresholds of first and most recent audiogram of 104 ears.

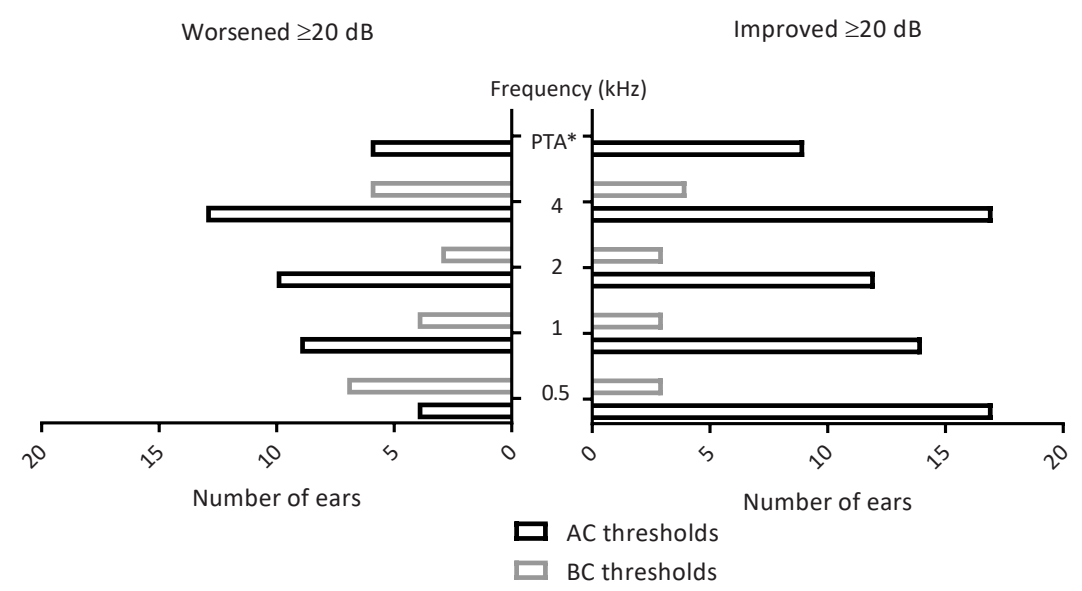

Figure 4. Numbers of ears with an improvement or worsening of $\geq 20 \mathrm{~dB}$ between first and most recent audiogram.

Abbreviation: Pure tone average (PTA)

\section{DISCUSSION}

We described the otologic features of 199 patients and the audiometric results of 163 ears with 22q11DS. Hearing loss was frequently present in our study population and was predominantly conductive with a mild severity. Previous studies regarding 22q11DS report similar results. ${ }^{11-14,16,17}$ Conductive hearing loss in patients diagnosed 
CHAPTER 3

with 22q11DS is associated with recurrent otitis media. ${ }^{10-14,16,17}$ Consistent with this finding, the cause of hearing loss in the present population is also related to otitis media. This appeared in different forms: some children suffered from OME at time of audiometric evaluation, some were diagnosed with a tympanic membrane perforation, which resulted after otitis media or grommet insertion, while another patient showed damage in the middle ear due to chronic otitis media (tympanosclerosis involving the ossicular chain).

At time of the most recent audiogram, $22.5 \%$ of all ears had OME. This number is higher compared to the normal population, where the reported prevalence of children aged 7.5-8 years is around 6\%.29 In another study on healthy children with a broad age range (5-14 years), such as our population, an overall prevalence of OME of $6.8 \%$ was found. ${ }^{30}$ In (non-syndromatic) children with a cleft palate, otitis media is also very common and suggested to be caused by Eustachian tube dysfunction. ${ }^{31,32}$ A cleft (mostly submucosal) is frequently present in the 22q11DS population. 5,10 Possibly, in patients with a cleft and in patients with 22q11DS otitis media is caused by the same pathophysiology. Especially since in mouse models for 22q11DS a hypoplastic levator veli palatini muscle was found. ${ }^{22}$

$\mathrm{AC}$ hearing thresholds seemed not to change with aging in our population. Moreover, age was not related to OME during most recent audiogram. This suggests that children with 22q11DS continue to be at risk for otitis media with effusion as they age. This is consistent with Reyes et al. who found the same prevalence of OME in age younger than 3 years, 4-7 years and older than 7 years. ${ }^{16}$ In the normal population the prevalence peak of OME is at 6 months to 4 year of age, after that age the prevalence decreases. ${ }^{33-35}$

Surprisingly, none of our patients had a pure sensorineural hearing loss and mixed hearing loss was only seen in four ears. This prevalence is considerably lower compared to other studies.11,12,14-18 One possible explanation for our low rate of sensorineural hearing loss is the fact that pure tone audiograms were only available in $51 \%$ of our study population. Theoretically, patients with mild hearing loss could have been diagnosed more often in a general hospital rather than in our tertiary care center. This would underestimate our reported prevalence of hearing loss. However, this is not supported by the fact that most of our patients with an available audiogram had mild hearing loss. Furthermore, the rate of patients with hearing loss with an sensorineural component differs much in reported studies (2.8-19.4\%). ${ }^{11,12,14-18}$ Patient ages were different among these studies, whereby three studies included older patients (mean 15, 16 and 24 years), ${ }^{15,17,18}$ compared to the other studies. ${ }^{11,12,14,16}$ In two studies with young patients audiometric testing involved behavioral pure tone audiometry or sound field testing. ${ }^{11,12}$ Although it is not possible to obtain pure tone audiometry in young non-cooperative children, these tests are less accurate than conventional pure tone audiometry. In addition, Zarchi et al. and Van Eynde et al. found sensorineural hearing 
loss more prominent in the high tones (Zarchi et al. tested frequencies $0.25-8 \mathrm{kHz}$ and Van Eynde et al. frequencies $0.125-11.2 \mathrm{kHz}){ }^{17,18}$ Due to our retrospective design we only used frequencies $0.5-4 \mathrm{kHz}$. Possibly, we missed poor $\mathrm{BC}$ thresholds in the high tones, which might explain our lower sensorineural hearing loss prevalence.

\section{Limitations}

The main limitation of this study was that it was performed in a tertiary referral center. Some of the more regular pathology such as otitis media or tympanic membrane perforation will presumably be treated in primary or secondary care. Our number of tympanic membrane perforations, a history of ventilation tubes or adenoidectomy could therefore be underestimated. Another limitation is the fact that audiograms were available in 51\%; selection bias is likely since patients with assumed normal hearing are less likely to undergo audiometric evaluation. Also, patients with OME or other otologic anomaly are more likely to receive an audiogram, therefore our results for otologic manifestations at time of most recent audiogram are likely overestimated.

\section{CONCLUSION}

Hearing loss and otitis media are frequently present in patients with 22q11DS. Moreover, our results suggest that children with 22q11DS remain susceptible for otitis media as they age. Although conductive hearing loss is presumably largely caused by otitis media, future studies are needed to assess the cause of sensorineural and conductive hearing loss. 


\section{REFERENCES}

1. Burn J, Takao A, Wilson D. Conotruncal anomaly face syndrome. Published online 1993:822-824.

2. Driscoll DA, Budarf ML, Emanuel BS. A Genetic Etiology for DiGeorge Syndrome : Consistent Deletions and Microdeletions of 22q I I. Published online 1992:924-933.

3. Scambler P, Kelly D, Lindsay E, et al. Velo-cardio-facial syndrome associated with chromosome 22 deletions encompassing the DiGeorge locus Viral-associated Viral-associated haemophagocyte syndrome in. Lancet. 1992;339:1138-1139.

4. Kelley R, Zackai E, Emanuel B, Kistenmacher M, Greenberg F, Punnet H. The association of the DiGeorge anomalad with partial monosomy of chromosome 22. J Pediatr. 1982;101(2):197-200

5. Bassett AS, Mcdonald-mcginn DM, Devriendt K, et al. Practical Guidelines for Managing Patients with 22q11.2 Deletion Syndrome. J Pediatr. 2011;159(2):332-339.e1. doi:10.1016/j.jpeds.2011.02.039

6. Bassett AS, Chow EWC, Husted J, et al. Clinical features of 78 adults with 22 q11 deletion syndrome. Am J Med Genet. 2005;138 A(4):307-313. doi:10.1002/ajmg.a.30984

7. Habel A, Herriot R, Kumararatne D, et al. Towards a safety net for management of 22 q11.2 deletion syndrome: guidelines for our times. Eur J Pediatr. 2014;173:757-765. doi:10.1007/s00431-013-2240-z

8. Shprintzen RJ. Velocardiofacial syndrome. Otolaryngol Clin North Am. 2000;33(6):1217-1240, vi.

9. Shprintzen RJ, Higgens AM, Antshel K, Fremont W, Roizen N, Kates W. Velo-cardio-facial syndrome. Curr Opin Pediatr. Published online 2005:725-730.

10. Ryan AK, Goodship JA, Wilson DI, et al. Spectrum of clinical features associated with interstitial chromosome 22q11 deletions: a European collaborative study. J Med Genet. 1997;34(10):798-804 doi:10.1136/jmg.34.10.798

11. Digilio MC, Pacifico C, Tieri L, Marino B, Giannotti A, Dallapiccola B. Audiological findings in patients with microdeletion 22q11 (diGeorge/velocardiofacial syndrome). Br J Audiol. 1999;33(5):329-333.

12. Dyce O, McDonald-McGinn DM, Kirschner RE, Zackai E, Young K, Jacobs IN. Otolaryngologic manifestations of the 22q11.2 deletion syndrome. Arch Otolaryngol Head Neck Surg. 2002;128(12):14081412

13. Ford LC, Sulprizio SL, Rasgon BM. Otolaryngological manifestations of velocardiofacial syndrome: a retrospective review of 35 patients. Laryngoscope. 2000;110(3 Pt 1):362-367.

14. Jiramongkolchai P, Kumar MS, Chinnadurai S, Wootten CT, Goudy SL. Prevalence of hearing loss in children with 22q11.2 deletion syndrome. Int J Pediatr Otorhinolaryngol. 2016;87:130-133. doi:10.1016/j. ijporl.2016.06.005

15. Persson C, Friman V, Oskarsdottir S, Jonsson R. Speech and hearing in adults with 22 q11.2 deletion syndrome. Am J Med Genet A. 2012;158A(12):3071-3079. doi:10.1002/ajmg.a.35589

16. Reyes MRT, LeBlanc EM, Bassila MK. Hearing loss and otitis media in velo-cardio-facial syndrome. Int $J$ Pediatr Otorhinolaryngol. 1999;47(3):227-233.

17. Van Eynde C, Swillen A, Lambeens E, et al. Prevalence and Nature of Hearing Loss in 22q11.2 Deletion Syndrome. J Speech, Lang Hear Res. 2016;59(3):583-589. doi:10.1044/2015

18. Zarchi O, Attias J, Raveh E, Basel-Vanagaite L, Saporta L, Gothelf D. A comparative study of hearing loss in two microdeletion syndromes: velocardiofacial (22q11.2 deletion) and Williams (7q11.23 deletion) syndromes. J Pediatr. 2011;158(2):301-306. doi:10.1016/j.jpeds.2010.07.056

19. Niskar AS, Kieszak SM, Holmes A, Esteban E, Rubin C, Brody DJ. Prevalence of Hearing Loss Among Children 6 to 19 Years of Age The Third National Health and Nutrition Examination Survey. 2017;279(14).

20. Fuchs JC, Zinnamon FA, Taylor RR, et al. Hearing loss in a mouse model of 22q11.2 Deletion Syndrome. PLoS One. 2013;8(11):e80104. doi:10.1371/journal.pone.0080104

21. Funke B, Epstein JA, Kochilas LK, et al. Mice overexpressing genes from the 22 q11 region deleted in velo-cardio-facial syndrome/DiGeorge syndrome have middle and inner ear defects. Hum Mol Genet. 2001;10(22):2549-2556.

22. Fuchs JC, Linden JF, Baldini A, Tucker AS. A defect in early myogenesis causes Otitis media in two mouse models of 22q11.2 deletion syndrome. Hum Mol Genet. 2014;24(7):1869-1882. doi:10.1093/hmg/ddu604

23. Cunningham ML, Perry RJ, Eby PR, Gibson RL, Opheim KE, Manning SC. Primary pulmonary dysgenesis in velocardiofacial syndrome: A second patient [2]. Am J Med Genet. 2003;121 A(2):177-179. http://www. embase.com/search/results? subaction=viewrecord\&from=export\&id=L37075527

24. Devriendt K, Swillen A, Schatteman I, Lemmerling M, Dhooge I. Middle and inner ear malformations in velocardiofacial syndrome. Am J Med Genet A. 2004;131(2):225-226. doi:10.1002/ajmg.a.30326 
25. Vitelli F, Viola A, Morishima M, Pramparo T, Baldini A, Lindsay E. TBX1 is required for inner ear morphogenesis. Hum Mol Genet. 2003;12(16):2041-2048.

26. Braunstein EM, Monks DC, Aggarwal VS, Arnold JS, Morrow BE. Tbx1 and Brn4 regulate retinoic acid metabolic genes during cochlear morphogenesis. BMC Dev Biol. 2009;9:31. doi:10.1186/1471-213X-9-31

27. Monsell EM. Committee on Hearing and Equilibrium guidelines for the evaluation of results of treatment of conductive hearing loss. Otolaryngol - Head Neck Surg. 1995;113(3):186-187. doi:10.1016/S01945998(95)70103-6

28. Groenwold RHH, Donders ART, Roes KCB, Harrell FE, Moons KGM. Dealing with missing outcome data in randomized trials and observational studies. Am J Epidemiol. 2012;175(3):210-217. doi:10.1093/aje/ kwr302

29. Schilder A, Zielhuis GA, Broek PVANDEN. The otological profile of a cohort of Dutch 7.5-8-year-olds. Clin Otolaryngol. 1993;18:48-54.

30. Martines F, Bentivegna D, Di F, Gioacchino P, Sciacca V, Martines E. The point prevalence of otitis media with effusion among primary school children in Western Sicily. Eur Arch Otorhinolaryngol. 2010;267:709714. doi:10.1007/s00405-009-1131-4

31. Sheahan P, Miller I, Sheahan JN, Earley MJ, Blayney AW. Incidence and outcome of middle ear disease in cleft lip and/or cleft palate. 2003;5876:785-793. doi:10.1016/S0165-5876(03)00098-3

32. Heidsieck DSP, Smarius BJA, Oomen KPQ, Breugem CC. The role of the tensor veli palatini muscle in the development of cleft palate-associated middle ear problems. Clin Oral Investig. Published online 2016:1389-1401. doi:10.1007/s00784-016-1828-x

33. Rosenfeld RM, Shin JJ, Schwartz SR, et al. Clinical Practice Guideline. Vol 154.; 2016. doi:10.1177/0194599815623467

34. Rovers M, Schilder A, Zielhuis G, Rosenfeld R. Otitis media. Lancet. 2004;363:443-475. doi:10.5005/jp/ books/13036_146

35. Zielhuis G, Rach G, van den Broek P. The occurrence of otitis media with effusion in Dutch pre-school children. Clin Otolaryngol Allied Sci. 1990;15(2):147-153. 
564555-L-bw-Verheij

Processed on: 16-9-2021 


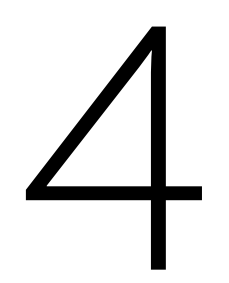

\section{ANATOMICAL MALFORMATIONS OF THE MIDDLE AND INNER EAR \\ IN 22q11.2 DELETION SYNDROME: \\ CASE SERIES AND LITERATURE REVIEW}

Emmy Verheij

Lisa Elden

T. Blaine Crowley

Frank A. Pameijer

Elaine H. Zackai

Donna M. McDonald-McGinn

Hans G.X.M. Thomeer 
CHAPTER 4

\section{ABSTRACT}

\section{Background and purpose}

The 22q11.2 deletion syndrome is characterized by a heterogenic phenotype, including hearing loss. The underlying cause for hearing loss, especially sensorineural hearing loss, is not yet clear. Therefore, our objective was to describe anatomical malformations in the middle and inner ear in patients with 22q11.2 deletion syndrome.

\section{Material and methods}

A retrospective case series was conducted in two tertiary referral centers. All patients with 22q11.2 deletion syndrome who had undergone CT or MR imaging of the temporal bones were included. Radiologic images were evaluated on predetermined parameters, including abnormalities of the ossicular chain, cochlea, semicircular canals and vestibule.

\section{Results}

There were 26 patients (52 ears) with a CT or MR imaging scan available. A dense stapes superstructure was found in 18 ears (36\%), an incomplete partition type II was suspected in 12 cochleas (23\%), the lateral semicircular canal was malformed with a small bony island in 17 ears (33\%) and the lateral semicircular canal and vestibule were fused to a single cavity in 15 ears (29\%).

\section{Conclusion}

Middle and inner ear abnormalities were frequently encountered in our cohort, including malformations of the lateral semicircular canal. 


\section{INTRODUCTION}

The 22q11.2 deletion syndrome (22q11DS), also known as velocardiofacial syndrome or DiGeorge syndrome, is caused by a microdeletion on the long arm of chromosome 22 and has a heterogenic phenotype. ${ }^{1-3}$ Otolaryngologic manifestations are frequently present; most well-known clinical otolaryngologic features are velopharyngeal insufficiency, cleft palate, recurrent otitis media and hearing loss. Hearing loss is most commonly the conductive type and might merely be related to recurrent otitis media. ${ }^{4-7}$ However, sensorineural or mixed hearing loss have also been described. ${ }^{4,5,7-11}$

The underlying cause for hearing impairment, especially the sensorineural component, is still not understood. There are case reports, describing middle or inner ear malformations on radiologic imaging. ${ }^{12-15}$ Recently, a cohort study was conducted where CT images of the temporal bones of 11 patients with 22q11DS were analyzed. This study found middle ear malformations as well as cochlear, vestibule and semicircular canal malformations. ${ }^{16}$ The anatomical malformations could be present due to genetic abnormalities leading to an error in the embryologic phase. Mouse studies have identified Tbx1 as a candidate gene responsible for ear abnormalities in 22q11DS. ${ }^{16-19}$ Inactivation of Tbx1 in the otic vesicle in mice leads to disruption of inner ear development. ${ }^{20}$

The aim of this study was to describe anatomical malformations of the middle and inner ear in these patients, shown on CT and/or MR imaging.

\section{MATERIAL AND METHODS}

We conducted a retrospective study in the University Medical Center Utrecht and Children's Hospital of Philadelphia. All patients diagnosed with 22q11DS, confirmed with a microdeletion, who received a CT or MR imaging scan of the temporal bones before May 2017 were included. Radiologic images from Children's Hospital of Philadelphia were de-identified and sent to the University Medical Center Utrecht for analysis. An approval from the institutional review board from Children's Hospital of Philadelphia was obtained and the Medical Ethics committee of the University Medical Center Utrecht deemed this study exempt from review.

The first author and F.A.P (head and neck radiologist with > 20 years' experience), evaluated the radiologic studies to determine the nature and prevalence of temporal bone abnormalities based on the following predetermined features. We assessed, ossicular chain abnormalities, course of the facial nerve, malformations of the cochlea, malformations of the semicircular canals, vestibule widening, enlargement of the vestibular aqueduct and carotid canal dehiscence. We scored features as present, partially present or absent. We measured the bony island of the lateral semicircular canal (LSCC) and vestibule width to compare with previously defined normal 
CHAPTER 4

measurements. ${ }^{21}$ The bony island was considered normal when the axial diameter was between 3.0 and $4.4 \mathrm{~mm}$. For the vestibule width an axial diameter between 2.8 and $4.0 \mathrm{~mm}$ was considered normal. For assessing the density of hearing ossicles, to our knowledge no normal ranges in densities are described in literature; therefore, we relied on the expertise of our head and neck radiologist. When one of the hearing ossicles displayed an increased density and/or general thickening (especially the stapes superstructure), we recorded this ossicle as 'dense'.

The medical records were reviewed to determine the primary reason for obtaining CT or MR imaging and to collect data including pure tone audiogram information. Furthermore, tympanometry information, history of chronic otitis media and history of dizziness of balance problems were collected. Hearing loss was defined as a pure tone average (average of $0.5,1,2$ and $4 \mathrm{kHz}$ ) of more than 20 decibel hearing level ( $\mathrm{dB} \mathrm{HL}$ ), in concordance with the American Academy of Otolaryngology-Head and Neck Surgery 1995 guidelines. ${ }^{22}$ Conductive hearing loss was considered when the average air conduction threshold was $>20 \mathrm{~dB}$, and the air-bone gap was $\geq 10 \mathrm{~dB}$ at $\geq 1$ frequencies. Sensorineural hearing loss was defined as hearing loss with an airbone gap $<10 \mathrm{~dB}$ in all frequencies and mixed hearing loss as an average air and bone conduction threshold of $>20 \mathrm{~dB}$, and an air-bone gap of $\geq 10 \mathrm{~dB}$ at $\geq 1$ frequency. Tympanometry results were classified into class $A$ (representing the normal situation), class B (flat curve, indicating middle ear effusion), type $C$ (negative peak pressure), type As (a small pressure peak, representing a decreased mobility of the ossicular chain) and type Ad (a high pressure peak, indicating an increased mobility of the ossicular chain).

\section{RESULTS}

\section{Baseline characteristics}

Out of approximately 300 patients followed at the University Medical Center Utrecht and the 1300 patients from Children's Hospital of Philadelphia, 26 patients (52 ears), 14 male and 12 female, underwent radiologic imaging of the temporal bones (11 patients from the University Medical Center Utrecht, 15 patients from Children's Hospital of Philadelphia). The indication for imaging was hearing loss which could not be explained by otoscopic findings $(n=10)$, chronic otitis media $(n=13)$, both unexplained hearing loss and chronic otitis media $(n=2)$, or aural atresia $(n=1)$. MR imaging was performed in one patient, all other patients underwent CT of the temporal bones. One patient likely had a second genetic disorder, in addition to a microdeletion on chromosome 22q11.2.

\section{Radiologic outcomes}

Radiologic findings are shown in Figure 1. 


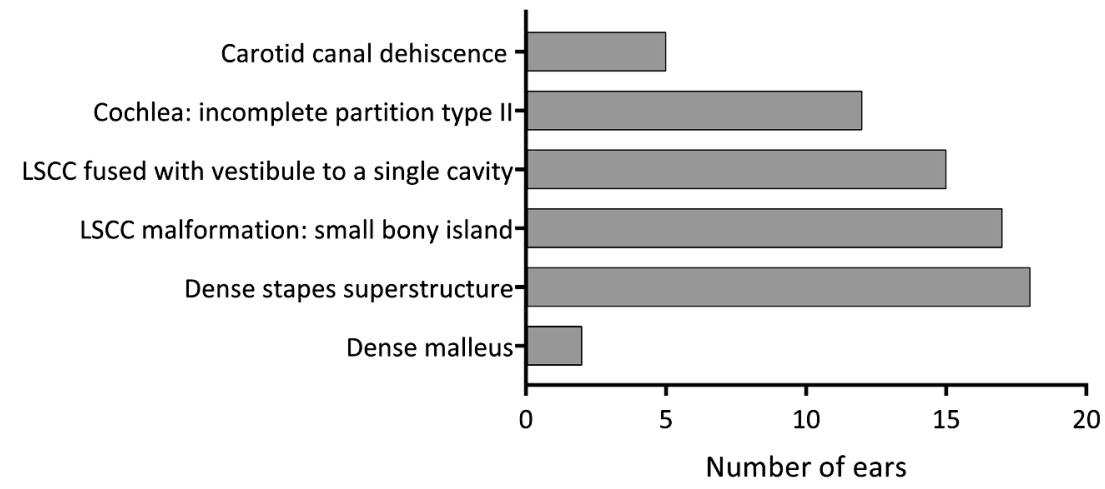

Figure 1. Radiologic malformations of the middle and inner ear encountered in 52 ears. Abbreviation: Lateral semicircular canal (LSCC)

\section{Middle ear}

Aural atresia was seen affecting the external auditory canal and middle ear in one ear. The middle ear was small and contained one rudimentary hearing ossicle. No stapes, stapes footplate or facial nerve could be identified. This ear belonged to the patient with a possible second genetic disorder. Eighteen ears (36\%) (13 patients) were found to have a dense stapes superstructure (Figure 2) and in two ears (one patient) the manubrium of the malleus was dense. No other abnormalities of the malleus or incus were encountered.

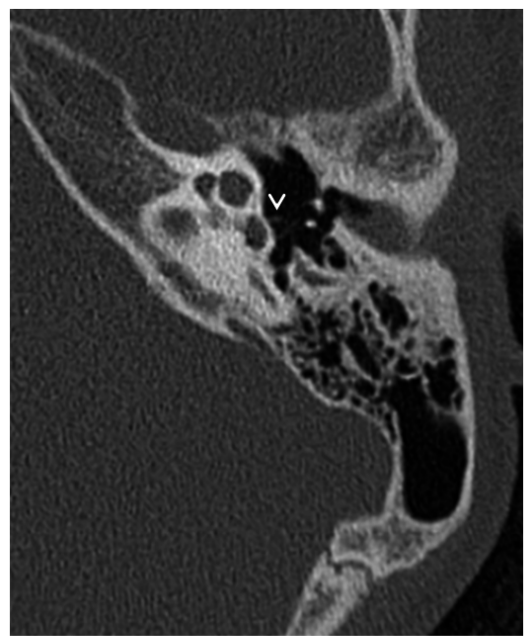

A.

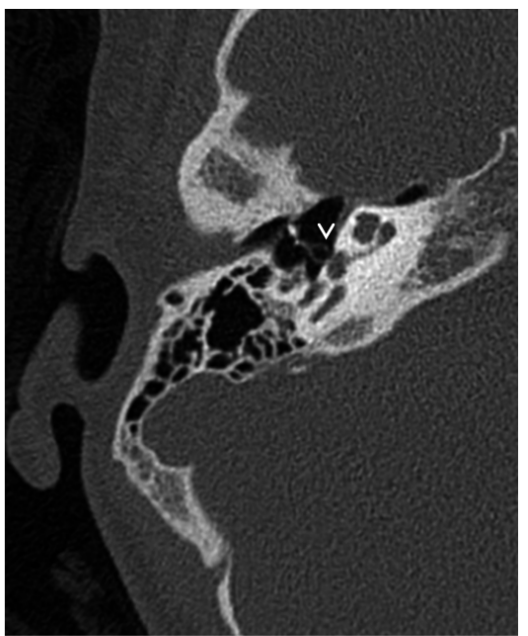

B.

Figure 2. A. Axial CT image of the left mastoid of a different patient showing a normal stapes superstructure for comparison to Figure 2B. B. Axial CT image of the right mastoid showing a dense and thick stapes superstructure. The pure tone audiogram of this patient is shown in Figure 5B. 
CHAPTER 4

\section{Inner ear}

Malformations of the cochlea and vestibular system were seen. As shown in Figure 1, an incomplete partition type II of the cochlea was suspected in 12 ears (23\%) (seven patients). This malformation was frequently subtle and easy to overlook (Figure 3).

In 17 ears (33\%) (11 patients) the bony island of the LSCC was small (Figure 4), measuring between 2.6 and $1.1 \mathrm{~mm}$. No evidence of widening of the vestibule was observed, including in the ears with a small bony island (widest vestibule measured $3.9 \mathrm{~mm}$ ). In 15 ears (29\%) (nine patients) the LSCC and vestibule were fused to a single cavity (Figure 5). Two patients had an LSCC with a small bony island in one ear and a single cavity in the contralateral ear. In addition, in one ear with a normally formed LSCC, there was a disruption of the posterior semicircular canal, consisting of two limbs not connected to each other. Superior semicircular canal dehiscence was seen in one ear. Last, in five ears (10\%) (four patients) a dehiscence of the carotid canal was present (Figure 6). The vestibular aqueduct and the facial nerve were normal in all cases, except in the ear with an aural atresia where the facial nerve could not be identified.

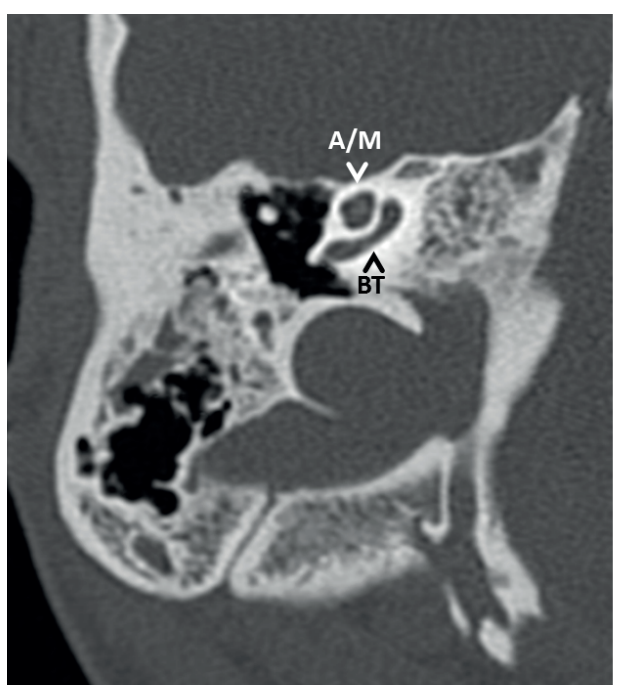

A.

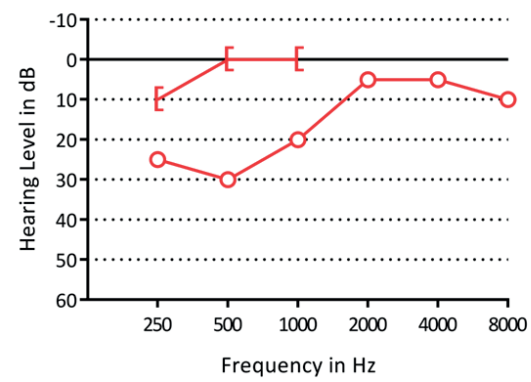

B.

Figure 3. A. Axial CT image of the right mastoid showing an incomplete partition type II of the cochlea. The basal turn (BT) of the cochlea is intact, the apical and middle turn (A/M) seem confluent. B. A pure tone audiogram of the same ear showing normal hearing.

Legend: o unmasked air conduction threshold, [ masked bone conduction threshold. 


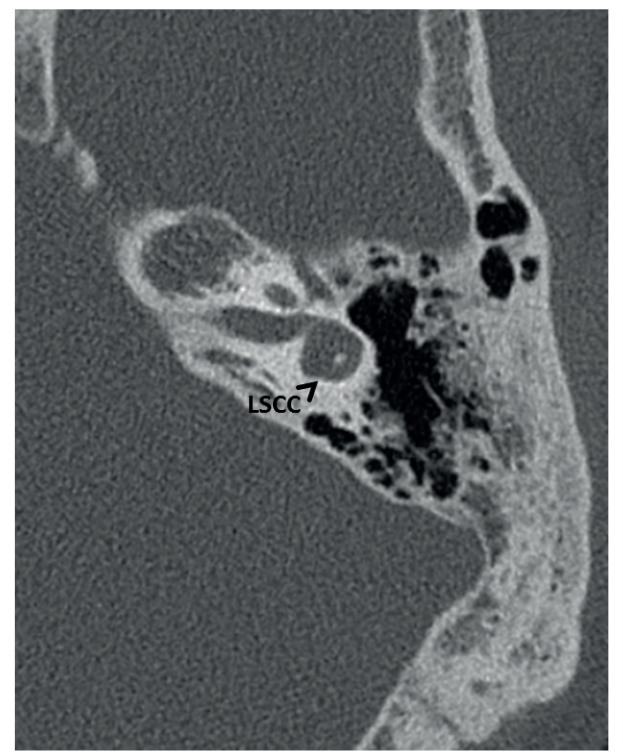

A.

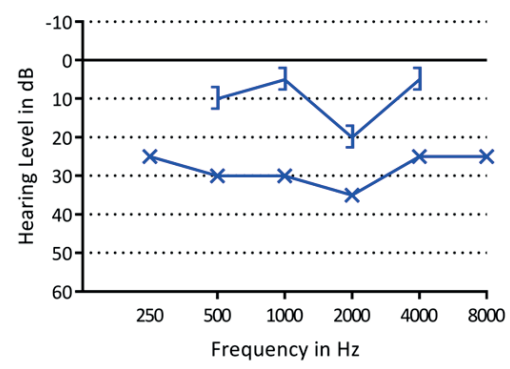

B.

Figure 4. A. Axial CT image of left mastoid bone showing the lateral semicircular canal (LSCC) with a small bony island. B. A pure tone audiogram of the same ear showing a mild conductive hearing loss.

Legend: $x$ unmasked air conduction threshold, ] masked bone conduction threshold.

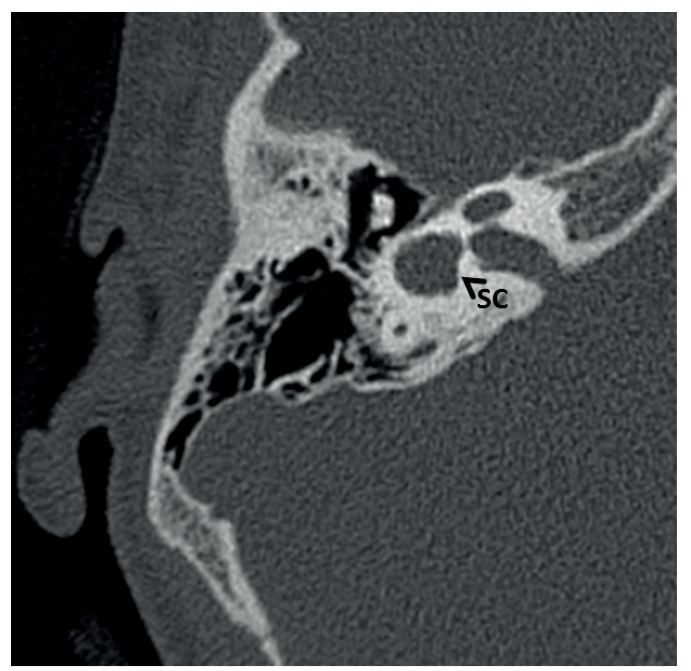

A.

Figure 5. A. Axial CT image of right mastoid bone. The bony island of the lateral semicircular canal is missing and the canal and vestibule are composed of a single cavity (SC). B. A pure tone audiogram of the same ear showing conductive hearing loss, more pronounced in the low frequencies.

Legend: See Figure 3.

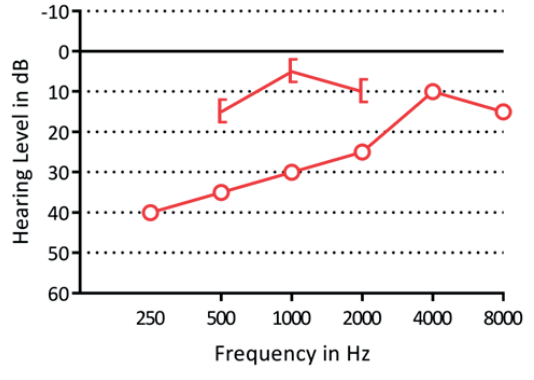

B. 
CHAPTER 4

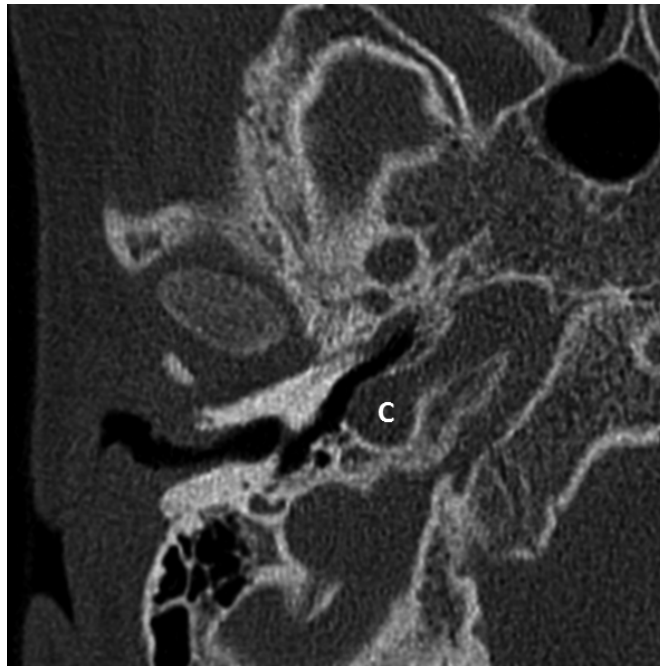

Figure 6. Axial CT image of right mastoid bone showing a carotid canal dehiscence (C).

\section{Audiologic findings}

Twenty-seven ears belonging to 18 patients showed hearing loss on a pure tone audiogram. Sixteen ears had conductive, six ears sensorineural and five ears mixed hearing loss. The median pure tone average of the ears with hearing loss was $33.75 \mathrm{~dB}$ $\mathrm{HL}$ (range, 21 - $100 \mathrm{~dB} \mathrm{HL}$ ). In one patient there was no pure tone audiogram available. This patient had received a visual reinforcement audiometry and a brainstem evoked response audiometry, which was suspected for a pure sensorineural hearing loss in the right ear and a mixed hearing loss in the left ear. The patient with an aural atresia did not have audiogram of the atretic ear. The type of hearing loss compared with the encountered anatomic malformations is summarized in Table 1. Tympanometry was performed in 42 ears, in four ears the test had failed and in the remaining six ears, no tympanogram was available in the medical files. A normal tympanogram (type A) was present in 18 ears, a type $B$ was present in five ears, a type $C$ in three ears, a type As in ten ears, a type Ad in one ear and in five ears a large volume was shown on tympanometry. The tympanometry results from the ears with middle ear abnormalities are shown in Table 1. Of the 12 ears with a dense stapes superstructure and an available tympanogram, three ears had a type As tympanogram, indicating a decreased mobility of the ossicular chain.

\section{Otologic and vestibular findings}

Five patients had no history of recurrent otitis media. All other patients $(n=21)$ had either recurrent otitis media with effusion (OME) or recurrent acute otitis media (OMA), 
or both. All patients with a dense hearing ossicle had a history of recurrent otitis media. Regarding vestibular symptoms, one patient was reported to experience occasional dizziness and another patient showed normal compensatory eye movements when testing the vestibulo-ocular reflex. The patient with occasional dizziness had an LSCC with a small bony island on one side and a single cavity on the other side. In the patient with normal compensatory eye movements, the vestibule and LSCC were bilaterally fused to a single cavity. We presume that no other patient had vestibular symptoms because these symptoms were not mentioned in the medical records.

Table 1. Number of ears with audiometric results per anatomical malformation

\begin{tabular}{|c|c|c|c|c|c|c|c|c|c|c|c|}
\hline \multirow{3}{*}{ Malformation } & \multicolumn{5}{|c|}{ Pure tone audiometry } & \multicolumn{6}{|c|}{ Tympanometry** } \\
\hline & \multirow{2}{*}{$\begin{array}{c}\text { No HL } \\
(\%)\end{array}$} & \multicolumn{4}{|c|}{$\mathrm{HL}$} & \multicolumn{6}{|c|}{ Type } \\
\hline & & $\mathrm{C}(\%)$ & SN (\%) & M (\%) & PTA range in $\mathrm{dB}$ & A & $\mathrm{B}$ & C & As & $\mathrm{Ad}$ & LV \\
\hline Dense malleus & $2(100)$ & - & - & - & - & - & - & - & - & - & - \\
\hline Dense stapes superstructure & $7(39)$ & $6(33)$ & $1(6)$ & $4(22)$ & $21-100$ & 3 & 3 & 1 & 3 & - & 2 \\
\hline IP type II & $5(42)$ & $3(25)$ & $1(8)^{*}$ & $3(25)$ & $38-100$ & & & & & & \\
\hline LSCC: small bony island & $7(41)$ & $4(24)$ & $3(18)^{*}$ & $3(18)^{*}$ & $35-100$ & & & & & & \\
\hline LSCC: single cavity & $6(40)$ & $5(33)$ & $2(13)$ & $2(13)$ & $25-96$ & & & & & & \\
\hline
\end{tabular}

\section{DISCUSSION}

By pooling data from two large centers (University Medical Center Utrecht and Children's Hospital of Philadelphia), we have presented the largest series describing radiographic malformations found in the middle and inner ears of patients with 22q11DS, to our knowledge. In a similar study by Loos et al., CT scans of the temporal bones of 11 patients were analyzed. ${ }^{16}$ Table 2 compares the total number of middle and inner ear malformations described in each study. Perhaps the most interesting but incidental finding was when the LSCC and vestibule consisted of a single cavity, as was seen in $29 \%$, and when the LSCC was malformed with a small bony island, present in $33 \%$.

\section{Inner ear malformations}

Regarding the specific types of vestibular malformations described in literature, those that resulted in a single cavity have previously been described in two case reports ${ }^{13,15}$ as well as by Loos et al. (Table 2). ${ }^{16}$ Other vestibular malformations were also reported in literature. One study retrospectively reviewed brain MR imaging and MRA scans of 24 patients with 22q11DS and found a vestibular dysplasia (The figure in the article showed a single cavity) in $13 \%$ of patients. None of these patients had sensorineural hearing 
CHAPTER 4

loss. ${ }^{23}$ This is a lower prevalence than we found. This could be due to the selection of our patients. The indication of radiology in the Bohm et $\mathrm{al}^{23}$ study were unexplained developmental delay, seizures of unknown etiology, and unilateral weakness, ${ }^{23}$ whereas the indication in our population was mainly hearing loss or otitis media. Furthermore, they did not report on a malformed LSCC with a small bony island or an incomplete partition type II of the cochlea. ${ }^{23}$ These abnormalities are more subtle and likely more difficult to detect on brain MR imaging compared with an MR imaging of the temporal bones. In addition, two case reports described three patients who had bilateral poorly formed LSCCs, and one patient who had bilateral dilation of the vestibule. ${ }^{12,24}$ Loos et al. also described 14 ears with a wide vestibule, of which three also had a wide LSCC. ${ }^{16}$ As described by Casselman et al. the vestibule can be considered large when the surface of the bony island of the LSCC is $<6 \mathrm{~mm}^{2} .{ }^{25}$ Therefore, we can assume that the malformed LSCC with a small bony island in our series of patients is the same anomaly as a wide vestibule reported by Loos et al, even though the vestibule was in our patients, in absolute terms, not wider than normal considering the measurements described by Purcell et al. ${ }^{21}$

Table 2. Overview of number of ears with middle and/or inner ear abnormalities reported by Loos et al. ${ }^{16}$ and in the present study

\begin{tabular}{cccc}
\hline Malformation & $\begin{array}{c}\text { Loos et al. }{ }^{16 ;} \text { number of ears (\%) } \\
\text { (total 22 ears) }\end{array}$ & $\begin{array}{c}\text { Present study; } \\
\text { number of ears (\%) } \\
\text { (total 52 ears) }\end{array}$ & $\begin{array}{c}\text { Total number of } \\
\text { ears (\%) } \\
\text { (total 74 ears) }\end{array}$ \\
\hline Malleus, incus or stapes abnormalities ${ }^{\text {a }}$ & $2(9)$ & $3\left(6^{b}\right)$ & $5\left(7^{c}\right)$ \\
Dense stapes superstructure & $10(45)$ & $18\left(36^{b}\right)$ & $28\left(39^{c}\right)$ \\
LSCC: single cavity & $4(18)$ & $15(29)$ & $19(26)$ \\
Wide vestibule / small bony island in LSCC & $14(64)$ & $17(33)$ & $31(42)$ \\
IP type II & $12(55)$ & $12(23)$ & $24(32)$ \\
Carotid canal dehiscence & $2(9)$ & $5\left(10^{b}\right)$ & $7\left(10^{c}\right)$ \\
\hline
\end{tabular}

Abbreviations: Lateral semicircular canal (LSCC), Incomplete partition (IP).

a Other than a dense stapes superstructure ${ }^{\mathrm{b}}$ Calculated from a total of 50 ears; bone structures in two ears in the present study could not be assessed on MR imaging ${ }^{c}$ Calculated from a total of 72 ears; bone structures in two ears in the present study could not be assessed on MR imaging

Malformations of the inner ear may result from an error in one of the developmental stages in embryogenesis. A malformed LSCC can occur in combination with normally shaped superior and posterior semicircular canals, because the LSCC is developed later compared with the superior and posterior semicircular canals. ${ }^{26}$ Between four and five weeks of gestation, the development of the membranous semicircular canals begins. They develop from the dorsal region of the otocyst, which enlarges, and with resorption of the medial walls, a semicircular shaped duct is formed. ${ }^{27}$ An error in this resorption will result in a confluent vestibule and canal. ${ }^{28}$ This was the case in 15 ears in our cohort. In patients with a malformed LSCC with a small bony island, but without a fusion of the canal and vestibule, the development is presumably disrupted at a later stage.27,29 
From our chart reviews, clinical findings that may have been directly attributed to inner ear vestibular problems such as vertigo or balance problems, were not present in those who had a malformed LSCC on imaging studies. Absent vestibular symptoms in patients without 22q11DS with a malformed LSCC were reported in previous studies. ${ }^{30-32}$ However, more subtle balance problems have frequently been described in the 22q11DS population. ${ }^{33-35}$ Many of these symptoms can relate to other neuromotor deficits, ${ }^{33}$ including motor delay ${ }^{36-38}$ or hypotonia ${ }^{33,38,39}$, but vestibular problems could also play a role. Prospective research is needed to assess the possible relation between anatomical malformations of the vestibular system, vestibular function and motor delay in patients with 22q11DS.

A subtle incomplete partition type II was frequently found in our patients. These findings are consistent with those in the study of Loos et al. (Table 2) ${ }^{16}$ An incomplete partition type II of the cochlea derives from a developmental arrest at the seventh week of gestation. Here the cochlea has 1.5 turns and there is a defect at the apex of the cochlea between the middle and apical turns. The basal turn and basal part of the modiolus are normally developed. ${ }^{40}$ Other cochlear malformations in 22q11DS have also been previously reported. Loos et al. reported on two ears with a large basal turn length. ${ }^{16}$ One patient described by Devriendt et al. had a malformed cochlea, where the basal turn was broad and the second and apical turns were short. ${ }^{13}$

At a genetic level, both the vestibular and cochlear malformations described in our patients may be associated with Tbx1. In patients with 22q11DS $\underline{T b \times 1}$ is hemizygously deleted. In mutated knockout $T b \times 1^{--}$mice, the vestibular system and cochlea are absent. 19,41 Mouse models show an expression of Tbx1 in the otic vesicle, which forms the membranous inner ear, and in the periotic mesenchyme, which forms the otic capsule and later the bony labyrinth. ${ }^{19,41}$ Studies have indicated that the expression of Tbx1 in the periotic mesenchym is necessary for cochlear outgrowth. ${ }^{42,43}$ In addition, Tbx1 is required for outer and middle ear development. ${ }^{20,44}$

Hearing impaired as normal hearing ears were found to have a dense stapes superstructure, incomplete partition type II of the cochlea or a malformed LSCC in this study. However, the relation between hearing loss and abnormalities of the middle or inner ear was not within the scope of this report because selection bias undoubtedly plays a large role. Due to the retrospective design, patients with hearing impairment are more likely to undergo imaging with $\mathrm{CT}$, compared to patients with normal hearing. In fact, the indication for the radiologic imaging in 12 patients was unexplained hearing impairment.

We found five ears with a dehiscence of the carotid canal. A carotid canal dehiscence is present in approximately $7 \%$ of the general population, ${ }^{45,46}$ in which case our findings suggest a slightly higher prevalence in patients with 22q11DS (10\%). In patients with a carotid canal dehiscence the internal carotid artery is (partly) no longer protected by a bony shield and is exposed in the middle ear. Since patients with 22q11DS often suffer 
CHAPTER 4

from middle ear infections requiring grommet insertion or even middle ear surgery, otorhinolaryngologists should be aware of the possible presence of a carotid canal dehiscence in patients with 22q11DS.

\section{Middle ear abnormalities}

We found one ear with an aural atresia, affecting both the external auditory canal and the middle ear. This patient may have had also a second genetic disorder. Therefore, in this patient, the aural atresia could have been attributed to a disorder other than 22q11DS. Aural atresia has previously been described in 22q11DS by Digilio et al. and by Derbent et al. ${ }^{47,48}$ The patients reported both by Digilio et al. and Derbent et al. all showed features resembling the oculo-auriculo-vertebral spectrum in addition to 22q11DS. ${ }^{47,48}$ Patients with the oculo-auriculo-vertebral spectrum show defects in organs deriving from the first and second pharyngeal arch. As a result, aural atresia is frequently observed. ${ }^{49}$ Also concluded by Digilio et al. features resembling the oculoauriculo-vertebral spectrum could occur in patients with 22q11DS, ${ }^{48}$ perhaps more frequently than expected.

In addition, 18 ears with a dense stapes superstructure were encountered. We acknowledge that the diagnosis of a dense stapes superstructure is subjective and these results should be viewed with caution. In the literature we could not found information on a standardization of the CT density of hearing ossicles. However, when analyzing the CT images of our patients, a dense stapes superstructure was relatively easy to detect by visual analysis. Furthermore, Loos et al. found approximately the same number of patients with a dense stapes superstructure (36\% vs $45 \%) .{ }^{16}$ This suggests that this finding may be a feature present in patients 22q11DS, although at present, we do not know its clinical significance. We initially assumed that the dense stapes superstructure was a result of chronic otitis media (ie tympanosclerosis). However, in the study from Loos et al., one patient showed this abnormality on day of life 9. This indicated a congenital instead of a post infectious cause, as stated by the authors. ${ }^{16}$ Possibly, the dense stapes superstructures we encountered were also of congenital origin. Moreover, only three of the 12 ears with a dense stapes superstructure in the present study showed signs of a stiffened ossicular chain on a tympanogram, suggesting a possibly different entity than tympanosclerosis.

Except for a dense manubrium of the malleus and dense stapes, we did not find other abnormalities of hearing ossicles. Much of the affected organs in patients with 22q11DS are derived from the pharyngeal arches. ${ }^{2}$ Although the more caudal arches are more affected in 22 q11DS ${ }^{50}$ and hearing ossicles develop from the cranial arches (malleus and incus form the first and stapes from the second pharyngeal arch), we expected to encounter more middle ear malformations. Anomalies of hearing ossicles in 22q11DS are reported in literature. The first was a patient with conductive hearing loss present since birth, whose imaging revealed 'malformation and subluxation of 
the stapes'. ${ }^{14}$ Another report described two patients, one patient had a 'fusion of the malleus with the incus and a monopodal stapes', shown on CT. CT images of the other patient revealed a 'fixation of the malleus at the annulus tympanicus'.13 This latter malformation was also encountered by Loos et al. in two ears where, in addition, the long process of the incus was thin and horizontally oriented. ${ }^{16}$ Furthermore, another study described one patient with a bilaterally malformed malleus and incus and one patient with a unilateral fusion of the malleus with the lateral wall of the middle ear. ${ }^{24}$

The main limitation in this study is selection bias due to the retrospective design. Only patients with a clinical indication, most likely unexplained hearing loss or chronic or recurrent otitis media, were likely to have undergone radiologic imaging. Therefore, no realistic prevalence should be extracted from this study. The primary purpose of the study was to describe the more common vestibular and cochlear malformations and to consider associations with balance and hearing problems in those who have 22q11DS. Furthermore, some of the encountered abnormalities, especially the incomplete partition type II, are very subtle. Likely there would be interobserver variability when the same images were also evaluated by a different team.

\section{CONCLUSION}

Cross-sectional imaging of the temporal bones in a 22q11DS cohort of 26 patients is presented and a review of the literature is performed. A dense stapes superstructure, suspected incomplete partition type II of the cochlea and LSCC malformations were frequently encountered.

Future studies in these patients should preferably include vestibular testing because balance problems are known to contribute to motor development delay in children. Correlation between LSCC malformations and vestibular function would be of interest. 


\section{REFERENCES}

1. Kobrynski LJ, Sullivan KE. Velocardiofacial syndrome, DiGeorge syndrome: the chromosome 22 q11.2 deletion syndromes. Lancet. 2007;370:1443-1452.

2. McDonald-McGinn DM, Sullivan KE, Marino B, et al. 22q11.2 deletion syndrome. Nat Rev Dis Prim 2015;1:15071.

3. Robin NH, Shprintzen RJ. Defining the clinical spectrum of deletion 22q11.2. J Pediatr. 2005:147:90-96.

4. Dyce O, McDonald-McGinn DM, Kirschner RE, et al. Otolaryngologic manifestations of the 22q11.2 deletion syndrome. Arch Otolaryngol Head Neck Surg. 2002;128:1408-1412.

5. Digilio MC, Pacifico C, Tieri L, et al. Audiological findings in patients with microdeletion 22q11 (diGeorge/ velocardiofacial syndrome). Br J Audiol. 1999;33:329-333.

6. Ford LC, Sulprizio SL, Rasgon BM. Otolaryngological manifestations of velocardiofacial syndrome: a retrospective review of 35 patients. Laryngoscope. 2000;110:362-367.

7. Reyes MRT, LeBlanc EM, Bassila MK. Hearing loss and otitis media in velo-cardio-facial syndrome. Int J Pediatr Otorhinolaryngol. 1999;47:227-233.

8. Persson C, Friman V, Óskarsdóttir S, et al. Speech and hearing in adults with $22 q 11.2$ deletion syndrome Am J Med Genet A. 2012;158A:3071-3079.

9. Van Eynde C, Swillen A, Lambeens $E$, et al. Prevalence and Nature of Hearing Loss in 22 q11.2 Deletion Syndrome. J Speech, Lang Hear Res. 2016;59:583-589.

10. Weir FW, Wallace SA, White DR, et al. Otologic and Audiologic Outcomes in Pediatric Patients With VeloCardio-Facial (22q11 Deletion) Syndrome. Otol Neurotol. 2016:38:73-78.

11. Zarchi $O$, Attias J, Raveh E, et al. A comparative study of hearing loss in two microdeletion syndromes: velocardiofacial (22q11.2 deletion) and Williams (7q11.23 deletion) syndromes. J Pediatr. 2011;158:301306.

12. Tabith Junior A, Haetinger R, Leite de Carvalho e Silva F, et al. Middle and inner ear malformations in two cases of velocardiofacial syndrome. Intl Arch Otorhinolaryngol. 2009:13:83-86.

13. Devriendt K, Swillen A, Schatteman I, et al. Middle and inner ear malformations in velocardiofacial syndrome. Am J Med Genet A. 2004;131:225-226.

14. Cunningham M, Perry RJ, Eby PR, et al. Primary Pulmonary Dysgenesis in Velocardiofacial Syndrome: A Second Patient. Am J Med Genet. 2003;179:177-179.

15. Hopsu E, Markkola A, Pitkaranta A. Labyrinthine malformation in the 22q11.2 deletion syndrome. Clin Dysmorphol. 2007:16:67-68.

16. Loos E, Verhaert N, Willaert A, et al. Malformations of the Middle and Inner Ear on CT Imaging in 22 q11 Deletion Syndrome. Am J Med Genet Part A. 2016:170:2975-2983.

17. Fuchs JC, Zinnamon FA, Taylor RR, et al. Hearing loss in a mouse model of 22q11.2 Deletion Syndrome PLOS One. 2013;8:e80104

18. Funke B, Epstein JA, Kochilas LK et al Mice overexpressing genes from the $22 \mathrm{q} 11$ region deleted in velo-cardio-facial syndrome/DiGeorge syndrome have middle and inner ear defects. Hum Mol Genet. 2001;10:2549-2556.

19. Vitelli F, Viola A, Morishima M, et al. TBX1 is required for inner ear morphogenesis. Hum Mol Genet 2003;12:2041-2048

20. Arnold JS, Braunstein EM, Ohyama T, et al. Tissue-specific roles of Tbx1 in the development of the outer, middle and inner ear, defective in 22q11DS patients. Hum Mol Genet. 2006:15:1629-1639.

21. Purcell D, Johnson J, Fischbein N, et al. Establishment of normative cochlear and vestibular measurements to aid in the diagnosis of inner ear malformations. Otolaryngol- Head Neck Surg. 2003;128:78-87.

22. Monsell EM. Committee on Hearing and Equilibrium guidelines for the evaluation of results of treatment of conductive hearing loss. Otolaryngol - Head Neck Surg. 1995;113:186-187.

23. Bohm LA, Zhou TC, Mingo TJ, et al. Neuroradiographic findings in 22q11.2 deletion syndrome. Am J Med Genet A. 2017;173:2158-2165.

24. Jiramongkolchai $P$, Kumar MS, Chinnadurai S, et al. Prevalence of hearing loss in children with $22 q 11.2$ deletion syndrome. Int J Pediatr Otorhinolaryngol. 2016;87:130-133.

25. Casselman JW, Delanote J, Kuhweide R, et al. Congenital Malformations of the Temporal Bone. In Lemmerling M, De Foer B, eds. Temporal Bone Imaging. Springer; 2015.

26. Rodriguez K, Shah RK, Kenna M. Anomalies of the Middle and Inner Ear. Otolaryngol Clin North Am. 2007:40:81-96

27. Lim R, Brichta AM. Anatomical and physiological development of the human inner ear. Hear Res. 2016:338:9-21. d

28. Jackler R, Luxford W, House W. Cochlear Malformations of the inner ear: A classification based on embryogenesis. Laryngoscope. 1987:97:2-14

29. Jeffery N, Spoor F. Prenatal growth and development of the modern human labyrinth. J Anat. 2004;204:71 92 
30. Matsunaga T, Hirota E. Familial lateral semicircular canal malformation with external and middle ear abnormalities. Am J Med Genet A. 2003;116A:360-367.

31. Johnson J, Lalwani AK. Sensorineural and conductive hearing loss associated with lateral semicircular canal malformation. Laryngoscope. 2000;110:1673-1679.

32. Michel G, Espitalier F, Delemazure AS, et al. Isolated lateral semicircular canal aplasia: Functional consequences. Eur Ann Otorhinolaryngol Head Neck Dis. 2016;133:199-201.

33. Óskarsdóttir S, Belfrage M, Sandstedt E, et al. Disabilities and cognition in children and adolescents with 22q11 deletion syndrome. Dev Med Child Neurol. 2005;47:177-184.

34. Roizen NJ, Higgins AM, Antshel KM, et al. 22q11.2 deletion syndrome: Are motor deficits more than expected for IQ level? J Pediatr. 2010;157:658-661.

35. Sobin C, Monk SH, Kiley-Brabeck K, et al. Neuromotor deficits in children with the 22 q11 deletion syndrome. Mov Disord. 2006;21:2082-2089.

36. Van Aken K, De Smedt B, Van Roie A, et al. Motor development in school-aged children with 22 q11 deletion (velocardiofacial/DiGeorge syndrome). Dev Med Child Neurol. 2007;49:210-213.

37. Roizen NJ, Antshel KM, Fremont W, et al. 22q11.2DS Deletion Syndrome: Developmental Milestones in Infants and Toddlers. J Dev Behav Pediatr. 2007;28:119-124.

38. Gerdes M, Solot C, Wang PP, et al. Cognitive and behavior profile of preschool children with chromosome 22q11.2 deletion. Am J Med Genet. 1999;85:127-133.

39. Swillen A, Devriendt K, Legius E, et al. The behavioural phenotype in velo-cardio-facial syndrome (VCFS): from infancy to adolescence. Genet Couns. 1999;10:79-88.

40. Sennaroglu L, Saatci I. A new classification for cochleovestibular malformations. Laryngoscope 2002;112:2230-2241

41. Raft S, Nowotschin S, Liao J, et al. Suppression of neural fate and control of inner ear morphogenesis by Tbx1. Development. 2004;131:1801-1812.

42. Braunstein EM, Monks DC, Aggarwal VS, et al. Tbx1 and Brn4 regulate retinoic acid metabolic genes during cochlear morphogenesis. BMC Dev Biol. 2009:9:31.

43. Monks DC, Morrow BE. Identification of putative retinoic acid target genes downstream of mesenchymal Tbx1 during inner ear development. Dev Dyn. 2012;241:563-573.

44. Jerome LA, Papaioannou VE. DiGeorge syndrome phenotype in mice mutant for the T-box gene, Tbx1. Nat Genet. 2001;27:286-291.

45. Moreano E, Paparella M, Zelterman D, et al. Prevalence of Carotid Canal Dehiscence in the Human Middle Ear: A Report of 1000 Temporal Bones. Laryngoscope. 1994;104:612-618.

46. Wang $\mathrm{CH}$, Shi ZP, Liu DW, et al. High computed tomographic correlations between carotid canal dehiscence and high jugular bulb in the middle ear. Audiol Neurotol. 2011;16:106-112.

47. Derbent M, Yilmaz Z, Baltaci V, et al. Chromosome 22q11.2 deletion and phenotypic features in 30 patients with conotruncal heart defects. Am J Med Genet A. 2003;116A:129-135.

48. Digilio MC, McDonald-McGinn DM, Heike $C$, et al. Three patients with oculo-auriculo-vertebral spectrum and microdeletion 22q11.2. Am J Med Genet A. 2009;149A:2860-2864.

49. Sleifer P, Gorsky NDS, Goetze TB, et al. Audiological findings in patients with oculo-auriculo-vertebral spectrum. Int Arch Otorhinolaryngol. 2013;19:5-9.

50. Baldini A. Dissecting contiguous gene defects: TBX1. Curr Opin Genet Dev. 2005;15:279-284. 
564555-L-bw-Verheij

Processed on: 16-9-2021 


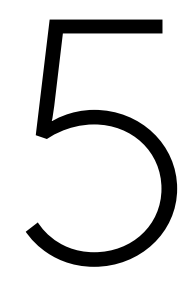

CASE REPORT:

CHALLENGING OTOLOGIC SURGERY

IN PATIENTS WITH 22q11.2 DELETION SYNDROME

Front Surg. 2020 Aug 18;7:53. doi: 10.3389/fsurg.2020.00053.

Emmy Verheij*

Laura M. Markodimitraki*

Robert J. Stokroos

Hans G.X.M. Thomeer

* Both authors contributed equally 


\section{ABSTRACT}

Patients with 22q11.2 deletion syndrome frequently have conductive hearing loss and/ or chronic otitis media. Otologic surgery is often opted for. We present two patients undergoing otologic surgery. This case report outlines the typical otologic surgical challenges in patients with 22q11.2 deletion syndrome.

Case one is a 52-year-old male patient with chronic otitis media who underwent a mastoidectomy. The pre-operative CT scan showed a fused lateral semicircular canal and vestibule. Peroperatively, the lateral semicircular canal could not be used as a landmark to identify the facial nerve. Case two is a 10 -year-old female patient with conductive hearing loss. A middle ear inspection was performed where a bony epitympanic fixation of the malleus was encountered. In addition, the manubrium of the malleus was atrophic and also fixated. The bony fixation was removed, as was the manubrium of the malleus.

Otologists should be aware of these typical anatomical variations of patients in 22q11DS. We recommend to use CT scanning of the middle and inner ear when preparing for otologic surgery in 22q11.2 deletion syndrome. 


\section{INTRODUCTION}

The 22q11.2 deletion syndrome (22q11DS), also known as DiGeorge syndrome or velocardiofacial syndrome, is caused by a microdeletion on chromosome 22 and is the most frequent microdeletion syndrome in humans, occurring in approximately 1 in every 3000 to 6000 live births. ${ }^{1}$ It has a heterogeneous presentation with a broad range of manifestations such as cardiac anomalies, immunodeficiency, velopharyngeal insufficiency and otologic problems. The severity of health issues varies within the 22q11DS patient population. . $^{1,2}$ Otologic manifestations reported in the literature are conductive or sensorineural hearing loss, the former being the more prevalent. Patients can suffer from recurrent or chronic otitis media, warranting surgical treatment in some cases. ${ }^{3-9}$ Anatomical malformations of the middle and inner ear have also been described. Among the otologic anatomic malformations found in patients with 22q11DS are ossicular chain anomalies, a malformed lateral semicircular canal and a fused lateral semicircular canal and vestibule. ${ }^{10-12}$ During mastoidectomy, the lateral semicircular canal is an important landmark for the inner ear in relation to the facial nerve. ${ }^{13} \mathrm{~A}$ limited number of reports have been provided thus far regarding 22q11DS and otologic surgery. We report two patients with 22q11DS who underwent otologic surgery and were found to have anatomical malformations of the middle and inner ear. It is of value to be acquainted surgically with the possible anatomical variations, to avoid surgical complications (i.e. deaf ear, iatrogenic damage to the labyrinth or facial nerve) and to plan ossicular chain surgery.

Informed consent was obtained of both described patients and/or parents.

\section{Case 1}

A 52-year-old man with known 22q11DS has visited our tertiary otologic clinic regularly for eight years due to chronic middle ear infections, for medical treatment of his chronic otitis media. He had an extensive medical history including diabetes mellitus type 2, morbid obesity, hypertension, Asperger syndrome, asthma, hypoparathyreoidy, anemia and obstructive sleep apnea. His otorhinolaryngologic history included pharyngoplasty at age 4, mastoid and ear surgery including mastoidectomy with atticoantrotomy on the left side at 7 years of age, revision surgeries performed at 11, 27 and 46 years old and chronic rhinosinusitis with nasal polyps. Audiometry tests showed a progression of preexistent mixed hearing loss over time. The CT scan showed a dense stapes superstructure, and the vestibule and lateral semicircular canal were fused to a single cavity (Figure 1) These malformations were present bilaterally. The cochlea was formed normally.

Due to persistent chronic otitis media he underwent revision surgery on the right side. A meatoplasty was performed to improve the diameter of the introitus of the external auditory meatus. A revision mastoidectomy was performed revealing 
CHAPTER 5

inflammatory tissue which was removed. The ossicles were intact and freely mobile. Identification of the facial nerve was challenging due to the malformed semicircular lateral canal, the facial nerve taking a relatively more lateral course. No iatrogenic damage to either structure was reported during surgery. The mastoid was obliterated with bone dust, with a bone chip closing the antrum. No cholesteatoma was encountered. Pure tone audiometry two months post-surgery was unchanged with a mixed hearing loss bilaterally (Figure 2).

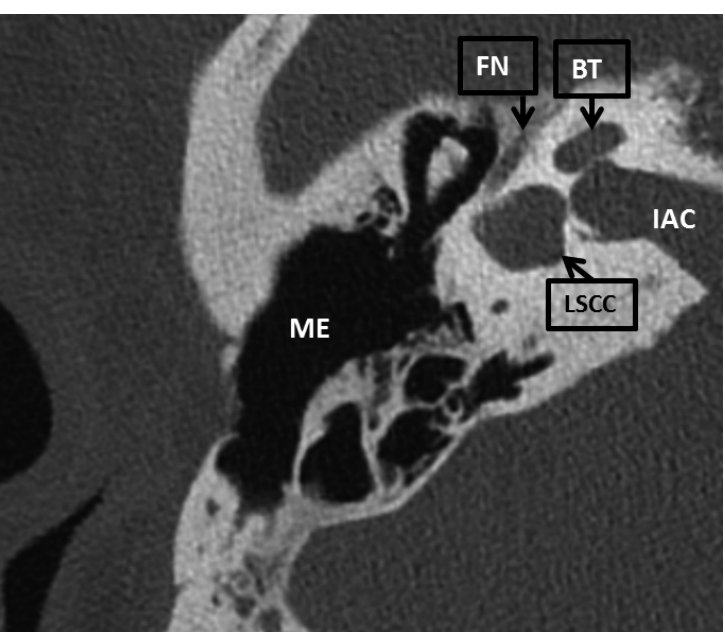

Figure 1. An axial CT scan of the right mastoid bone of patient 1

The lateral semicirculair canal is fused with the vestibule to a single cavity.

Legend: $\mathrm{LSCC}=$ lateral semicirculair canal. $\mathrm{BT}=$ basal turn of the cochlea. $\mathrm{IAC}=$ inner auditory canal. $\mathrm{FN}=$ facial nerve. $\mathrm{ME}=$ middle ear

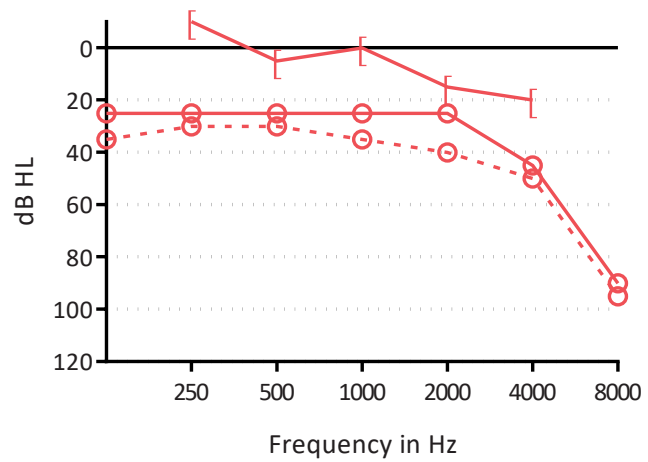

Figure 2. Pre- and postoperative hearing thresholds of the right ear of patient 1.

Legend: $[-[=$ postoperative bone conduction thresholds. $\mathrm{O}-\mathrm{O}=$ postoperative air conduction thresholds. O-- $\mathrm{O}=$ preoperative air conduction thresholds. 


\section{Case 2}

A 10 -year-old female patient with known 22q11DS was seen at our otorhinolaryngologic department for 8 years. Her relevant medical history includes cardiac anomalies (atrial septal defect, ventricular septal defects and pulmonary artery defect), conductive hearing loss bilaterally (Figure 3), malformed ossicular chain and narrow ear canals. The patient underwent tympanostomy tube placement due to Eustachian-tube problems at 3 years of age. The patient wore hearing aids since the age of 4 . The indication for middle ear inspection was made, due to a conductive hearing loss and problems wearing hearing aids in combination with glasses. Pre-operatively, a CT scan was performed to assess the middle and inner ear. This showed a more horizontal orientation of the incus, epitympanic ossicular fixation (Figure 4) and dehiscent facial nerve canal on the left side.

A middle ear inspection and ossicular reconstruction on the left side was performed. A retroauricular incision was made, the external auditory canal was saucerized and widened both anteriorly and posteriorly. There was an epitympanic fixation of the malleus, which was curetted. In addition, the manubrium of the malleus was atrophic and anteriorly fixated, and therefore removed. This resulted in a mobile ossicular chain. Audiometry tests showed a hearing improvement of frequencies $0.25,5,1$ and $2 \mathrm{kHz}$. (Figure 3)

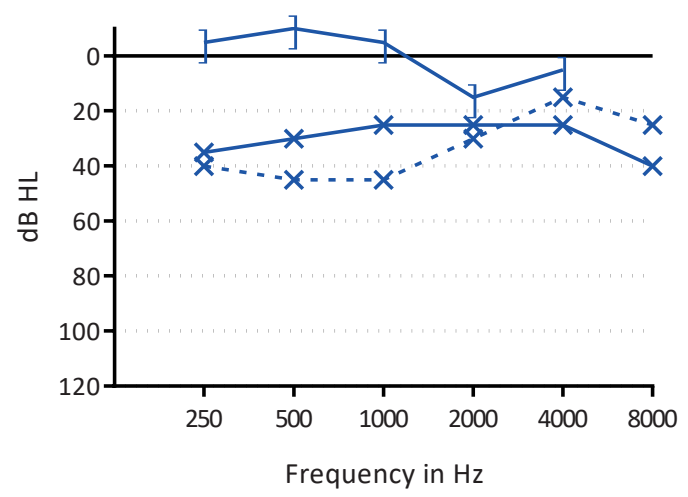

Figure 3. Pre- and postoperative hearing thresholds of patient 2.

Legend: ]-] = postoperative bone conduction thresholds. $x-x=$ postoperative air conduction thresholds. $x--x$ $=$ preoperative air conduction thresholds. 
CHAPTER 5

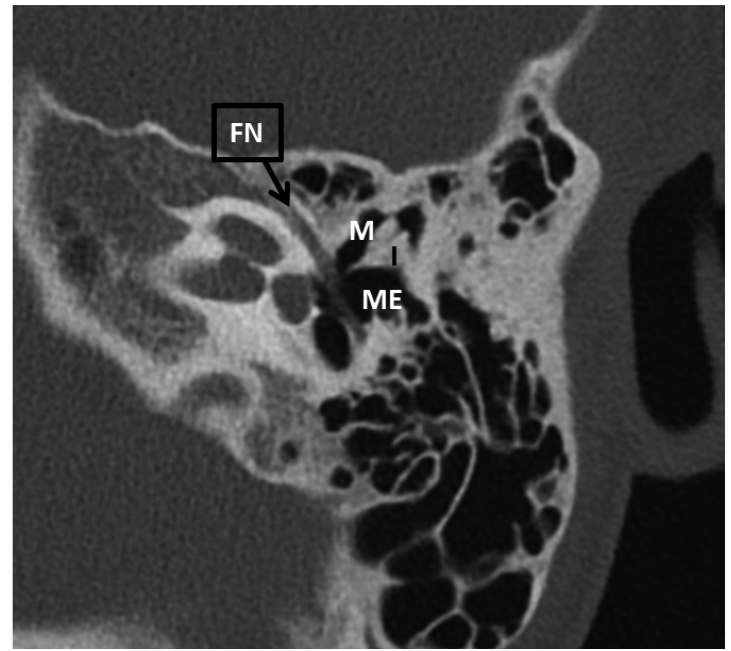

Figure 4. An axial CT scan of the left mastoid bone of patient 2.

There is an epitympanic fixation involving the malleus.

Legend: $F N=$ facial nerve. $I=$ incus. $M=$ malleus. $M E=$ middle ear.

\section{DISCUSSION}

The exact prevalence of clinical otologic manifestations in patients with 22q11DS is unknown in the current literature partly due to reporting heterogeneity. ${ }^{6}$ Otologists should be aware of the increased risk for middle- and inner ear malformations that have been reported in 22q11DS patients, since typical otologic problems in 22q11DS might need surgical interventions. ${ }^{14}$ Pre-operative radiologic screening in otologic surgery is warranted in patients with 22q11DS to identify these anatomical malformations.

We present a case of a 22q11DS patient with an abnormally formed lateral semicircular canal, which is an important landmark to identify the facial nerve during surgery in normal temporal bones. This makes identification of the facial nerve more challenging. The nerve took an abnormal, more lateral course in relation the lateral semicircular canal. The facial nerve could be identified using the short process of the incus, and digastric ridge as landmarks. ${ }^{13}$ In addition, intra-operative facial nerve stimulation is very useful in identifying the facial nerve. ${ }^{15}$

Bilateral and unilateral malformations of the lateral semicircular canal are reported to be one of the most common radiological inner ear malformations and are associated with sensorineural as well as conductive hearing loss. ${ }^{16,17}$ Inner ear anomalies in 22q11DS patients, concerning the lateral semicircular canal have been reported previously. One case series retrospectively assessing imaging, found a malformed lateral semicircular canal with a small bony island in $33 \%$ of the 52 ears, and a lateral semicircular canal 
and vestibule fused to a single cavity in $29 \%$ of ears. ${ }^{11}$ Another study found a fused vestibule and lateral semicircular canal in $18 \%$ of 22 ears, and a wide vestibule in $64 \%$ of ears. ${ }^{10}$ Possibly, a malformed semicircular canal with a small bony island and a wide vestibule describe the same deformity. One case report described a fused lateral semicircular canal and vestibule in one patient and a dysplastic semicircular canal in another patient. ${ }^{12}$ Another study reported on a patient with poorly formed lateral semicircular canals bilaterally and another patient with bilateral vestibular dilatation. ${ }^{4}$

Our second case was a patient with an anomaly of the ossicular chain, resulting in conductive hearing loss. This was a Class III middle ear anomaly, according to the Teunissen Cremers classification. ${ }^{18}$ A Class III compromises an ossicular chain malformation with a mobile stapes footplate.

Vincent et al. published a case series and literature review analyzing audiometric results following surgical treatment of Teunissen and Cremers Class III patients. ${ }^{19}$ They reported an postoperative air-bone gap closure tot $10 \mathrm{~dB} \mathrm{HL}$ or less in $63 \%$, and an postoperative air-bone gap closure to $20 \mathrm{~dB}$ or less in $75 \% .{ }^{19}$ In our patient, although her hearing improved mainly in the low frequencies, the air-bone gap postoperatively was $25 \mathrm{~dB} \mathrm{HL}$, averaged over frequencies $0.5-4 \mathrm{kHz}$. In the series by Vincent et al. a malleus fixation was encountered in three patients. In all three cases a bony bridge between the malleus and outer meatus was drilled out, leaving the ossicular chain intact. They had a post-operative air-bone gap of $31 \mathrm{~dB} \mathrm{HL}, 4 \mathrm{~dB} \mathrm{HL}$ and $0 \mathrm{~dB} H \mathrm{H}$ subsequently. ${ }^{19}$

Zhan et al reported on five pediatric cases with an isolated malleus fixation. An ossified mallear ligament was dissected if present, and the bone responsible for the fixation was removed. Postoperatively, they had an air-bone gap of $0-15 \mathrm{~dB} \mathrm{HL}^{20}$ Unlike the cases of Vincent and Zhan et al, in our case the malleus handle was also removed, perhaps explaining the remaining air-bone gap.

In the meta-analysis of Crutcher et al. ossicular chain mobilization was compared to ossiculair chain reconstruction (removing malleus head and incus and reconstructing the ossicular chain) in isolated malleus and/or incus fixation. There was no statistical difference in hearing outcome between the two techniques. ${ }^{21}$

In patients with 22q11DS a range of different middle ear malformations are described. Loos et al described a patient with a malleus with fixation to the tympanic annulus and a thin and horizontally oriented long process of the incus. ${ }^{10}$ Verheij et al. and Loos et al. both reported patients with 22q11DS with a dense stapes suprastructure. ${ }^{10,11}$ In addition, Verheij et al. found a dense manubrium of the malleus. ${ }^{11} \mathrm{~A}$ malformation and subluxation of the stapes was described by Cunningham et al. ${ }^{22} \mathrm{~A}$ fusion of the malleus and incus and a monopodal stapes was reported by DeVriendt et al. ${ }^{23}$ Jiramongkolchai et al. described a bilaterally malformed malleus and incus and a unilateral fusion of the malleus with the lateral wall of the middle ear. ${ }^{4} \mathrm{~A}$ recent case report by Kennel et al. described a patient with 22q11DS that underwent middle ear surgery during which 
CHAPTER 5

an stapes subluxation took place. This unnatural mobility of the stapes was due to an absent stapedial tendon and a weak connection to the oval window. ${ }^{14}$

In summary, we present two patients with 22q11DS who underwent otologic surgery. In the first patient the anatomy of the lateral semicircular canal was malformed, challenging the identification of the facial nerve during mastoidectomy surgery. The second patient had an malformed middle ear anatomy. Otologists should be aware of these typical anatomical variations of patients in 22q11DS. We recommend to use CT scanning of the middle and inner ear when preparing for otologic surgery in 22q11.2 deletion syndrome, in addition to intra-operative facial nerve stimulation. 


\section{REFERENCES}

1. McDonald-McGinn DM, Kirschner R, Goldmuntz E, et al. The Philadelphia story: the 22q11.2 deletion: report on 250 patients. Genet Couns. 1999;10(1):11-24.

2. Kobrynski LJ, Sullivan KE. Velocardiofacial syndrome, DiGeorge syndrome: the chromosome $22 q 11.2$ deletion syndromes. Lancet. 2007;370(9596):1443-1452.

3. Dyce O, McDonald-McGinn DM, Kirschner RE, Zackai E, Young K, Jacobs IN. Otolaryngologic manifestations of the 22q11.2 deletion syndrome. Arch Otolaryngol Head Neck Surg. 2002;128(12):1408-1412.

4. Jiramongkolchai P, Kumar MS, Chinnadurai S, Wootten CT, Goudy SL. Prevalence of hearing loss in children with 22q11.2 deletion syndrome. Int J Pediatr Otorhinolaryngol. 2016;87:130-133. doi:10.1016/j.jporl.2016.06.005

5. Van Eynde C, Swillen A, Lambeens E, et al. Prevalence and Nature of Hearing Loss in 22q11.2 Deletion Syndrome. J Speech, Lang Hear Res. 2016;59(3):583-589. doi:10.1044/2015

6. Verheij E, Derks LSM, Stegeman I, Thomeer HGXM. Prevalence of hearing loss and clinical otologic manifestations in patients with 22q11.2 deletion syndrome: A literature review. Clin Otolaryngol. 2017:42:1319-1328. doi:10.1111/coa.12874

7. Digilio MC, Pacifico C, Tieri L, Marino B, Giannotti A, Dallapiccola B. Audiological findings in patients with microdeletion 22q11 (diGeorge/velocardiofacial syndrome). Br J Audiol. 1999;33(5):329-333.

8. Weir FW, Wallace SA, White DR, Hatch JL, Nguyen SA, Meyer TA. Otologic and Audiologic Outcomes in Pediatric Patients With Velo-Cardio-Facial (22q11 Deletion) Syndrome. Otol Neurotol. 2016;38(1):7378. doi:10.1097/MAO.0000000000001226

9. Zarchi O, Attias J, Raveh E, Basel-Vanagaite L, Saporta L, Gothelf D. A comparative study of hearing loss in two microdeletion syndromes: velocardiofacial (22q11.2 deletion) and Williams (7q11.23 deletion) syndromes. J Pediatr. 2011;158(2):301-306. doi:10.1016/j.jpeds.2010.07.056

10. Loos E, Verhaert N, Willaert A, et al. Malformations of the Middle and Inner Ear on CT Imaging in $22 \mathrm{q} 11$ Deletion Syndrome. Am J Med Genet Part A. 2016;170(11):2975-2983. doi:10.1002/ajmg.a.37872

11. Verheij E, Elden L, Crowley TB, et al. Anatomic Malformations of the Middle and Inner Ear in 22q11.2 Deletion Syndrome: Case Series and Literature Review. AJNR Am J Neuroradiol. 2018;39(5):928-934.

12. Tabith Junior A, Haetinger R, Leite de Carvalho e Silva F, De Castro Gudmon M. Middle and inner ear malformations in two cases of velocardiofacial syndrome. Intl Arch Otorhinolaryngol. 2009;13(1):8386. doi:10.1002/ajmg.a.30326

13. Sanna M, Sunose H, Mancini F, Russo A, Taibah A, Flacioni M. Chapter 12. Simple Mastoidectomy. In Middle Ear and Mastoid Microsurgery. 2nd ed. (Sanna M, Sunose H, Mancini F, eds.). Thieme; 2012.

14. Kennel CE, Cousins JP, Rivera AL. Easy Stapes Subluxation in 22q11.2 Deletion Syndrome: A Clinical Capsule and Literature Review. Otol Neurotol. 2019;40(6):e606-e611. doi:10.1097/ MAO.0000000000002271

15. Noss RS, Lalwani AK, Yingling CD. Facial nerve monitoring in middle ear and mastoid surgery Laryngoscope. 2001;111(5):831-836. doi:10.1097/00005537-200105000-00014

16. Venkatasamy A, Foll D Le, Eyermann C, et al. Malformations of the lateral semicircular canal correlated with data from the audiogram. Eur Arch Oto-Rhino-Laryngology. 2019;276(4):1029-1034. doi:10.1007/s00405-019-05294-y

17. Johnson J, Lalwani AK. Sensorineural and conductive hearing loss associated with lateral semicircular canal malformation. Laryngoscope. 2000;110(10 Pt 1):1673-1679. doi:10.1097/00005537200010000-00019

18. Teunissen EB, Cremers CWRJ. Classification of congenital middle ear anomalies report on 144 ears Ann Otol Rhinol Laryngol. 1993;102(8):606-612. doi:10.1177/000348949310200807

19. Vincent R, Wegner I, Derks LSM, Grolman W. Congenital ossicular chain malformations with mobile stapes in children: Results in 17 cases. Laryngoscope. 2016;126(3):682-688. doi:10.1002/lary.25351

20. Zhan KY, Mattingly JK, Adunka OF. Isolated malleus fixation: A pediatric case series. Int J Pediatr Otorhinolaryngol. 2019;124(March):1-5. doi:10.1016/j.ijporl.2019.05.021

21. Crutcher WL, Tassone P, Pelosi S. Ossicular chain mobilisation versus reconstruction in surgery for isolated malleus and/or incus fixation: Systematic review and meta-analysis. J Laryngol Otol. 2018;132(10):858-865. doi:10.1017/S0022215118001494 
CHAPTER 5

22. Cunningham M, Perry RJ, Eby PR, Gibson RL, Opheim KE, Manning S. Primary Pulmonary Dysgenesis in Velocardiofacial Syndrome: A Second Patient. Am J Med Genet. 2003;179(February):177-179. doi:10.1002/ajmg.a.20142

23. Devriendt K, Swillen A, Schatteman I, Lemmerling M, Dhooge I. Middle and inner ear malformations in velocardiofacial syndrome. Am J Med Genet A. 2004;131(2):225-226. doi:10.1002/ajmg.a.30326 
CASE REPORT: CHALLENGING OTOLOGIC SURGERY IN PATIENTS WITH 22q11.2 DELETION SYNDROME

564555-L-bw-Verheij

Processed on: 16-9-2021 
564555-L-bw-Verheij

Processed on: 16-9-2021 
VESTIBULOLOGY 
564555-L-bw-Verheij

Processed on: 16-9-2021 


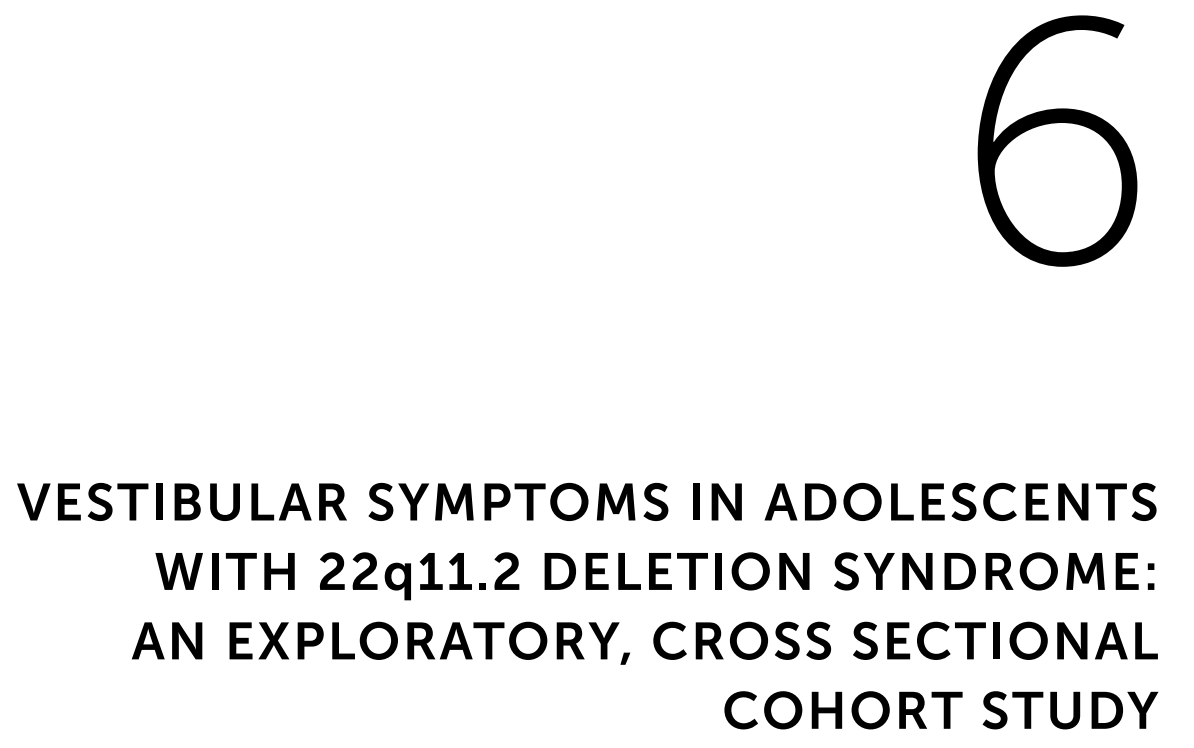

Submitted

Emmy Verheij

Laura M Markodimitraki Hans GXM Thomeer 


\section{ABSTRACT}

\section{Objective}

In patients with 22q11.2 deletion syndrome congenital malformations of the vestibular system have been reported. Our objective was to explore whether children with 22q11DS report subjective symptoms of vestibular function impairment.

\section{Methods}

A questionnaire on vestibular symptoms was developed. Children with 22q11DS between 12 and 18 years and a control group of children aged between 12 and 18 years were asked to fill in the questionnaire. All results were descriptive.

\section{Results}

A total of 26 children with 22q11DS with a median age of 15 years (range 12-17 years) filled in the questionnaire. The control group consisted of 26 children with a median age of 16 years (range 12-18). Children with and without 22q11DS reported to experience dizziness. The control group showed to have more orthostatic hypotension like symptoms such as dizziness when getting up $(92 \%$ of the children in the control group who reported dizziness compared to $54 \%$ of the children with 22q11DS who reported dizziness). Balance difficulties were more prevalent in the 22q11DS group (58\% versus $27 \%$ ). More difficult situations such as walking in the dark did not induce more dizziness in the 22q11DS group. Children with 22q11DS started walking at an average age of 22 months (range 12-48), compared to an average age of 13 months in the control group (range 8-18).

\section{Conclusion}

Children with 22q11DS seem to experience balance problems, which could be an contributing factor in motor development delay. Physiotherapy is advised to support motor skills. 


\section{INTRODUCTION}

The 22q11.2 deletion syndrome (22q11DS) is the most prevalent microdeletion syndrome and occurs in 1:3000-6000 live births. ${ }^{1-3}$ It is characterized by a highly variable phenotype. ${ }^{2,4,5}$ Congenital malformations of the vestibular system have been reported in this patient population in recent studies ${ }^{6.7}$, although an association with balance disorders or vestibular complaints has not yet been described. Our group reported on radiologic deformities of the vestibular system in patients with 22q11DS. ${ }^{6}$ We found a malformed lateral semicircular canal with a small bony island in $33 \%$ of ears, and a fused lateral semicircular canal and vestibule to a single cavity in $29 \%$ of ears. ${ }^{6}$ In addition, Loos et al. analyzed CT scans of patients with 22q11DS in another subsequent study and found a wide vestibule in $64 \%$ of ears and a fused lateral semicircular canal and vestibule to a single cavity in $18 \%$ of ears. ${ }^{7}$ However, the clinical implication of these radiological findings, was not demonstrated. The performed radiological images were indicated in patients with other pathology (i.e. hearing loss, chronic otitis media.). Therefore these images might not be extrapolated to all 22q11DS patients, overall. Willaert et al. conducted a study where they found $90 \%$ (18 out of 20) 22q11DS patients undergoing caloric testing to have uni- or bilateral weak caloric responses. ${ }^{8}$ Balance difficulties are also previously described, although this was mainly contributed to hypotonia. ${ }^{9-12}$ Moreover, vestibular difficulties could lead to motor developmental delay ${ }^{13-22}$, which is a known feature in patients with 22q11DS. ${ }^{10,11,23}$ It might be informative to know if patients attained with balance disorders and vestibular complaints, have a concomitant abnormality visualized on CT or MRI radiological images.

The aim of this study was to explore subjective symptoms due to possible vestibular loss of function in adolescents with 22q11DS. This would be a preparatory study to assess and quantify the amount of regular outpatient 22q11DS children with possible non-diagnosed vestibular disorder or balance handicap. We will compare the outcome with a control group of the general population.

\section{METHODS}

\section{Patients}

Children with 22q11DS between 12 and 18 years old were included. Patients were recruited via the Dutch 22q11DS patient society (Steun Stichting 22q11) and another study cohort of the Psychiatric department in our university medical center. Inclusions were carried out from April to August 2017. The control group consisted of children without 22q11DS and was recruited from November 2019 until January 2021 via the outpatient clinic for traumatology, and via personal contacts. The only exclusion criterion for children in the control group was 22q11DS, the only inclusion criterion was age between 12 and 
CHAPTER 6

18 years. All patients provided informed consent to participate. The patients filled in an online questionnaire with or without explanatory support of their parents.

The Medical Research Ethics Committee confirmed that the Medical Research Involving Human Subjects Act does not apply to this study and an official approval by the Medical Research Ethics Committee was not required (METC protocol number 17-260/C).

\section{Questionnaire}

We developed a (non-validated) exploratory questionnaire on vestibular symptoms in the Dutch language. We were specifically interested if children experienced dizziness or unbalance and if more subtle vestibular symptoms were present. See Supplement 1 for the full translated version of our developed questionnaire. The questions were first tested on children aged 15-17 years without 22q11DS, who attended a school where they received extra guidance in their education. This group was specifically chosen since the average IQ of 22q11DS patients is approximately $70^{2}$. The final version of the questionnaire was made and distributed digitally, in an online program (NetQ version 6.5). Halfway through the study, the University Medical Center Utrecht switched to a different online program (Castor EDC v2019.2). All children with 22q11DS filled in the questionnaire in NetQ, the children in the control group filled in the questionnaire in Castor.

\section{Data analysis}

This was an explorative study, all outcome data were descriptive.

\section{RESULTS}

We included 26 22q11DS adolescents, two from the 22q11DS patient society and 24 from the psychiatric study cohort. Subsequently 26 children were included in de control group. Baseline characteristics are shown in Table 1. The patient and control group were similar in age and gender, but differed in the use of medication; $23 \%$ of children with 22q11DS used medication that could induce dizziness.

13 children with 22q11DS (56\%) and 12 children in the control group (46\%) were dizzy at least once every 6 months (Table 2). The duration of dizziness was in the control group mostly seconds, whereas in the 22q11DS group the duration varied from 15 minutes to seconds. In addition, $92 \%$ of children who experienced dizziness in the control group were dizzy when getting up, in children in de 22q11DS the dizziness could be induced by more divers situations. There were 15 children with 22q11DS (58\%) and seven children in the control group (27\%) who indicated to experience a balance difficulty. Seven children with 22q11DS (28\%) reported they felt their surroundings moving when they were walking or turning, which could be a sign of oscillopsia. In the 
control group one case (4\%) answered this question positively.

Table 1. Baseline characteristics

\begin{tabular}{lll}
\hline & Children with 22q11DS (\%) & Control group (\%) \\
\hline Median age in years (range) & $15(12-17)$ & $16(12-18)$ \\
Male : Female & $10: 16$ & $13: 13$ \\
Use of hearing aid & $3(12)$ & $1(4)$ \\
Use of medication which could induce dizziness & $6(23)^{*}$ & $0(0)$ \\
Use of alcohol & $1(4)$ & $7(27)$ \\
Use of recreational drugs & $0(0)$ & $0(0)$ \\
\hline * The medication used was: risperidone and melatonin in one patient, melatonin in one patient, sertraline and \\
amitriptyline in one patient, oxcarbazepine in one patient, melatonin, clobazam and sometimes midazolam in \\
one patient, methylphenidate in one patient, and methotrexate in one patient.
\end{tabular}

Table 2. Questionnaire outcomes: vestibular and balance difficulties

\begin{tabular}{|c|c|c|c|c|}
\hline \multirow[b]{2}{*}{ Dizziness frequency } & \multicolumn{2}{|c|}{ Children with 22q11DS } & \multicolumn{2}{|c|}{ Control group } \\
\hline & (total $n=26)$ & $(\%)$ & (total $n=26)$ & (\%) \\
\hline Every day & 4 & 15 & 0 & 0 \\
\hline Between once a month and once a week & 5 & 19 & 8 & 31 \\
\hline Between once every 6 months and once a month & 4 & 15 & 4 & 15 \\
\hline Never & 10 & 38 & 10 & 38 \\
\hline I do not know & 3 & 12 & 4 & 15 \\
\hline Dizziness symptoms & (total $n=13)$ & $(\%)$ & (total $n=12)$ & (\%) \\
\hline Spinning sensation* & 7 & 58 & 12 & 100 \\
\hline Lightheaded* & 9 & 82 & 11 & 92 \\
\hline Nausea and/or vomiting* & 6 & 46 & 5 & 42 \\
\hline Dizziness duration & (total $n=13$ ) & (\%) & (total $n=12$ ) & (\%) \\
\hline Seconds & 4 & 31 & 8 & 67 \\
\hline 1 minute & 3 & 23 & 1 & 8 \\
\hline 5 minutes & 3 & 23 & 1 & 8 \\
\hline 15 minutes & 2 & 15 & 1 & 8 \\
\hline 30 minutes & 0 & 0 & 1 & 8 \\
\hline I do not know & 1 & 1 & 0 & 0 \\
\hline Dizziness situation & (total $n=13$ ) & $(\%)$ & (total $n=12$ ) & (\%) \\
\hline Turning in bed & 2 & 15 & 0 & 0 \\
\hline Getting up & 7 & 54 & 11 & 92 \\
\hline Sitting & 2 & 15 & 1 & 8 \\
\hline Walking & 3 & 23 & 1 & 8 \\
\hline Riding a bicycle & 0 & 0 & 1 & 8 \\
\hline Doing sports & 6 & 46 & 4 & 33 \\
\hline Balance difficulties frequency & (total $n=26)$ & (\%) & (total $n=26)$ & (\%) \\
\hline 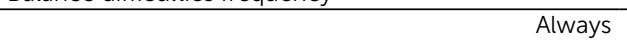 & 1 & 4 & 0 & 0 \\
\hline Often & 3 & 12 & 0 & 0 \\
\hline Sometimes & 11 & 42 & 7 & 27 \\
\hline Never & 11 & 42 & 19 & 73 \\
\hline I do not know & 0 & 0 & 0 & 0 \\
\hline Balance difficulties situation & (total $n=15)$ & (\%) & (total $n=7)$ & (\%) \\
\hline Getting up & 5 & 33 & 3 & 43 \\
\hline Walking & 8 & 53 & 1 & 14 \\
\hline Riding a bicycle & 8 & 53 & 0 & 0 \\
\hline Doing sports & 6 & 40 & 1 & 14 \\
\hline Other & $2^{* *}$ & 13 & 1 1** & 14 \\
\hline $\begin{array}{l}\text { Signs of oscillopsia (moving surroundings when } \\
\text { walking or turning ) }(n=26)^{*}\end{array}$ & 7 & 28 & 1 & 4 \\
\hline
\end{tabular}


CHAPTER 6

Table 3 shows the number of children who reported to have more subtle symptoms which could suggest vestibular dysfunction. Approximately the same number of adolescents in the control group and 22q11DS group had trouble walking in the dark or walking on uneven grounds. For the question at what age the child started walking; we excluded answers younger than eight months since these are not reliable answers. The 22q11DS group started walking later on average than the control group (22 months versus 13 months). During sports six children with 22q11DS felt dizzy and six children with 22q11DS felt unbalanced during sports, versus five children and one child respectively in the control group. A majority in both groups enjoyed sports.

Table 3. Questionnaire outcomes: symptoms suggestive for vestibular dysfunction

\begin{tabular}{lcccc}
\hline & $\begin{array}{c}\text { Children with 22q11DS } \\
\text { Total }\end{array}$ & $\begin{array}{c}\text { Control group } \\
\text { (\% / range) }\end{array}$ & $\begin{array}{c}\text { Total } \\
\text { (\% / range) }\end{array}$ \\
\hline Difficulty walking in the dark & 10 & 43 & 11 & 44 \\
Difficulty walking on uneven ground & 12 & 46 & 9 & 36 \\
Dizziness or balance difficulty with quick head movements & 14 & 54 & 12 & 46 \\
Signs of carsickness & 13 & 50 & 20 & 78 \\
Riding a train forwards rather than backwards & 7 & 35 & 8 & 42 \\
Nausea when riding a carousel & 11 & 44 & 16 & 67 \\
Nausea when riding a rollercoaster & 4 & 16 & 0 & 0 \\
Sport enjoyment & 21 & 81 & 22 & 88 \\
Sport participation & 23 & 88 & 24 & 92 \\
Median age of start walking in months (range) & 22 & $12-48$ & 13 & $8-18$ \\
Visit to a physician for symptoms of vertigo, dizziness or & 5 & 19 & 2 & 8 \\
balance difficulties & & & & 8 \\
\hline
\end{tabular}

NB Children answering "I do not know" were excluded from the outcome data therefore when calculating percentages the total number of children was not necessarily the same as the indicated total number of children.

\section{DISCUSSION}

This descriptive study assessing 26 children with 22q11DS shows that within the 22 q11DS group 59\% experienced episodes of dizziness in some occasions, and $18 \%$ was dizzy every day. The dizziness could be a lightheadedness (present in $82 \%$ of the children with 22q11DS who were dizzy), arising when getting up from a sitting or prone position (present in 64\% of the children with 22q11DS who are dizzy). No vestibular dysfunction was suspected in these cases as the underlying cause, presumably orthostatic hypotension or similar conditions are suspected. In the control group this seemed to be even more frequently present as $92 \%$ felt dizzy when getting up. However, spinning sensations were also present (of the children who indicated to be dizzy; $58 \%$ in the 22q11DS group and $100 \%$ in the control group). Interestingly, balance difficulties seemed to be more present in the 22q11DS group, 58\% in the 22q11DS group versus $27 \%$ in the control group had at least sometimes balance difficulties. Challenging vestibular situations such as walking in the dark did not induce more 
dizziness in the 22q11DS group than in the control group.

During sport activities, especially when the sport involves frequent head movements and accelerations and decelerations, the tested vestibular system is more likely to reveal dysfunction compared to a situation with less changes of the body posture. However, in both groups approximately the same number children felt dizzy during sports (six children in the 22q11DS group (46\% of the children with 22q11DS who indicated to be dizzy) and four children in the control group (33\% of the children in the control group who indicated to be dizzy)). Children with 22q11DS felt more frequently unbalanced during sports than children in the control group (six children in the 22q11DS group ( $40 \%$ of children with 22q11DS who indicated to feel unbalanced) versus one child in the control group (14\% of children in the control group who indicated to feel unbalanced)). Still, overall the majority of children enjoyed and participated in sport activities.

Balance, postural stability and coordination difficulties have previously been reported in a number of studies in patients with 22q11DS. ${ }^{9-12}$ Balance and coordination difficulties in this patient population are mainly attributed to hypotonia $a^{10,24}$ and axial instability. ${ }^{24}$ Additionally, vertigo symptoms due to vestibular dysfunction might be another important contributing factor. This could also be the case in motor developmental delay, which many patients with 22q11DS suffer from..$^{11,12,23,25}$ Motor developmental delay in patients with 22q11DS is likely a multifactorial problem where conditions such as hypotonia ${ }^{23,25}$ and IQ ${ }^{11}$ might play an important role. In addition, it is known that in general, vestibular loss of function also leads to a motor development delay. ${ }^{13-22}$ Our group of children with 22q11DS started walking at a median age of 22 months. In patients with 22q11DS the possibly failing peripheral vestibular system could be contributive to this delay.

Objective vestibular dysfunction is reported to be frequently present in the 22q11DS population. ${ }^{8}$ Our hypothesis therefore is that the high prevalence of the described congenital malformations of the inner ear ${ }^{6.7}$ is an important underlying contributing factor for motor developmental delay and unbalance.

This study is the first to report on subjective balance problems out of a cohort of 22q11DS patients. Its value lies in its in detailed descriptive and exploratory character. We did not statistically compare the patient group with the control group, because this was an explorative study where we did not perform an power analysis or validated our questionnaire. We did not use the Dizziness Handicap Inventory, a validated questionnaire, because our objective was to explore whether there were vestibular symptoms present rather than to explore the dizziness itself and the burden of the dizziness. Another limitation of this study is the low number of patients and the fact that selection bias could have influenced the results. Patients with balance problems were possibly more likely to respond than 22q11DS patients without vestibular complaints. Lastly, we do not know how many patient filled in the questionnaire alone or with the 
CHAPTER 6

help of their parents. Although we tried to formulate the questions as easy and clearcut as possible, the help of parents could have influenced the outcomes.

Future research should focus on the relation between anatomic malformations of the inner ear, objective vestibular dysfunction, motor development and subjective symptoms or patient related outcome measures (PROM). Ideally, a validated questionnaire measuring PROMs on vestibular symptoms should be developed

\section{CONCLUSION}

Children with 22q11DS seem to experience balance problems, which could be a contributing factor in reported motor development delay. We advocate for awareness of dizziness or balance problems in children with 22q11DS and inform the patients and parents. Physiotherapy is advised to support motor skills. 


\section{REFERENCES}

1. Grati FR, Gomes DM, Carlos J, et al. Prevalence of recurrent pathogenic microdeletions and microduplications in over 9500 pregnancies. Prenat Diagn. 2015;35:801-809. doi:10.1002/pd.4613

2. McDonald-McGinn DM, Sullivan KE, Marino B, et al. 22q11.2 deletion syndrome. Nat Rev Dis Prim. 2015;1:15071. doi:10.1038/nrdp.2015.71.22q11.2

3. Óskarsdóttir S, Vujic M, Fasth A. Incidence and prevalence of the 22 q11 deletion syndrome: a populationbased study in Western Sweden. Arch Dis Child. 2004;89:148-152. doi:10.1136/adc.2003.026880

4. Kobrynski LJ, Sullivan KE. Velocardiofacial syndrome, DiGeorge syndrome: the chromosome $22 q 11.2$ deletion syndromes. Lancet. 2007;370(9596):1443-1452.

5. Robin NH, Shprintzen RJ. Defining the clinical spectrum of deletion 22q11.2. J Pediatr. 2005;147(1):90-96

6. Verheij E, Elden L, Crowley TB, et al. Anatomic Malformations of the Middle and Inner Ear in 22q11.2 Deletion Syndrome: Case Series and Literature Review. AJNR Am J Neuroradiol. 2018;39(5):928-934.

7. Loos E, Verhaert N, Willaert A, et al. Malformations of the Middle and Inner Ear on CT Imaging in 22q11 Deletion Syndrome. Am J Med Genet Part A. 2016;170(11):2975-2983. doi:10.1002/ajmg.a.37872

8. Willaert A, Van Eynde C, Verhaert N, et al. Vestibular dysfunction is a manifestation of 22 q11.2 deletion syndrome. Am J Med Genet Part A. 2019;179(3):448-454. doi:10.1002/ajmg.a.7

9. Sobin C, Monk SH, Kiley-Brabeck K, Khuri J, Karayiorgou M. Neuromotor deficits in children with the 22q11 deletion syndrome. Mov Disord. 2006;21(12):2082-2089. doi:10.1002/mds.21103

10. Óskarsdóttir S, Belfrage M, Sandstedt E, Viggedal G, Uvebrant P. Disabilities and cognition in children and adolescents with 22q11 deletion syndrome. Dev Med Child Neurol. 2005;47(3):177-184. doi:10.1017/ S0012162205000320

11. Van Aken K, De Smedt B, Van Roie A, et al. Motor development in school-aged children with 22 q11 deletion (velocardiofacial/DiGeorge syndrome). Dev Med Child Neurol. 2007;49(3):210-213. doi:10.1111/ j.1469-8749.2007.00210.x

12. Swillen A, Devriendt K, Legius E, et al. The behavioural phenotype in velo-cardio-facial syndrome (VCFS): from infancy to adolescence. Genet Couns. 1999;10(1):79-88.

13. De Kegel A, Maes L, Baetens T, Dhooge I, Van Waelvelde H. The Influence of a Vestibular Dysfunction on the Motor Development of Hearing-Impaired Children. Laryngoscope. 2012;122:2837-2843. doi:10.1002/ lary. 23529

14. Geisler HC, Van der Fits IBM, Gramsbergen A. The effects of early vestibular deprivation on the moto development in the rat. Behav Brain Res. 1997;86:89-96.

15. Inoue A, Iwasaki S, Ushio M, Chihara Y. Effect of Vestibular Dysfunction on the Development of Gross Motor Function in Children with Profound Hearing Loss. Audiol Neurotol. 2013;18:143-151. doi:10.1159/000346344

16. Jafari Z, Asad Malayeri S. The effect of saccular function on static balance ability of profound hearingimpaired children. Int J Pediatr Otorhinolaryngol. 2011;75(7):919-924. doi:10.1016/j.ijporl.2011.04.006

17. Kaga K, Suzuki J, Marsh RR, Tainaka Y. Influence of labyrinth hypoactivity on gross motor development of infants. Ann N Y Acad Sci. 1981;374:412-420.

18. Maes L, De Kegel A, Van Waelvelde H, Dhooge I. Association Between Vestibular Function and Motor Performance in Hearing-impaired Children. Otol Neurotol. 2014;35(10):e343-347.

19. Rine RM, Cornwall G, Gan K, et al. Evidence of progressive delay of motor development in children with sensorineural hearing loss and concurrent vestibular dysfunction. Percept Mot Ski. 2000;90:1101-1112.

20. Shall MS. The Importance of Saccular Function to Motor Development in Children with Hearing Impairments. Int J Otolaryngol. 2009;2009:972565. doi:10.1155/2009/972565

21. Springate JE. The neuroanatomic basis of early motor development: A review. J Dev Behav Pediatr. 1981;2(4):146-150

22. Wiener-Vacher SR, Obeid R, Abou-elew M. Vestibular Impairment after Bacterial Meningitis Delays Infant Posturomotor Development. J Pediatr. 2012;161(2):246-251.e1. doi:10.1016/j.jpeds.2012.02.009

23. Roizen NJ, Antshel KM, Fremont W, et al. 22q11.2DS Deletion Syndrome: Developmental Milestones in Infants and Toddlers. J Dev Behav Pediatr. 2007;28(2):119-124. doi:10.1097/01.DBP.0000267554.96081.12

24. Roizen NJ, Higgins AM, Antshel KM, Fremont W, Shprintzen R, Kates WR. 22q11.2 deletion syndrome: Are motor deficits more than expected for IQ level? J Pediatr. 2010;157(4):658-661. doi:10.1016/j. jpeds.2010.04.073

25. Gerdes M, Solot C, Wang PP, et al. Cognitive and behavior profile of preschool children with chromosome 22q11.2 deletion. Am J Med Genet. 1999:85(2):127-133. 
564555-L-bw-Verheij

Processed on: 16-9-2021 
LARYNGOLOGY 
564555-L-bw-Verheij

Processed on: 16-9-2021 


\section{CONGENITAL RESPIRATORY TRACT DISORDERS IN 22q11.2 DELETION SYNDROME}




\section{ABSTRACT}

\section{Objective}

Respiratory tract disorders have been reported in patients with 22q11.2 deletion syndrome, however infrequently. This study describes the respiratory tract disorders encountered in a cohort of 278 patients with 22q11.2 deletion syndrome.

\section{Methods}

We conducted a retrospective, cross-sectional study, at a single tertiary referral center. We identified the patients with 22q11.2 deletion syndrome and with an upper and/or lower respiratory tract disorder at our otorhinolaryngologic department. The different disorders were described.

\section{Results}

Out of 278 patients referred to the otorhinolaryngologic department, we identified 14 patients with a laryngeal and/or tracheal disorder. Nine patients had more than one congenital disorder in this anatomical area. Disorders included a choanal stenosis $(n=1)$, laryngeal web $(n=5)$, laryngeal cleft $(n=2)$, subglottic stenosis $(n=3)$, pharyngo-, laryngo-, tracheo- and/or bronchomalacia $(n=12)$ and tracheal stenosis $(n=1)$.

\section{Conclusion}

Different types of respiratory tract disorders can be present in patients with 22q11DS. Clinicians should be aware of this clinical association for timely and accurate diagnosis and treatment. In addition, the diagnosis 22q11DS should be considered in patients presenting with a congenital respiratory tract disorder. 


\section{INTRODUCTION}

The 22q11.2 deletion syndrome (22q11DS) is caused by a deletion on the long arm of chromosome 22 and characterized by many different disorders, such as dysmorphic facial features, congenital cardiac anomalies ( 75\%), immunodeficiency ( 75\%), palatal abnormalities (70-100\%), including velopharyngeal insufficiency ( 30-90\%), endocrine abnormalities, including hypocalcaemia (50-65\%) and psychiatric problems, including schizophrenia (25\%). ${ }^{1-3}$ Respiratory tract disorders are also described, however less frequently. These occur in different forms and include subglottic stenosis, laryngeal web, laryngeal cleft, laryngo-, trachea and/or bronchomalacia.4,5,14,15,6-13 Although rarely reported, respiratory tract disorders have important clinical implications and can even be fatal. ${ }^{16}$ Attentiveness to these disorders in children with 22q11DS is essential, as they should be detected early and treated to avoid severe complications.

The objectives of this study were: 1 . to describe the respiratory tract disorders, present in patients with 22q11DS who presented for clinical follow-up at our otorhinolaryngology department, and 2. to give an overview of reported respiratory tract disorders in 22q11DS in the literature.

\section{METHODS}

We conducted a retrospective, cross-sectional, study at a single tertiary referral center. We reviewed medical files of all patients diagnosed with 22q11DS and assessed by our otorhinolaryngology department from 1993 through April 2017. Since 2007, patients with 22q11DS have been universally referred to our institution's multidisciplinary 22q11DS team. As part of this referral, assessment by otorhinolaryngology is standard care, and does not depend on symptoms. The diagnosis 22q11DS was confirmed with fluorescence in situ hybridization or multiplex ligation-dependent probe amplification. We identified all patients with a respiratory tract disorder including pharyngeal-, laryngeal-, tracheal- and bronchial disorders. The Medical Ethics Review Committee deemed this study exempt from review due to its retrospective design.

Data including the presence of prematurity (born <37 weeks of gestation), history of velopharyngeal insufficiency and history of congenital cardiac diseases were collected. Clinical presentation of a respiratory tract disorder comprising presence of stridor, dyspnea, a history of recurrent respiratory tract infections, feeding difficulties (including insufficient intake or swallowing dysfunction), signs of aspiration (including recurrent respiratory tract infections) or voice abnormalities were described.

We described laryngeal clefts using the classification described by Benjamin and Inglis. ${ }^{17}$ The severity of a subglottic stenosis was graded according to the Myer-Cotton classification. ${ }^{18}$ In describing laryngeal webs, we used the Cohen's classification. ${ }^{19}$ 
CHAPTER 7

Other disorders, including laryngo-, tracheo- and bronchomalacia, vocal cord anomalies or other encountered abnormalities were described by location and severity.

\section{RESULTS}

Out of 278 patients who were assessed by our department, we identified 14 patients with a respiratory tract disorder. All 14 patients were referred to our multidisciplinary 22q11DS team. See Table 1 for demographic characteristics. Six of the nine patients who were of appropriate age for speech assessment demonstrated velopharyngeal insufficiency.

Table 1. Demographic characteristics

\begin{tabular}{|c|c|}
\hline & Patients $(n=14)$ \\
\hline Median follow-up time between first DLB and last clinic visit in months (range) ( $n=9^{\text {la }}$ & $14(0-71)$ \\
\hline Male:female & $3: 11$ \\
\hline Number of patients with DLB (\%) & $11(79)$ \\
\hline Median age in months at (first) DLB (range) $(n=9)^{a}$ & $7(0-35)$ \\
\hline Prematurity (\%) & $6(43)$ \\
\hline Velopharyngeal insufficiency $(\%)(n=9)^{b}$ & $6(67)$ \\
\hline Congenital cardiac disease (\%) & $8(57)$ \\
\hline
\end{tabular}

Eleven patients underwent a direct laryngoscopy and bronchoscopy (DLB) for evaluation of stridor, dysphagia, dyspnea or the evaluation prior to tracheostomy tube decannulation. There were no airway-related mortalities in our cohort (median age at last consultation was 5 years).

Table 2 provides an overview of all encountered disorders. It shows that nine patients had more than one respiratory tract disorder (patients 1, 2, 4, 8, 9, 10, 11, 13, 14). Three patients required a tracheostomy (patients 10, 13 and 14).

As shown in Table 2, there were five patients with a laryngeal web (see Table 2). One patient had a type 1 web, two patients had a type 2, one patient a type 3 web and in one patient the grade of the web was unknown. This patient also had a tracheal stenosis which necessitated a tracheostomy at age 7 days, with subsequently dilating and stenting of the trachea. Three patients required incising of the web (patients 3, 4 and 9). In addition, there were three patients with a subglottic stenosis. Two patients had a grade 1 and one patient had a grade 3 stenosis. The latter required a single stage laryngotracheal reconstruction, with anterior and posterior costal cartilage grafting (patient 4). 
CONGENITAL RESPIRATORY TRACT DISORDERS IN 22q11.2 DELETION SYNDROME

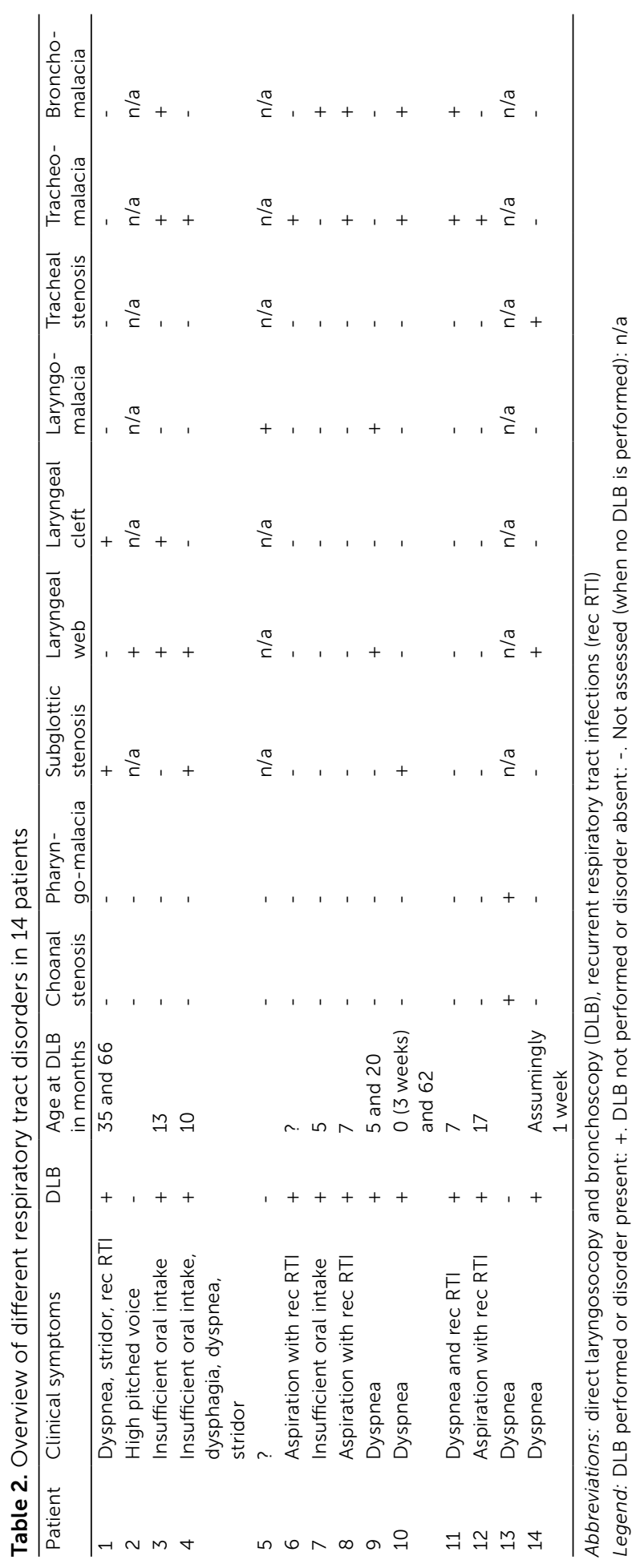


CHAPTER 7

The laryngeal cleft present in patients 1 and 3 (see Table 2) were both a type 1 (a cleft limited to the supraglottic and interarytenoid area) and did not require surgical treatment.

Five patients suffered from an airway malacia caused by a vascular structure compressing the airway (patients 3, 7, 8, 11 and 12). These vascular structures included a arteria lusoria, right sided aortic arch and brachiocephalic artery. The arteria lusoria was in all cases divided (patients $8,11,12$ ). In one patient the tracheomalacia was treated with an aortopexy (patient 8).

\section{DISCUSSION}

Our results showed that many different respiratory tract disorders can be present in patients with 22q11DS, and more than one disorder can occur in one patient. In addition, we report vascular anomalies which impair the airway as well.

Congenital malformations of the larynx are known to develop from embryogenetic defects. The development of the larynx begins at week 4 of gestation. The respiratory diverticulum is an outpouching of the foregut lumen and grows ventrally and caudally. Meanwhile, the tracheoesophageal septum is formed, separating the oesophagus from the laryngotracheal tube (respiratory diverticulum). ${ }^{20,21} \mathrm{~A}$ laryngeal cleft, present in two patients in our population (patients 1 and 3), can result from an inadequate fusion of the interarytenoid tissues, cricoid cartilage or the tracheoesophageal septum. ${ }^{21}$ After the formation of the tracheooesophageal septum, the primitive laryngopharynx, which later gives rise to the supraglottis, becomes obliterated and the epithelial lamina arises. The epithelial lamina recanalizes by 10 weeks of gestation, forming a lumen. An aberrant recanalization during this developmental stage can cause a laryngeal web, as seen in five of our patients (patients 2, 3, 4, 9 and 14) or laryngeal stenosis, encountered in three patients in our population (patients 1, 4 and 10). ${ }^{20,21}$

In literature, various respiratory tract disorders in patients with 22q11DS are described, see Table 3 for an overview. Sacca et al. found that $71 \%$ of patients who received a microlaryngoscopy and/or bronchoscopy were identified with an airway anomaly. Different airway anomalies were encountered, including a tracheomalacia (36\%), subglottic stenosis (28\%), laryngomalacia $(26 \%)$, glottic web $(21 \%)$ and bronchomalacia (16\%). ${ }^{9}$ These high prevalences are likely not representative of the overall 22q11DS population, as this study only included patients whose airways were assessed by microlaryngoscopy and/or bronchoscopy. Leopold et al. described five patients with a respiratory tract disorder, of whom four had more than one abnormality. ${ }^{4}$ Furthermore, Dyce et al. found 14 patients with a respiratory tract disorder, including a laryngeal cleft, tracheomalacia and (sub)glottic stenosis. ${ }^{5} 2 \%$ of the patients included by Ryan et al. had a tracheo- or laryngomalacia and $1 \%$ a laryngeal web ${ }^{6}$ and Ford et al. 
reported on one patient, out of 35 included patients, with a laryngeal web with vocal fold paralysis, and one patient with vocal fold weakness. ${ }^{7}$ Miyomoto et al. reported that $65 \%$ of all patients diagnosed with an anterior glottic web in their center, tested positive for a 22q11.2 deletion. ${ }^{15}$ In addition, there are case reports describing similar anomalies in patients with 22q11DS, including laryngeal web, ${ }^{11-14}$ glottis-subglottic stenosis, ${ }^{22}$ laryngo-, or bronchomalacia, ${ }^{23,24}$ and supernumerary tracheal bronchus. ${ }^{25}$ Tracheomalacia associated with vascular rings and vascular compression has also been described in prior reports. ${ }^{26,27}$

Table 3. Previously reported congenital respiratory tract disorders in 22q11DS patients

$\begin{array}{rrr}\text { Disorder } & \begin{array}{c}\text { Total number of patients } \\ \text { reported in literature }\end{array} & \text { Reference } \\ \text { Vocal fold hypomobility or paralysis } & 7 & 6,9 \\ \text { Laryngeal cleft } & 8 & 4,5,7,9 \\ \text { Laryngeal web } & 2 & 5 \\ \text { Glottic stenosis } & >58^{\text {a }} & 4,6,22,26,7,9-15 \\ \text { Subglottic stenosis } & 2 & 4 \\ \text { Glottic atresia } & 30 & 9 \\ \text { Subglottic cyst } & 7 & 9 \\ \text { Pharyngo-, laryngo-, tracheo- and/or bronchomalacia } & 1 & 4-6,8,9,23,24,26 \\ \text { Tracheoosophageal fistula } & 3 & 5,9 \\ \text { Tracheobronchial branching branching abnormalities } & 4 & 4,5,25 \\ \text { Tracheal stenosis } & 1 & 9 \\ \text { Oesophageal atresia } & 3 & 9\end{array}$

Tbx1 is a gene considered responsible for several features in 22q11DS. ${ }^{28}$ In a mouse model where mice were generated hemizygous for a $1.5 \mathrm{Mb}$ deletion (including Tbx1) corresponding to that in 22q11DS, $5 \%$ of the mouse embryos showed to have a vascular ring compressing the trachea. ${ }^{29}$ However, to our knowledge, no other mouse models on Tbx1 reported on the earlier mentioned respiratory tract disorders.

Therapeutic options for and prognosis of respiratory tract disorders vary widely, depending on the type and severity of the disorder. In previous studies, up to $30 \%$ of patients with 22q11DS and a respiratory tract disorder required tracheostomy. 4,9,11,24 In Repetto et al.'s retrospective study of 252 patients with 22q11DS and airway symptoms, congenital heart diseases, hypocalcemia, and airway malacia were all noted to be poor prognostic factors and independently associated with mortality. ${ }^{16}$ All of the patients in our series have recovered well from their airway pathologies, with or without surgical intervention, although three patients required a tracheostomy. There were no mortalities in our series. Nonetheless, there should be a standard otorhinolaryngologic consultation in a specialized tertiary referral center for 22q11DS patients. Moreover, the possibility of the presence of 22q11DS in patients presenting with a congenital 
CHAPTER 7

respiratory tract disorder should be considered.

The main limitation of this study is its retrospective design. Due to a high risk of missing outcome data and probable selection bias, we were not able to reliably calculate the incidence of respiratory tract disorders. We therefore did not provide an incidence number. Furthermore, we only included patients with a respiratory tract disorder, we did not identify how many patients were only suspected of having such a disorder or underwent a DLB. Consequently, we could not distinguish certain parameters which could be predictive for the presence of a respiratory tract disorder in 22q11DS.

\section{CONCLUSION}

Respiratory tract disorders in patients with 22q11DS occur in different forms, including concomitant vascular malformations compressing part of the airway. These disorders should be detected early and if necessary treated. We therefore recommend a standard otorhinolaryngologic consultation including a fiberoptic laryngoscopy when clinical symptoms are present in patients with 22q11DS. In addition, the diagnosis 22q11DS should be considered in patients presenting with a congenital respiratory tract disorder. 


\section{REFERENCES}

1. McDonald-McGinn DM, Sullivan KE, Marino B, et al. 22q11.2 deletion syndrome. Nat Rev Dis Prim 2015;1:15071. doi:10.1038/nrdp.2015.71.22q11.2

2. Kobrynski LJ, Sullivan KE. Velocardiofacial syndrome, DiGeorge syndrome: the chromosome $22 \mathrm{q} 11.2$ deletion syndromes. Lancet. 2007;370(9596):1443-1452.

3. Robin NH, Shprintzen RJ. Defining the clinical spectrum of deletion 22q11.2. J Pediatr. 2005;147(1):90-96

4. Leopold C, De Barros A, Cellier C, Drouin-Garraud V, Dehesdin D, Marie J-P. Laryngeal abnormalities are frequent in the 22q11 deletion syndrome. Int J Pediatr Otorhinolaryngol. 2012;76(1):36-40. doi:10.1016/j. ijporl.2011.09.025

5. Dyce O, McDonald-McGinn DM, Kirschner RE, Zackai E, Young K, Jacobs IN. Otolaryngologic manifestations of the 22q11.2 deletion syndrome. Arch Otolaryngol Head Neck Surg. 2002;128(12):1408-1412.

6. Ryan AK, Goodship JA, Wilson DI, et al. Spectrum of clinical features associated with interstitial chromosome 22q11 deletions: a European collaborative study. J Med Genet. 1997;34(10):798-804 doi:10.1136/jmg.34.10.798

7. Ford LC, Sulprizio SL, Rasgon BM. Otolaryngological manifestations of velocardiofacial syndrome: a retrospective review of 35 patients. Laryngoscope. 2000;110(3 Pt 1):362-367.

8. Vantrappen G, Devriendt K, Swillen A, et al. Presenting symptoms and clinical features in 130 patients with the velo-cardio-facial syndrome. The Leuven experience. Genet Couns. 1999;10(1):3-9.

9. Sacca R, Zur KB, Crowley TB, Zackai EH, Valverde KD, Mcdonald-mcginn DM. Association of airway abnormalities with 22q11. 2 deletion syndrome. Int J Pediatr Otorhinolaryngol. 2017;96:11-14. doi:10.1016/j.ijporl.2017.02.012

10. McElhinney DB, Jacobs I, Mcdonald-mcginn DM, Zackai H, Goldmuntz E. Chromosomal and cardio v ascular anomalies associated with congenital laryngeal web. Int J Pediatr Otorhinolaryngol. 2002;66:23-27.

11. Fokstuen S, Bottani A, Medeiros PF V, Antonarakis SE, Stoll C, Schinzel A. Laryngeal Atresia Type III ( Glottic Web ) With 22q11 . 2 Microdeletion : Report of Three Patients. Am J Med Genet. 1997;70(2):130-133.

12. Marble M, Morava E, Tsien F, Amedee R, Pierce M. Subglottic Web in a Mother and Son With $22 q 11.2$ Deletion. Am J Med Genet. 1998;75:537.

13. Rosa RFM, Rosa RCM, Krumenauer RCP, Varella-Garcia M, Paskulin GA. Anterior laryngeal membrane and 22q11 deletion syndrome. Braz J Otorhinolaryngol. 2011;77(4):540. http://www.embase.com/search/ results?subaction=viewrecord\&from =export\&id $=\mathrm{L} 362414203$

14. Stoler JM, Ladoulis M, Holmes LB. Anterior Laryngeal Webs and 22q11 Deletions. Am J Med Genet 1998;79:152.

15. Miyamoto RC, Cotton RT, Rope AF, et al. Association of anterior glottic webs with velocardiofacial syndrome (chromosome 22q11. 2 deletion ). Otolaryngol Head Neck Surg. 2004;130(4):415-417. doi:10.1016/j.otohns.2003.12.014

16. Repetto GM, Guzmán ML, Delgado I, et al. Case fatality rate and associated factors in patients with 22 11 microdeletion syndrome : a retrospective cohort study. BMJ Open. 2014;4:e005041. doi:10.1136/ bmjopen-2014-005041

17. Benjamin B, Inglis A. Minor congenital laryngeal clefts: diagnosis and classification. Ann Otol Rhinol Laryngol. 1989;98:417-420

18. Myer III CM, O'Connor DM, Cotton RT. Proposed grading system for subglottic stenosis based on endotracheal tube sizes. Ann Otol Rhinol Laryngol. 1994;103:319-323.

19. Cohen SR. Congenital glottic webs in children. A retrospective review of 51 patients. Ann Otol Rhinol Laryngol Suppl. 1985;121:2-16

20. Hartnick CJ, Cotton RT. Congenital laryngeal anomalies. Laryngeal atresia, stenosis, webs, and clefts Otolaryngol Clin North Am. 2000;33(6):1293-1308.

21. Windsor A, Clemmens C, Jacobs IN. Rare Upper Airway Anomalies. Paediatr Respir Rev. 2016;17:24-28. doi:10.1016/j.prrv.2015.07.001

22. Bottero S, Peradotto F, Roma R, Tucci F. Laryngotracheal reconstruction in glottic-subglottic stenosis associated with DiGeorge syndrome in a four and a half-month-old infant. Acta Otorhinolaryngol Ital. 2015;35:53-57

23. Yamagishi H, Maeda J, Higuchi M, Katada Y, Yamagishi C, Matsuo N. Bronchomalacia associated with pulmonary atresia, ventricular septal defect and major aortopulmonary collateral arteries, and 
CHAPTER 7

chromosome 22q11.2 deletion. Clin Genet. 2002;62(3):214-219.

24. Markert ML, Majure M, Harville TO, Hulka G, Oldham K. Severe laryngomalacia and bronchomalacia in DiGeorge syndrome and CHARGE association. Pediatr Pulmonol. 1997;24(5):364-369.

25. Bertolani MF, Bergamini BM, Predieri B, et al. Tracheobronchial Anomalies in Chromosome 22q11 . 2 Microdeletion. Am J Med Genet Part A. 2006;140(7):790-793. doi:10.1002/ajmg.a

26. McDonald-McGinn DM, Kirschner R, Goldmuntz E, et al. The Philadelphia story: the 22 q11.2 deletion: report on 250 patients. Genet Couns. 1999;10(1):11-24.

27. Kaneko Y, Yoda H, Tsuchiya K. Airway Compression by Major Aortopulmonary Collaterals with 22 q11 Deletion. Asian Cardiovasc Thorac Ann. 2007;15(1):e9-11.

28. Jerome LA, Papaioannou VE. DiGeorge syndrome phenotype in mice mutant for the T-box gene, Tbx1. Nat Genet. 2001:27(3):286-291.

29. Merscher S, Funke B, Epstein JA, et al. TBX1 Is Responsible for Cardiovascular Defects in Velo-CardioFacial / DiGeorge Syndrome. Cell. 2001;104(4):619-629. 
CONGENITAL RESPIRATORY TRACT DISORDERS IN 22q11.2 DELETION SYNDROME

564555-L-bw-Verheij 
564555-L-bw-Verheij

Processed on: 16-9-2021 


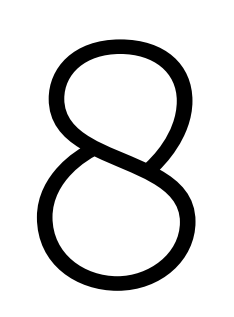

\section{GENERAL DISCUSSION}


CHAPTER 8

22q11.2 deletion syndrome (22q11DS) is a complex syndrome with a variable phenotypic expression. A broad variety of anomalies in 22q11DS have been documented (heart defects, immunodeficiency, hypocalcaemia, velopharyngeal insufficiency, orthopedic anomalies, genitourinary anomalies, a lower intelligence with a mean IQ of approximately 70 and psychiatric disorders). ${ }^{1-4}$ This thesis provides an overview of otorhinolaryngologic manifestations in 22q11DS, including hearing impairment (conductive and mixed types), (recurrent) otitis media and inner ear malformations, anatomic malformations of the vestibular system and airway anomalies. It is important to adequately diagnose and treat relatively smaller issues, which can have a major impact on quality of life. With this thesis we aim to increase awareness of otorhinolaryngologic manifestations to assist clinicians in treating this group of patients.

\section{OTOLOGIC MANIFESTATIONS}

Patients with 22q11DS often have hearing loss (38\% of ears), mainly of conductive nature. This could be due to a high rate of recurrent otologic problems, as we also encountered a tympanic membrane perforation (present in $16 \%$ at time of the most recent audiogram and most likely common after recurrent otitis media) and otitis media with effusion (present in $23 \%$ at time of the most recent audiogram). The frequent occurrence of otitis media is also reported in other 22q11DS reports (chapter 2). This otitis media might well be caused by a combination of Eustachian tube dysfunction, supported by a mouse model for 22q11DS showing a hypoplastic levator veli palatine muscle in $\mathrm{Tb} 1^{+/-}$mice, and an immunodeficiency present in approximately $75 \%$ of patients. ${ }^{1,5}$

In spite of a high number of patients with an incomplete partition type II of the cochlea (inner ear malformation), we did not encounter a high rate of sensorineural hearing loss in our study (chapter 4). Also, frequently more than one anomaly in the middle and/or inner ear was found, hindering statistical analysis and conclusions relating the hearing loss to a specific anomaly. Although there are studies reporting on patients with a cochlear implant due to an incomplete partition type II, it seems an incomplete partition does not necessarily affect hearing. ${ }^{6,7}$ In line with our findings, Ahadizadeh et al. did not find a statistical relation between hearing and an incomplete partition type II, in patients with an incomplete partition type II and an enlarged vestibular aqueduct. ${ }^{6}$

Sennaroglu et al. described an incomplete partition type II as a cochlea with 1,5 turns, where the middle and apical turn form 1 cyst, accompanied by a large vestibule and an enlarged vestibular aqueduct. ${ }^{8}$ In our study however we defined an incomplete partition of the cochlea as the above mentioned malformation of the cochlea alone. We described in $33 \%$ of the studied ears a small bony island of the lateral semicircular 
canal. Presumably this malformation is comparable with a large vestibule described by Sennaroglu et al., although the vestibule in our study, in absolute terms, was not enlarged according to the reference standard reported by Purcell et al. (chapter 4). ${ }^{9}$ We did not find an enlarged vestibular aqueduct in our patients, suggesting that an incomplete partition type II described by Sennaroglu et al. does not per se has to consist of the combination of the three anomalies together. When one anomaly can coexist with a normally formed other part of the labyrinth the embryologic disruption does perhaps not affect the whole labyrinth at that stage.

\section{Treatment}

As described in our case report (chapter 5) ear surgery is feasible as a treatment option in selected patients. In case of a deformed ossicular chain, middle ear reconstructive surgery can be considered aiming to improve conductive hearing impairment.

The Teunissen Cremers classification can be of help in determining the indication and aids in classifying from a surgical perspective. ${ }^{10}$ If conservative treatment fails in patients with chronic refractory otitis media, these patients might benefit from an additional mastoidectomy. In 22q11DS we emphasize to perform a preoperative CT scan for optimal surgical preparation, especially regarding possible lateral semicircular canal malformation. The semicircular canal is often malformed in 22q11DS patients and in these cases does not serve as a reliable landmark to identify the facial nerve.

When middle ear surgery is not an option, hearing rehabilitation with hearing aids is a good alternative for patient with solely conductive hearing loss and the first choice of treatment in patients with mixed hearing loss or in isolated sensorineural hearing loss. Especially in young children it is important to facilitate hearing rehabilitation on early note, since speech and language development benefit from early hearing rehabilitation as concluded from studies on newborn hearing screening. ${ }^{11}$

\section{Future perspectives}

Many mouse models found Tbx1 as a potential gene which could play an important role in the encountered malformations in 22q11DS. ${ }^{1}$ However, Tbx1 is nested between low copy repeat $22 \mathrm{~A}$ and $\mathrm{B}$, where there are also patients with a more distal deletion. ${ }^{1}$ To our knowledge is it not known if patients with more distal deletions express ear malformations. It would be interesting to investigate hearing and inner ear malformations in patients with more distal deletions.

Tbx1 is a gene expressing in the pharyngeal arches ${ }^{1}$. In literature it is reported that organs derived from the pharyngeal arches are frequently involved.,12 The hearing ossicles develop from the first and second pharyngeal arch. ${ }^{13}$ In our paper on radiologic malformations, we did find malformations of the hearing ossicles, mostly involving the stapes (36\%), and in a small number involving the malleus (4\%) (chapter 4). It would be interesting to conduct a radiologic study in a large 22q11DS population investigating 
CHAPTER 8

isolated middle ear anomalies.

In 22q11DS, other symptoms can develop and manifest over time. Prognostic studies show that early cognitive decline is a predictor for developing psychosis. ${ }^{14}$ Patients with 22q11DS are at risk to develop early onset Parkinson's Disease. ${ }^{15}$ Hearing loss in 22q11DS is thought to be related to congenital anatomical malformations, or damage from otitis media, and not an early manifestation of presbyacusis. ${ }^{16-22}$ In our retrospective study on otologic manifestations (chapter 3) we performed a linear regression analysis on age and hearing loss. After removing the outliners, we did not find a correlation. However, the oldest patient was 20 years of age. To investigate if hearing in 22q11DS worsens more rapidly with age compared to the regular population a larger prospective study is needed.

\section{VESTIBULAR MANIFESTATIONS}

In addition to cochlear malformations, CT scans of the mastoid bones of patients with 22q11DS frequently showed a malformed lateral semicircular canal (chapter 4). In literature, a malformed lateral semicircular canal is noted without and with sensorineural or conductive hearing loss. ${ }^{23-29}$ As for an incomplete partition type II, in our cohort some patients with a malformed lateral semicircular canal indeed showed hearing loss whilst others did not have hearing impairment (chapter 4).

The malformed lateral semicircular canal led to the hypothesis that vestibular dysfunction might be prevalent in 22q11DS. Willaert et al proved this in their study where they found $90 \%$ (18 out of 20) 22q11DS patients undergoing caloric testing to have uni- or bilateral weak caloric responses. ${ }^{30}$

The malformed vestibular system and dysfunction likely has a congenital origin. Clinically, more subtle symptoms (i.e. unsteady walking in the dark) and balance problems instead of vertigo will be present. ${ }^{31}$ Problems in balance, postural stability, coordination and motor delay are described in patients with 22q11DS 32-35, although this is reported in studies focusing mostly on hypotonia and axial instability. ${ }^{32,35-38}$ In our questionnaire study we also found that children with 22q11DS frequently have balance difficulties and started walking later in life compared to a control group (chapter 6). Vestibular dysfunction could contribute to a delayed motor development, imbalance or postural instability. During consultations at our outpatient clinic, balance is not an standard item that is discussed. With more attention to balance issues we could make our clinical care more complete.

\section{Treatment options}

When the malformed lateral semicircular canal in 22q11DS patients lead to vestibular dysfunction, informing the patients (and their parents) about challenging situations 
(sports, riding a bicycle) is needed. Physiotherapy is advised for supporting and improvement of the patient's motor development and skills.

\section{Future perspectives}

Future research could investigate the relation between anatomical malformations of the inner ear and vestibular dysfunction. Since congenital malformations of the vestibular system lead to motor developmental delay ${ }^{31}$, data on motor development would provide very useful information. In addition to data on motor development, pure tone audiogram information, vestibular test results such as caloric test, video head impulse test and rotary chair test, and patient related outcome measures (PROMs) can be analyzed in relation to CT or MRI information of the inner ear. 22q11DS could serve as a model for patients with inner ear malformations.

\section{AIRWAY MANIFESTATIONS}

A number of different airway anomalies are described in 22q11DS, including subglottic stenosis, airway malacia, laryngeal cleft and laryngeal web (chapter 7). In a study performed by Miyomoto et al. $65 \%$ of all patients with an anterior glottic web had 22q11DS. ${ }^{39}$ A glottic or laryngeal web is caused by an anomalous recanalization of the larynx, occurring at week 10 of gestation. ${ }^{40} \mathrm{~A}$ disruption at this point in embryologic development can also lead to a subglottic stenosis. A subglottic stenosis is indeed reported to be prevalent in 22q11DS. In our patient series 1 patient out of 3 patients with a subglottic stenosis required surgical correction. Moreover, we found in five patients in our patients cohort an airway malacia caused by an abnormal vascular structure compressing the airway, out of 8 patients with a tracheo- and/or bronchomalacia (chapter 7). Possibly, the cause of a trachea- and/or bronchomalacia in 22q11DS is more frequently an abnormal vascular structure compressing the airway than in the regular population. Additionally, an abnormal vascular structure might in some patients manifest as an airway malacia.

\section{Treatment options}

In airway malformations, surgical intervention is can be necessary to alleviate symptoms. A laryngeal web can be incised, a subglottic stenosis can be dilated and in some case a single stage laryngotracheoplasty can be performed placing a cartilage graft in the cricoid cartilage, a large cleft can be closed with a temporary filler or sutures. When an aberrant right subclavian artery (arteria lusoria) is present compressing the airway causing airway malacia the aberrant artery can be divided. In rare cases a tracheostomy is needed to secure a safe airway (chapter 7). In literature, 20-30\% of patients with 22q11DS an airway anomaly required a (temporary) tracheostomy. ${ }^{41-45}$ 
A medial displacement of the internal carotid artery can be present in patients with 22q11DS. . $^{1846} \mathrm{An} \mathrm{MRI}$ is in some countries advocated prior to tonsillectomy, adenoidectomy or pharyngeal surgery. ${ }^{46}$ Carotid injury due to pharyngeal surgery is not reported. ${ }^{46}$ Therefore although an MRI might not be necessary in preparation of a tonsillectomy or adenoidectomy, but awareness during surgery is imperative.

\section{Future perspectives}

As previously noted by Sacca et al. and Jones et al., there might be an association between congenital heart disease and airway anomalies in 22q11DS.41.45 It would be of value to investigate this relation and which airway anomaly is associated with what type of congenital heart disease specifically. Furthermore, as noted above, it is our hypothesis that in the 22q11DS population the cause of tracheo- and/or bronchomalacia is more frequently a vascular anomaly then in the regular patients with tracheo- and/or bronchomalacia. This should be researched with a case control study. 


\section{REFERENCES}

1. McDonald-McGinn DM, Sullivan KE, Marino B, et al. 22q11.2 deletion syndrome. Nat Rev Dis Prim 2015;1:15071. doi:10.1038/nrdp.2015.71.22q11.2

2. Robin NH, Shprintzen RJ. Defining the clinical spectrum of deletion 22q11.2. J Pediatr. 2005;147(1):90-96

3. Shprintzen RJ, Higgens AM, Antshel K, Fremont W, Roizen N, Kates W. Velo-cardio-facial syndrome. Curr Opin Pediatr. Published online 2005:725-730

4. Bassett AS, Mcdonald-mcginn DM, Devriendt K, et al. Practical Guidelines for Managing Patients with 22q11.2 Deletion Syndrome. J Pediatr. 2011;159(2):332-339.e1. doi:10.1016/j.jpeds.2011.02.039

5. Fuchs JC, Linden JF, Baldini A, Tucker AS. A defect in early myogenesis causes Otitis media in two mouse models of 22q11.2 Deletion Syndrome. Hum Mol Genet. 2015;24(7):1869-1882. doi:10.1093/hmg/ddu604

6. Ahadizadeh $\mathrm{E}$, Ascha M, Manzoor N, et al. Hearing loss in enlarged vestibular aqueduct and incomplete partition type II. Am J Otolaryngol - Head Neck Med Surg. 2017;38(6):692-697. doi:10.1016/j. amjoto.2017.06.010

7. Daneshi A, Farhadi M, Ajalloueyan M, et al. Cochlear implantation in children with inner ear malformation: A multicenter study on auditory performance and speech production outcomes. Int $\mathrm{J}$ Pediatr Otorhinolaryngol. 2020;132(November 2019):109901. doi:10.1016/j.ijporl.2020.109901

8. Sennaroglu L, Saatci I. A new classification for cochleovestibular malformations. Laryngoscope 2002;112(12):2230-2241. doi:10.1097/00005537-200212000-00019

9. Purcell D, Johnson J, Fischbein N, Lalwani AK. Establishment of normative cochlear and vestibular measurements to aid in the diagnosis of inner ear malformations. Otolaryngol - Head Neck Surg. 2003:128(1):78-87. doi:10.1067/mhn.2003.51

10. Teunissen EB, Cremers CWRJ. Classification of congenital middle ear anomalies report on 144 ears. Ann Otol Rhinol Laryngol. 1993;102(8):606-612. doi:10.1177/000348949310200807

11. Wolff R, Hommerich J, Riemsma R, Antes G, Lange S, Kleijnen J. Hearing screening in newborns: Systematic review of accuracy, effectiveness, and effects of interventions after screening. Arch Dis Child. 2010;95(2):130-135. doi:10.1136/adc.2008.151092

12. Baldini A. Dissecting contiguous gene defects: TBX1. Curr Opin Genet Dev. 2005;15(3 SPEC. ISS.):279 284. doi:10.1016/j.gde.2005.03.001

13. Anthwal $\mathrm{N}$, Thompson $\mathrm{H}$. The development of the mammalian outer and middle ear. J Anat 2016;228(2):217-232. doi:10.1111/joa.12344

14. Vorstman JAS, Breetvelt EJ, Duijff SN, et al. Cognitive decline preceding the onset of psychosis in patients with 22q11.2 deletion syndrome. JAMA Psychiatry. 2015;72(4):377-385. doi:10.1001/ jamapsychiatry.2014.2671

15. Butcher NJ, Kiehl T-R, Hazrati L-N, et al. Association Between Early-Onset Parkinson Disease and 22q11.2 Deletion Syndrome. JAMA Neurol. 2013;70(11):1359. doi:10.1001/jamaneurol.2013.3646

16. Van Eynde C, Swillen A, Lambeens E, et al. Prevalence and Nature of Hearing Loss in 22q11.2 Deletion Syndrome. J Speech, Lang Hear Res. 2016;59(3):583-589. doi:10.1044/2015

17. Loos E, Verhaert N, Willaert A, et al. Malformations of the Middle and Inner Ear on CT Imaging in 22 q11 Deletion Syndrome. Am J Med Genet Part A. 2016;170(11):2975-2983. doi:10.1002/ajmg.a.37872

18. Dyce O, McDonald-McGinn DM, Kirschner RE, Zackai E, Young K, Jacobs IN. Otolaryngologic manifestations of the 22q11.2 deletion syndrome. Arch Otolaryngol Head Neck Surg. 2002;128(12):14081412.

19. Jiramongkolchai P, Kumar MS, Chinnadurai S, Wootten CT, Goudy SL. Prevalence of hearing loss in children with 22q11.2 deletion syndrome. Int J Pediatr Otorhinolaryngol. 2016;87:130-133. doi:10.1016/j. ijporl.2016.06.005

20. Zarchi O, Attias J, Raveh E, Basel-Vanagaite L, Saporta L, Gothelf D. A comparative study of hearing loss in two microdeletion syndromes: velocardiofacial (22q11.2 deletion) and Williams (7q11.23 deletion) syndromes. J Pediatr. 2011;158(2):301-306. doi:10.1016/j.jpeds.2010.07.056

21. Ford LC, Sulprizio SL, Rasgon BM. Otolaryngological manifestations of velocardiofacial syndrome: a retrospective review of 35 patients. Laryngoscope. 2000;110(3 Pt 1):362-367.

22. Reyes MRT, LeBlanc EM, Bassila MK. Hearing loss and otitis media in velo-cardio-facial syndrome. Int $J$ Pediatr Otorhinolaryngol. 1999;47(3):227-233.

23. Jackler R, Luxford W, House W. Cochlear Malformations of the inner ear: A classification based on 
embryogenesis. Laryngoscope. 1987;97(3 Pt 2 Suppl 40):2-14

24. Johnson J, Lalwani AK. Sensorineural and conductive hearing loss associated with lateral semicircular canal malformation. Laryngoscope. 2000;110(10 Pt 1):1673-1679. doi:10.1097/00005537-20001000000019

25. Yamashita K, Yoshiura T, Hiwatashi A, et al. Sensorineural hearing loss: there is no correlation with isolated dysplasia of the lateral semi-circular canal on temporal bone CT. Acta radiol. 2011;52(2):229-233. doi:10.1258/ar.2010.100324

26. Yu KK, Mukherji S, Carrasco V, Pillsbury HC, Shores CG. Molecular genetic advances in semicircula canal abnormalities and sensorineural hearing loss: A report of 16 cases. Otolaryngol - Head Neck Surg. 2003;129(6):637-646. doi:10.1016/S0194-5998(03)01593-6

27. Yukawa K, Horiguchi S, Suzuki M. Congenital inner ear malformations without sensorineural hearing loss Auris Nasus Larynx. 2008;35(1):121-126.

28. Ozeki M, Kato Z, Sasai H, et al. Congenital inner ear malformations without sensorineural hearing loss in children. Int J Pediatr Otorhinolaryngol. 2009;73(10):1484-1487. doi:10.1016/j.ijporl.2009.07.013

29. Dallan I, Berrettini S, Neri E, Casani AP. Bilateral, isolated, lateral semicircular canal malformation without hearing loss. J Laryngol Otol. 2008;122(08):858-860. doi:10.1017/S0022215108002740

30. Willaert A, Van Eynde $C$, Verhaert $N$, et al. Vestibular dysfunction is a manifestation of $22 q 11.2$ deletion syndrome. Am J Med Genet Part A. 2019;179(3):448-454. doi:10.1002/ajmg.a.7

31. Kingma H, van de Berg R. Chapter 1. Anatomy, Physiology, and Physics of the Peripheral Vestibular System. Vol 137. 1st ed. Elsevier B.V.; 2016. doi:10.1016/B978-0-444-63437-5.00001-7

32. Swillen A, Devriendt $K$, Legius $E$, et al. The behavioural phenotype in velo-cardio-facial syndrome (VCFS) from infancy to adolescence. Genet Couns. 1999;10(1):79-88

33. Sobin C, Monk SH, Kiley-Brabeck K, Khuri J, Karayiorgou M. Neuromotor deficits in children with the 22q11 deletion syndrome. Mov Disord. 2006;21(12):2082-2089. doi:10.1002/mds.21103

34. Van Aken K, De Smedt B, Van Roie A, et al. Motor development in school-aged children with 22 q11 deletion (velocardiofacial/DiGeorge syndrome). Dev Med Child Neurol. 2007;49(3):210-213. doi:10.1111/ j.1469-8749.2007.00210.x

35. Óskarsdóttir S, Belfrage M, Sandstedt E, Viggedal G, Uvebrant P. Disabilities and cognition in children and adolescents with 22q11 deletion syndrome. Dev Med Child Neurol. 2005;47(3):177-184. doi:10.1017/ S0012162205000320

36. Gerdes M, Solot C, Wang PP, et al. Cognitive and behavior profile of preschool children with chromosome 22q11.2 deletion. Am J Med Genet. 1999;85(2):127-133.

37. Roizen NJ, Higgins AM, Antshel KM, Fremont W, Shprintzen R, Kates WR. 22q11.2 deletion syndrome: Are motor deficits more than expected for IQ level? J Pediatr. 2010;157(4):658-661. doi:10.1016/j. jpeds.2010.04.073

38. Roizen NJ, Antshel KM, Fremont W, et al. 22q11.2DS Deletion Syndrome: Developmental Milestones in Infants and Toddlers. J Dev Behav Pediatr. 2007;28(2):119-124. doi:10.1097/01.DBP.0000267554.96081.12

39. Miyamoto RC, Cotton RT, Rope AF, et al. Association of anterior glottic webs with velocardiofacial syndrome (chromosome 22q11. 2 deletion ). Otolaryngol Head Neck Surg. 2004;130(4):415-417. doi:10.1016/j.otohns.2003.12.014

40. Windsor A, Clemmens C, Jacobs IN. Rare Upper Airway Anomalies. Paediatr Respir Rev. 2016;17:24-28 doi:10.1016/j.prrv.2015.07.001

41. Jones JW, Tracy M, Perryman M, Arganbright JM. Airway Anomalies in Patients With 22 q11.2 Deletion Syndrome:A5-YearReview.AnnOtolRhinol Laryngol.2018;127(6):384-389. doi:10.1177/0003489418771711

42. Leopold C, De Barros A, Cellier C, Drouin-Garraud V, Dehesdin D, Marie J-P. Laryngeal abnormalities are frequent in the 22q11 deletion syndrome. Int J Pediatr Otorhinolaryngol. 2012;76(1):36-40. doi:10.1016/j. ijporl.2011.09.025

43. Ebert B, Sidman J, Morrell N, Roby BB. Congenital and iatrogenic laryngeal and vocal abnormalities in patients with 22q11.2 deletion. Int J Pediatr Otorhinolaryngol. 2018;109(March):17-20. doi:10.1016/j. ijporl.2018.03.006

44. Verheij E, Speleman L, Mink van der Molen AB, Thomeer HGXM. Congenital respiratory tract disorders in 22q11.2 deletion syndrome. Int J Pediatr Otorhinolaryngol. 2018;104. doi:10.1016/j.ijporl.2017.10.028

45. Sacca R, Zur KB, Crowley TB, Zackai EH, Valverde KD, Mcdonald-mcginn DM. Association of airway abnormalities with 22q11. 2 deletion syndrome. Int J Pediatr Otorhinolaryngol. 2017;96:11-14. doi:10.1016/j.ijporl.2017.02.012

46. Kimia R, Elden L, Dailey J, et al. Magnetic resonance angiography (MRA) in preoperative planning for 
patients with 22q11.2 deletion syndrome undergoing craniofacial and otorhinolaryngologic procedures. Int J Pediatr Otorhinolaryngol. 2020;138(June):110236. doi:10.1016/j.ijporl.2020.110236

564555-L-bw-Verheij 
564555-L-bw-Verheij

Processed on: 16-9-2021 

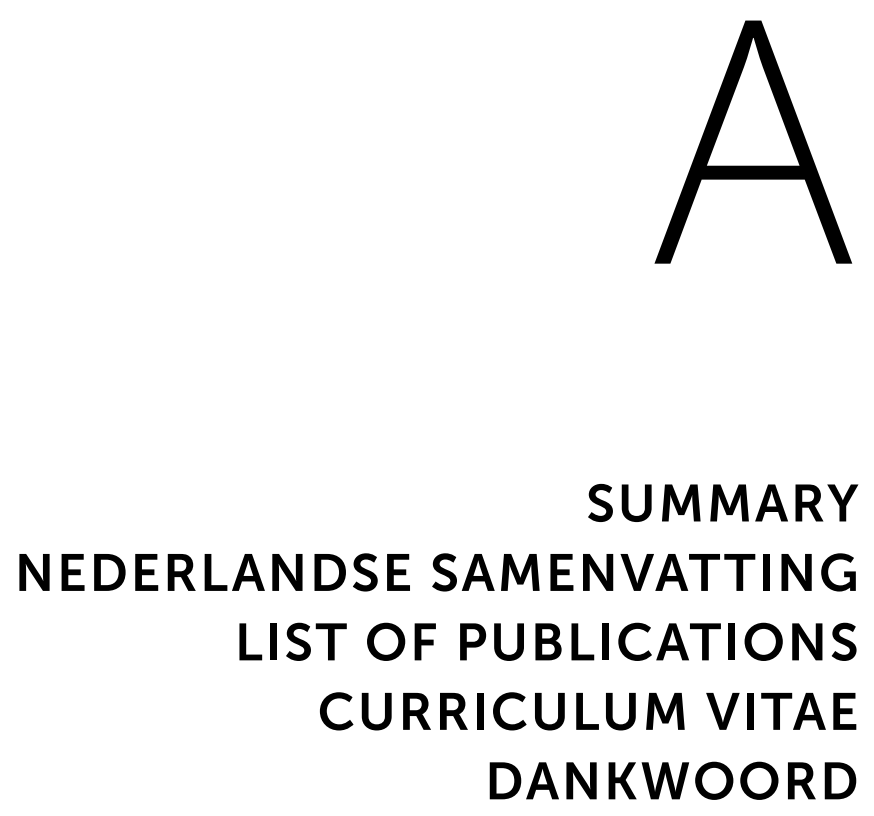
APPENDIX

\section{SUMMARY}

22q11.2 deletion syndrome (22q11DS) is caused by a microdeletion on chromosome 22. It occurs in approximately 1:3000-6000 live births. Patients with 22q11DS can suffer from a wide range of different pathologies, over 180 clinical conditions are described. ${ }^{1,2}$ The aim of this thesis was to give an overview of otorhinolaryngologic manifestations in 22q11DS.

\section{Otologic manifestations}

In chapter 2 we performed a systematic review describing all otologic manifestations reported in 22q11DS in the literature thus far. We found 21 studies describing hearing loss and 21 studies reporting on other otologic manifestations. The range of hearing loss varied greatly, from 6.0 to $60.3 \%$. The hearing loss was mostly conductive in origin. Recurrent or chronic otitis media was described in $2.2-89.8 \%$. In our retrospective study where we described the otologic manifestations (chapter 3), we included 199 patients with 22q11DS who had visited our clinic, independently of symptoms. 102 patients had received an audiogram. $38 \%$ of ears had hearing loss, $94 \%$ of the ears with hearing loss were conductive in nature, and $4 \%$ were found to be mixed hearing losses. At time of most recent audiogram, $22,5 \%$ had a concomitant otitis media with effusion. $61 \%$ of patients had a history of tympanic membrane tube placement. $10 \%$ of patients used conventional hearing aids or a bone conduction device. We found no relation between age and hearing thresholds or otitis media. Overall, we concluded that hearing loss and otitis media are frequently present in patients with 22q11DS. Chapter 4 is a retrospective case series where we analyzed radiologic images of the mastoid bones of 11 patients with 22q11DS from the University Medical Center Utrecht and 15 patients with 22q11DS from Children's Hospital of Philadelphia. One patient had undergone MRI scanning, the other 25 patients a CT scan of the mastoid bones. Indications for radiologic imaging were reported hearing loss which could not be explained by otoscopic findings (38\%), chronic otitis media (50\%), both unexplained hearing loss and chronic otitis media ( $8 \%$ ), or aural atresia (4\%). We frequently encountered innerand middle ear malformations in this patient group. A dense stapes superstructure was present in $36 \%$ of ears, an incomplete partition type II of the cochlea in $23 \%$ of ears, a malformed lateral semicircular canal with a small bony island in $33 \%$ of ears and fusing of the lateral semicircular canal and vestibule to a single cavity in $29 \%$ of ears. Future studies should research the relation between a malformation of the lateral semicircular canal and vestibular function. In addition, the lateral semicircular canal is an important landmark for identifying the facial nerve during mastoid surgery. As described in our case report in chapter 5, to avoid iatrogenic facial nerve damage otologic surgeons should be aware of this anomaly, perform a CT scan prior to surgery and use facial nerve monitoring during surgery by default in patients with 22q11DS. 
In addition to mastoid surgery, ossicular chain reconstruction is a feasible alternative treatment (compared to hearing aids) in patients with 22q11DS with an ossicular chain malformation causing hearing impairment (see chapter 5 ).

\section{Vestibular manifestations}

After we found a high prevalence of malformed lateral semicircular canals in patients with 22q11DS, we performed a questionnaire study on vestibular symptoms (chapter 6). Our hypothesis was that patients with 22q11DS suffer relatively more from subtle vestibular symptoms than the general population. We found that children with 22q11DS experienced balance difficulties more often and were older when they started walking compared to children in the control group. Dizziness seemed not to be more frequently reported in children with 22q11DS.

\section{Airway manifestations}

In chapter 7 we describe 14 patients with 22q11DS and an airway malformation. There was one patient with a choanal stenosis, five patients with a laryngeal web, two patients with a laryngeal cleft, three patients with a subglottic stenosis, 11 patients with a pharyngo-, laryngo-, tracheo-, and/or bronchomalacia and one patient with a tracheal stenosis. Nine patients had more than one disorder simultaneously. In five patients a vascular structure (right sided aortic arch, brachiocephalic artery or abbarant right subclavian artery (lusorian artery)) compressed the airway causing an airway malacia. There were three patients who required a tracheostomy; one patient with a tracheal stenosis and laryngeal web, one patient with choanal stenosis a pharyngeal malacia, and one patient with a subglottic stenosis and tracheobronchomalacia. We concluded that different types of airway malformations can be present in 22q11DS and clinicians should be aware of airway malformations in 22q11DS, and start early treatment if necessary. In addition, the diagnosis 22q11DS should be considered in patients with an (or more than one) airway anomaly.

\section{References}

1. Robin NH, Shprintzen RJ. Defining the clinical spectrum of deletion 22q11.2. J Pediatr. 2005;147(1):90-96

2. McDonald-McGinn DM, Sullivan KE, Marino B, et al. 22q11.2 deletion syndrome. Nat Rev Dis Prim. 2015;1:15071. doi:10.1038/nrdp.2015.71.22q11.2 
APPENDIX

\section{NEDERLANDSE SAMENVATTING}

Het 22q11.2 deletie syndroom (22q11DS) wordt veroorzaakt door een microdeletie op chromosoom 22. Het komt voor in ongeveer 1:3000-6000 levendgeborenen. Patiënten met 22q11DS kunnen veel verschillende uitingen van het syndroom hebben, meer dan 180 klinische afwijkingen zijn beschreven in de literatuur. ${ }^{1,2}$ Het doel van dit proefschrift was om een overzicht te creëren van de verschillende keel-, neus- en oor manifestaties in 22q11DS.

\section{Otologische manifestaties}

In hoofdstuk 2 bestaat uit een systematisch overzicht van de literatuur van alle otologische manifestaties die tot dusver zijn beschreven. We vonden 21 studies die gehoorverlies rapporteren, en 21 studies die andere otologische manifestaties rapporteren. De prevalentie die in de verschillende studies wordt beschreven varieert erg; tussen de 6,0 en 60,3\%. Het gehoorverlies was in de meeste gevallen conductief van aard. Recidiverende of chronische otitis media werd beschreven in 2,2 - 89,9\%. In onze retrospectieve studie (hoofdstuk 3) waar we otologische manifestaties hebben beschreven, hebben we 199 patiënten met 22q11DS geïncludeerd. Alle patiënten hadden onze keel-, neus- en oorheelkunde kliniek bezocht, ongeacht of ze klachten hadden. Van 102 patiënten was een audiogram beschikbaar. 38\% van de oren met een audiogram had gehoorverlies, 94\% hiervan was een conductief gehoorverlies en $4 \%$ een gemengd gehoorverlies. Tijdens het meest recente audiogram had 22,5\% van de patiënten een otitis media met effusie. $61 \%$ van de patiënten had een voorgeschiedenis van een trommelvliesbuisje. 10\% gebruikte conventionele hoortoestellen of een beengeleidingshoortoestel. We vonden geen relatie tussen leeftijd en gehoordrempels of otitis media. We concludeerden dat gehoorverlies en otitis media vaak voorkomen bij patiënten met 22q11DS. Hoofdstuk 4 is een retrospectieve case series waarin we radiologische beelden van het mastoid hebben geanalyseerd. 11 patiënten met 22q11DS van het Universitair Medisch Centrum Utrecht en 15 patiënten met 22q11DS van het Children's Hospital of Philadelphia zijn geïncludeerd. Er was een MRI-scan beschikbaar van één patiënt, van de overige 25 patiënten was een CT-scan beschikbaar. De indicaties voor het maken van beeldvorming waren gerapporteerd gehoorverlies die niet kon worden verklaard door het otologisch beeld (38\%), chronische otitis media (50\%), beiden ( $8 \%$ ) of atresie van het oor (4\%). Binnen- en middenoorafwijkingen kwamen vaak voor. We vonden een dense stapes bovenbouw in $36 \%$ van de oren, een incomplete partitie type II van de cochlea in $23 \%$ van de oren, een afwijkend lateraal semicirculair kanaal met een klein boteiland in 33\% van de oren, en een gefuseerd lateraal semicirculair kanaal met het vestibulum tot één holte in $39 \%$ van de oren. Toekomstig onderzoek zou zich moeten richten op de mogelijke relatie tussen een afwijkend lateraal semicirculair kanaal en de vestibulaire functie. Het laterale 
semicirculaire kanaal is daarnaast een belangrijke landmark voor het identificeren van de nervus facialis tijdens een mastoidectomie. Zoals ook beschreven in ons case report in hoofdstuk 5, om iatrogene schade aan de nervus facialis te voorkomen is het van belang dat otologen hiervan op de hoogte zijn, standaard preoperatief een CT-scan vervaardigen en een facialis monitor gebruiken peroperatief bij patiënten met 22q11DS. Naast een mastoidectomie kan chirurgie aan de gehoorbeenketen een optie zijn in patiënten met 22q11DS en een afwijking aan de gehoorbeenketen met als gevolg daarvan gehoorverlies (hoofdstuk 5).

\section{Vestibulaire manifestaties}

Nadat we een hoge prevalentie afwijkende laterale semicirculaire kanalen bij patiënten met 22q11DS vonden hebben we een vragenlijst studie uitgevoerd om vestibulaire symptomen nader te onderzoeken (hoofdstuk 6). Onze hypothese was dat patiënten met 22q11DS relatief vaker subtiele vestibulaire symptomen hadden dan de algemene populatie. We vonden dat kinderen met 22q11DS meer last hadden van balansproblemen en ook ouder waren toen ze begonnen met lopen, vergeleken met kinderen in een controlegroep. Duizeligheid was niet vaker aanwezig bij de kinderen met 22q11DS.

\section{Luchtweg manifestaties}

In hoofdstuk 7 beschrijven we 14 patiënten met 22q11DS en een luchtweg afwijking Er was één patiënt met een choane stenose, vijf patiënten met een larynx web, twee patiënten met een larynx cleft, drie patiënten met een subglottische stenose, 11 patiënten met een pharynx, laryngo-, tracheo-, en/of bronchomalacie, en één patiënt met een tracheastenose. Negen patiënten hadden meer dan één aandoening tegelijkertijd. Een vasculaire structuur (rechter aortaboog, arteria brachiocephalica, aberrante rechter arteria subclavia (arteria lusoria) was de oorzaak van een luchtweg malacie doordat de structuur op de luchtweg drukte in vijf patiënten. Drie patiënten hadden een tracheotomie nodig; één patiënt met een tracheastenose en larynxweb, één patiënt met een choane stenose en malacie van de pharynx en één patiënt met een subglottische stenose en tracheobronchomalacie. We concludeerden dat verschillende afwijkingen in de luchtweg aanwezig kunnen zijn in 22q11DS. Artsen moeten beducht zijn voor luchtwegafwijkingen bij patiënten met 22q11DS en behandeling zo snel mogelijk starten indien nodig. Daarnaast moet de diagnose 22q11DS worden overwogen bij patiënten met een (of meer dan één) luchtwegafwijking.

\section{Referenties}

1. Robin NH, Shprintzen RJ. Defining the clinical spectrum of deletion 22q11.2. J Pediatr. 2005;147(1):90-96.

2. McDonald-McGinn DM, Sullivan KE, Marino B, et al. 22q11.2 deletion syndrome. Nat Rev Dis Prim. 2015;1:15071. doi:10.1038/nrdp.2015.71.22q11.2 


\section{LIST OF PUBLICATIONS}

Verheij E, Markodimitraki LM, Stokroos RJ, Thomeer HGXM. Case Report: Challenging Otologic Surgery in Patients With 22q11.2 Deletion Syndrome. Front Surg. 2020;7(August):1-5. doi:10.3389/fsurg.2020.00053

Verheij E, Elden L, Crowley TB, et al. Anatomic malformations of the middle and inner ear in 22q11.2 deletion syndrome: Case series and literature review. Am J Neuroradiol. 2018;39(5). doi:10.3174/ajnr.A5588

Verheij E, Speleman L, Mink van der Molen AB, Thomeer HGXM. Congenital respiratory tract disorders in 22q11.2 deletion syndrome. Int J Pediatr Otorhinolaryngol. 2018;104. doi:10.1016/j.ijporl.2017.10.028

Verheij E, Derks LSM, Stegeman I, Thomeer HGXM. Prevalence of hearing loss and clinical otologic manifestations in patients with 22q11.2 deletion syndrome: A literature review. Clin Otolaryngol. 2017;42(6). doi:10.1111/coa.12874

Verheij E, Kist AL, Mink Van Der Molen A, Stegeman I. Otologic and audiologic findings in 22q11.2 deletion syndrome. Eur Arch Oto-Rhino-Laryngology. 2017;274:765-

771. doi:10.1007/s00405-016-4365-y

Verheij E, Thomeer HGXM, Pameijer FA, Topsakal V. Middle Ear Abnormalities in Van Maldergem Syndrome. Am J Med Genet. 2017;173A:239-244. doi:10.1002/ ajmg.a.37990

Verheij E, Bezdjian A, Grolman W, Thomeer HGXM. A Systematic Review on Complications of Tissue Preservation Surgical Techniques in Percutaneous Bone Conduction Hearing Devices. Otol Neurotol. 2016;37(7). doi:10.1097/ MAO.0000000000001091

Verheij E, Oomen KPQ, Smetsers SE, van Zanten GA, Speleman L. Hearing loss and speech perception in noise difficulties in Fanconi anemia. Laryngoscope. 2017:127(10). doi:10.1002/lary.26480 


\section{CURRICULUM VITAE}

Emmy Verheij was born on August 31 1989 in Leiden. She grew up in Noordwijk and Bilthoven and obtained her Gymnasium diploma at Het Nieuwe Lyceum in Bilthoven. After graduating she moved to Utrecht where she started medical school in 2007. In 2011 she went to Paramaribo for a gynaecology intership at 's Lands Hospitaal. In her last year of medical school, she did her senior internship at the otorhinolaryngology department at the University Medical

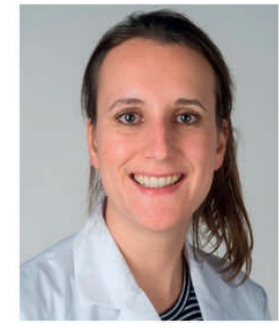
Center Utrecht. After obtaining her medical degree in 2014 she started working as a resident at the emergency department of the University Medical Center Utrecht. She worked there for approximately one year when she got the opportunity to switch to the otorhinolaryngology department to work as a researcher and a subsequently as a PhD candidate under the supervision of dr. Hans Thomeer, prof. dr. Aebele Mink van der Molen, prof. dr. Wilco Grolman and later prof. dr. Robert Stokroos. The results of this project are presented in this thesis. In January 2019 she started residency at the department of otorhinolaryngology at the University Medical Center Utrecht. 
APPENDIX

\section{DANKWOORD}

Dit proefschrift zou niet tot stand zijn gekomen zonder de bijdrage op verschillende manieren van verschillende mensen. ledereen daarvan wil ik graag bedanken, een paar daarvan in het bijzonder.

Hans Thomeer, beste Hans. Aan jou heb ik te danken dat dit traject is gestart, maar al helemaal dat dit traject is voortgezet en is volbracht tot een goed einde. Ik heb veel geleerd van jouw pragmatisme en oplossingsgerichtheid. Jouw energie werkte erg motiverend, na elk overleg had ik altijd weer goede moed en inspiratie. Ik wil je ontzettend bedanken voor je begeleiding en betrokkenheid.

Aebele Mink van der Molen, beste Aebele. Heel erg fijn om iemand van het 22q11 team als nauwe betrokkene te hebben bij dit project. Jij liet me op weer een net andere manier nadenken over 22q11 en zorgde voor nieuwe invalshoeken. Heel erg bedankt voor je betrokkenheid.

Robert Stokroos, beste Robert. Ik heb me altijd gesteund gevoeld. Ik voelde me vrij, maar je wist ons op het goede moment in de goede hoek te sturen. Heel erg bedankt hiervoor.

Laura Markodimitraki, beste Laura. De laatste loodjes wegen het zwaarst zeggen ze. Zo voelde dat voor mij ook, totdat jij mij kwam helpen. Bedankt voor je hulp met de vragenlijsten, zonder jou was dit nooit af gekomen.

Frank Pameijer, beste Frank. Jouw plezier in het beoordelen van CT-scans is erg aanstekelijk. Veel dank voor je hulp.

Inge Stegeman, beste Inge. Ik vond het fijn dat ik bij je kon binnenlopen om te sparren over bepaalde zaken waar ik tegen aan liep, met name tijdens het maken van een METC aanvraag. Dank hiervoor.

Graag wil ik ook alle overige co-auteurs bedanken: Lucienne Speleman, Bert van Zanten, Inge Stegeman, Alwine Kist, Wilco Grolman en Laura Derks. Heel erg bedankt voor jullie inzet, hulp en fijne samenwerking.

Donna McDonald-McGinn and Lisa Elden, thank you for the pleasant cooperation which resulted in a very nice article. 
De leden van de leescommissie, prof. dr. Frenkel, prof. dr. Bleys, prof. Dr. Rosenberg, prof. dr. Van Amelsvoort en prof. dr. Wijnen. Bedankt voor het kritisch beoordelen van dit proefschrift.

Collegae van het 22q11 team: Ania, Jelle, Michiel, Dirk, Jacob, Elemy, Sasja, MarieJose. In het begin zagen we elkaar nog elke donderdag op een kamer bij de afdeling psychiatrie, later in het WKZ. De laatste jaren redde ik het niet (altijd) meer om erbij te zijn, maar desalniettemin heb ik jullie interesse erg gewaardeerd.

Anne en Veronique, wat fijn dat jullie naast mij staan tijdens de verdediging. Mijn hele KNO-carrière zijn jullie erbij, samen onderzoeken, samen de opleiding beginnen en inmiddels ook weer samen een eindje de opleiding in. Zo gezellig om jullie als collega's in het ziekenhuis te hebben maar vooral ook als goede vrienden daarbuiten.

ledereen van de H02 gang: Geerte, Ruben, Aren, Bernard, Jeroen, Laura en Jan. Heel erg bedankt voor jullie gezelligheid tijdens werkuren en daarbuiten. En ook labgenoten Huib, Dyan, Henk en Ferry. De koffietrein komt vaak weer terug in deze dankwoorden, en terecht want in deze trein was het goed vertoeven.

Vrienden en vriendinnen, voor alle plezier, gezelligheid en ontspanning. Met in het bijzonder: Nicola bij wie ik altijd kan aanschuiven en dat ook regelmatig doe, Annelies, mijn bijna-buurvrouw, Lisette, mijn trouwe vakantiebuddy, hardloopmaten (inclusief ondersteuning) Otto, Hannah, Jacob en natuurlijk Sabine en Nienke, mijn alleroudste vriendinnen.

En familie: Em en Ro, Teun en Fien, en natuurlijk papa en mama, voor jullie belangstelling, wijze adviezen en oneindige steun. Teun, bedankt voor je hulp bij de cover. Papa en mama, jullie staan altijd voor me klaar, waardoor (onder andere) dit proefschrift tot een goed einde is gekomen. Bedankt ook voor je goede inzichten bij de cover mam, ik ben trots op het resultaat. 
564555-L-bw-Verheij

Processed on: 16-9-2021 
564555-L-bw-Verheij

Processed on: 16-9-2021 